\title{
Master of Clinical
}

Science

\section{Maternal mortality in Cambodia, Malaysia, Thailand and Sri Lanka: a review of practice and policy strategies.}

Alexandra (Alexa) McArthur RN RM MPHC

Student number a1 187533

The Joanna Briggs Institute

Faculty of Health Sciences

The University of Adelaide

alexa.mcarthur@adelaide.edu.au

30 June 2011 
Supervisors:

Professor Judy Lumby A.M. RN BA MHPEd PhD

Emeritus Professor: University of Technology, Sydney

Adjunct Professor: The University of Sydney, University of Western Sydney and The University of Adelaide

judy.lumby@adelaide.edu.au

Craig Lockwood RN BN GradDipNSc (Acute Care) MNSc

The Joanna Briggs Institute

Faculty of Health Sciences

The University of Adelaide

craig.lockwood@adelaide.edu.au 


\section{Table of Contents}

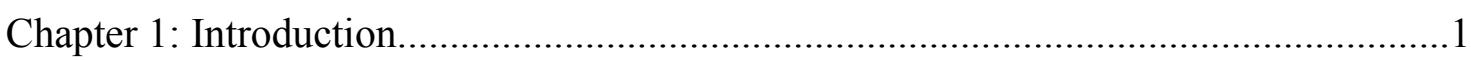

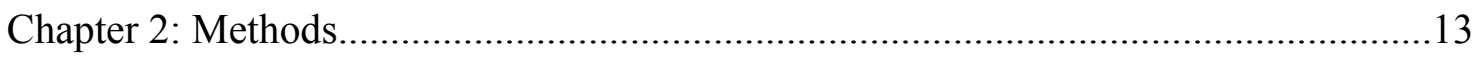



Chapter 4: Discussion and Conclusion.........................................................................



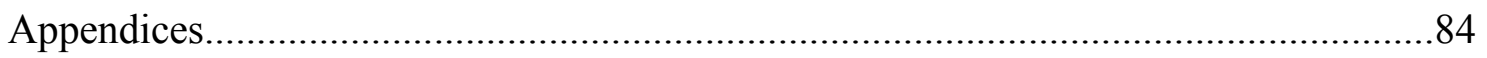




\section{List of Figures and Tables}

Figure 1 Material Mortality since the 1960's in Malaysia, Sri Lanka and Thailand........ 6

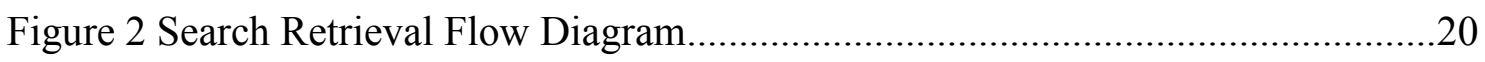

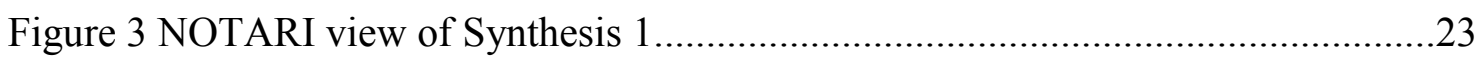

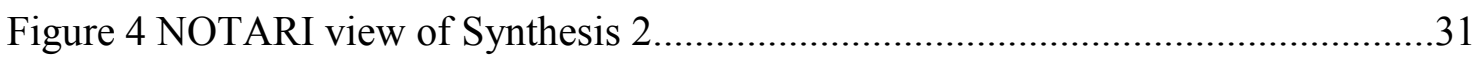

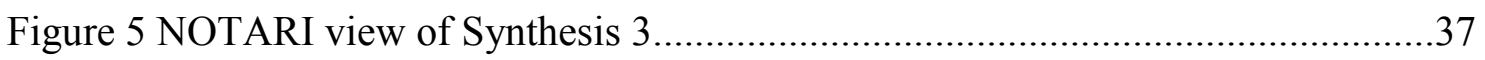

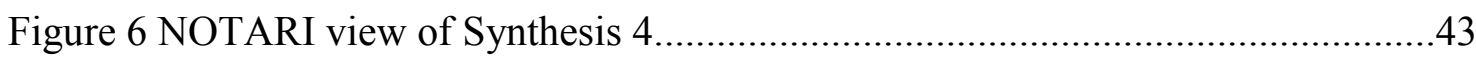

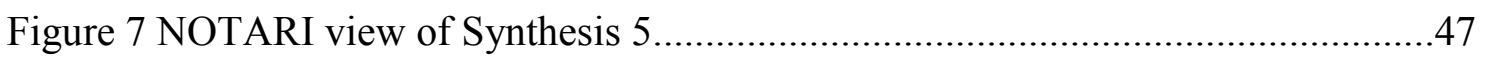

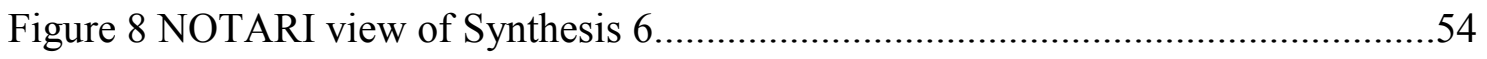



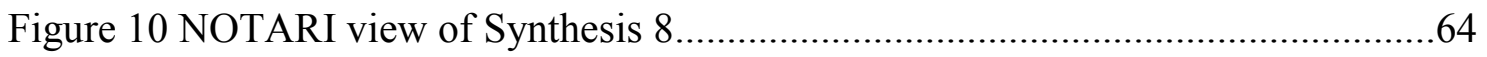

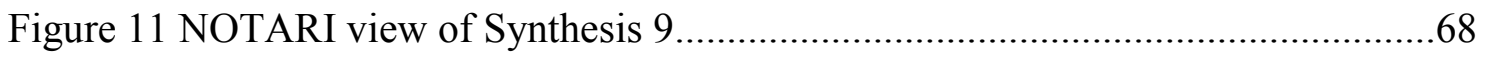

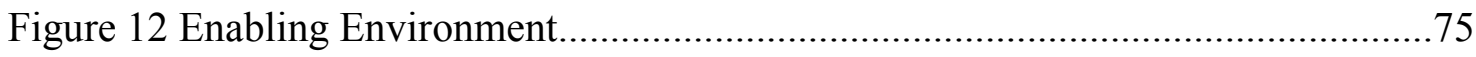

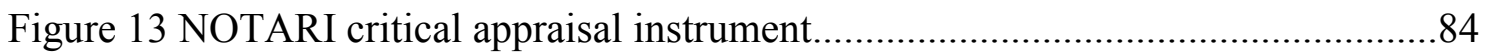

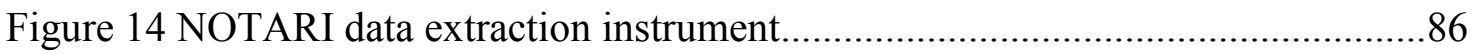

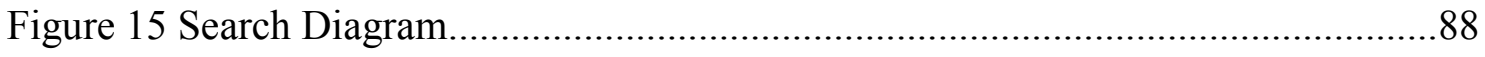

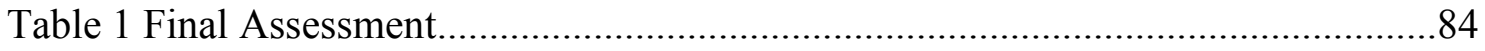

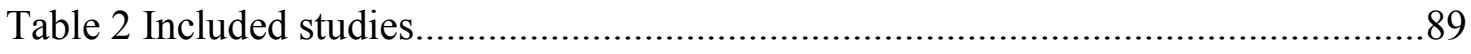




\section{Abstract}

Objectives: To systematically review the strategies that have reduced maternal mortality within four countries; Cambodia, Malaysia, Thailand and Sri Lanka.

Methods: Published and unpublished English language articles from 2000 through 2010 relating to maternal mortality were identified with electronic searches of medical and social science databases. In addition, bibliographies of articles were examined for eligible studies. A systematic review of text and opinion papers was conducted, as outlined in the methods chapter.

Results: Thirty-three text and opinion papers met the inclusion / exclusion criteria. The textual papers were analysed using JBI-NOTARI. The process of meta-synthesis involved the extraction of conclusions, which were grouped into categories, then analysed to generate synthesised findings. Nine syntheses were derived with key themes related to decreasing maternal mortality, including professionalization of midwifery, free and equitable health care, strengthening of health systems, appropriate taskshifting, access issues for women, empowerment of women, improved data collection methods and global assistance.

Conclusion: A combination of these nine essential factors, empowered by an enabling environment, will lead to an improvement in provision of skilled attendance for birthing women. All governments, health professionals who work to provide skilled attendance, and women and their communities must work together, with a shared commitment to tackle these issues of maternal mortality.

Keywords: maternal mortality, skilled birth attendant, Cambodia, Malaysia, Thailand, Sri Lanka. 


\section{Student Declaration}

This work contains no material which has been accepted for the award of any other degree or diploma in any university or other tertiary institution to Alexa McArthur and, to the best of my knowledge and belief, contains no material previously published or written by another person, except where due reference has been made in the text.

I give consent to this copy of my thesis, when deposited in the University Library, being made available for loan and photocopying, subject to the provisions of the Copyright Act 1968.

I also give permission for the digital version of my thesis to be made available on the web, via the University's digital research repository, the Library catalogue and also through web search engines, unless permission has been granted by the University to restrict access for a period of time.

Signed:

Dated: 30 June 2011 


\section{Acknowledgements}

I thank my supervisors Craig Lockwood and Professor Judy Lumby, for their guidance, support and comments while undertaking this Master of Clinical Science. Heartfelt thanks also to Anthea Court for her expert assistance in editing the final draft. To my colleagues at the Joanna Briggs Institute - you are extremely hard working and diligent, and I thank you for helpful comments, assistance with an assortment of questions, and encouraging me when I needed it most. To my family, for giving me the time, love, support and courage to step out of my comfort zone. Most importantly, I acknowledge all the women in this world who have birthed without the support of skilled attendance - may future generations of women never have to experience this. 


\section{Chapter 1: Introduction}

\section{Context of the review}

Maternal mortality remains unacceptably high in many parts of the world today, even though the majority of these deaths are preventable. This thesis discusses and reports on the past and current strategies to reduce maternal mortality within four countries; Cambodia, Malaysia, Thailand and Sri Lanka. My interest in this area arises from my experience as a midwife working with Traditional Birth Attendants in Somalia in the early 90's, and later in the mid 2000's at a rural district hospital in Nepal, during the introduction of a Skilled Birth Attendant program. This chapter will provide the background details outlining the importance of this review, situate the historical context, and explain current reasons for the state of maternal health within these four countries.

The background of the fifth Millennium Development Goal (MDG 5) has never made the time more urgent to reassess where we are in regards to maternal health. Between 1990 and 2015, MDG 5 aspires to reach the goal of reducing by $75 \%$ maternal mortality, and in many low-income countries, this ambitious target appears to be beyond reach. ${ }^{1}$ Much rhetoric about what needs to be done is simply not translating into practice, with maternal death rates 50 to 400 times higher in low-income countries, compared with high-income countries. ${ }^{2}$ However, evidence suggests that some lowincome countries are able to provide high levels of service and reduce maternal mortality with low levels of health care expenditure. ${ }^{3}$ The strategies they employ are not based on finances alone, but show the benefits of an efficient and comprehensive package of services for improving maternal mortality rates.

Maternal mortality is defined as death resulting either directly during pregnancy or childbirth or indirectly as a result of complications of either pregnancy or childbirth. ${ }^{1}$ It is a leading cause of death and disability among women in low income countries. It is estimated that worldwide there are approximately 342,900 maternal deaths (in 2008), down from more than 500,000 women in $1990 .{ }^{4}$ At least 10 million women suffer injuries resulting from childbirth, infection and disabilities. ${ }^{1}$ Evidence suggests that 
increasing the number of births overseen by skilled birth attendants, as opposed to traditional birth attendants, is the single most effective means of decreasing the maternal mortality rate. ${ }^{5}$

For many years in low income countries, traditional birth attendant training has been promoted by the World Health Organisation, where 'lay midwives' who are usually older women within the community have been trained to give assistance to women during pregnancy and childbirth. ${ }^{6}$ Recently, reports have concluded that traditional birth attendants have not made a significant impact on reducing maternal mortality and morbidity. The skill level or training that traditional birth attendants have received can vary widely, and the degree to which they can identify complications and then make a referral has been questioned. ${ }^{6}$ A new focus on training skilled birth attendants has emerged, and in 2004 a joint statement was released by the World Health Organisation (WHO), International Confederation of Midwives (ICM) and the International Federation of Gynaecology and Obstetrics (FIGO), concerning the role of the skilled birth attendant, and their central importance. ${ }^{5}$

A skilled birth attendant is a health professional (midwife, doctor or nurse) who has been accredited, educated and trained to manage normal, uncomplicated births. He/she is also able to identify, manage and/or refer complicated cases to the nearest referral health centre. ${ }^{5}$ This is in contrast to traditional birth attendants who are not primarily healthcare professionals, but often older women within the community.

In many instances, funding has ceased for traditional birth attendant training, and the new focus has been to build the capacity of skilled birth attendants. The Millenium Development Goal for maternal health (MDG 5) is to see the maternal mortality ratio reduced by three-quarters by the year $2015{ }^{1}$ This is a very ambitious target, given that other targets were to cut poverty in half, and child mortality by two-thirds. But what is the best way forwards? Is there one approach, one policy that will fit every country? While it might be simplistic to assume that what has worked in one country may be helpful in another, it may be of benefit to consider the emerging themes and similarities that arise between these countries. For this reason I have focused only on textual papers that highlight the strategies that have decreased maternal mortality rates. 
For the purpose of this thesis, the focus will be on women giving birth in Cambodia, Thailand, Malaysia and Sri Lanka. These countries have been chosen as they lie within a similar geographical context, yet Thailand, Malaysia and Sri Lanka have all been able to drastically reduce their maternal mortality rate over recent years. ${ }^{6}$ Cambodia has one of the highest maternal mortality rates in southeast Asia; 266 per 100,000 live births, ${ }^{4}$ where $68 \%$ of births take place without the help of a skilled birth attendant. ${ }^{7}$ In 2008 , the maternal mortality rates were 30 (per 100,000 live births) in Sri Lanka, 42 (per 100,000 live births) in Malaysia, and 47 (per 100,000 live births) in Thailand. ${ }^{4}$ Accuracy in collection of maternal mortality data is often questioned, but a concerted effort since the mid 90's with improved data collection from many countries has been established with support from WHO, UNICEF, UNFPA and the World Bank. ${ }^{4}$ Cambodia is defined as a low income country by the World Bank, as it had a gross national income per capita of $\$ 935$ (USD) or less in $2008 .{ }^{8}$ Over the last few decades, Thailand, Malaysia and Sri Lanka have all managed to improve maternal health, through a variety of strategies. Sri Lanka and Thailand are defined as lower middle income countries, with a gross national product (GNP) of between $\$ 936$ - 3,855 USD, and Malaysia as an upper middle income country, with a GNP of $\$ 3,856-\$ 11,905$ USD. ${ }^{8}$ From my perspective, having worked in maternal health in both low and high income countries, the main question was to explore whether financial reasons alone, (providing more healthcare professionals, better facilities for emergencies, etc) were responsible for this improvement, or were there other reasons/strategies that can be identified?

A lack of cohesion around maternal health issues amongst global experts has proved challenging in the past few decades, with the main focus being on training traditional birth attendants, and the provision of antenatal care. Then in 1990, on the recommendation of international agencies and academics, funding for traditional birth attendant training was ceased, with little evidence base to support this decision. ${ }^{9}$ Evaluation of these programs had found them to be ineffective, in terms of reducing maternal mortality, and the common theme emerging was the need for provision of skilled attendants during pregnancy and childbirth, to provide care, manage or refer major complications. ${ }^{2}$ In 2004 a joint statement was released by the World Health Organisation (WHO), International Confederation of Midwives (ICM) and the 
International Federation of Gynaecology and Obstetrics (FIGO), concerning the role of the skilled birth attendant, and their central importance in improving maternal health. ${ }^{5}$

Progress by many countries is slowly reducing maternal mortality rates. Trends are emerging that reflect four main reasons for this, namely a decrease in the total fertility rate, a general rise in income per head, education levels for girls and women is improving, and an increase in the number of women giving birth with the assistance of a skilled attendant. ${ }^{4}$ This progress is reported in very broad terms, and obviously countries will vary.

The impact of skilled attendance at birth is influenced by a variety of factors, such as the level of resources available (both staff and equipment), and access issues (long distances to reach health care facility, expense of transport). A prohibiting factor may be the expense of accessing treatment. ${ }^{10}$ Interventions that can be easily scheduled, such as immunisation services and antenatal care, are much easier to administer, whereas clinical services that require access over 24 hours, such as skilled birth and/or emergency care are harder to provide. ${ }^{11}$ Others argue that traditional birth attendants still have a place alongside skilled birth attendants and that by working together, in collaboration and true partnership, respecting each others skills, the greatest impact on improving maternal mortality will be achieved. ${ }^{12}$

Wider issues involve women's status and position of disadvantage within their society. Maternal mortality rates worldwide tend to reflect the position of women within their culture. The more equitably women are treated by society, the less likely they are to die during childbirth. ${ }^{13}$ This also directly relates to education for girls, better nutrition for pregnant women and access to family planning. Commitment from governments to provide the health system structure is vital, not only to provide a skilled birth attendant for each pregnant woman, but also the importance of health clinics and hospitals where referrals can be managed appropriately. ${ }^{13}$ The issue of maternal mortality is a complex one, with no easy solutions. However the opportunity that the Millennium Development Goal 5 presents is to place maternal mortality in the spotlight on the world stage, demanding a global response to this unacceptable burden for many women and their families. ${ }^{14}$ 
There is a vast amount of literature on the issues associated with maternal mortality. As preliminary background reading, I found many recent reports and systematic reviews of effects by experts in the field of maternal and child health, focusing on a variety of interventions. After many years of working as a midwife within both low and high income settings, I have considered these issues from a variety of perspectives. The question of whether effectiveness provides an accurate and reliable basis for decision making is something I have struggled with in relation to maternal health in less developed settings, and I was keen to broaden my understanding and knowledge of these complex issues. Many other authors have also voiced similar concerns. ${ }^{15,16,17}$ It is difficult to produce evidence for multi-dimensional packages of interventions, which may be affected by many unpredictable circumstances over a long period of time. ${ }^{17}$ When there is strong consensus on what is effective by global experts, how is that translated to a country where they may have inadequate resources, or staff who are not informed, or even if informed may not have capacity to implement the practice? ${ }^{18}$ In regards to maternal health, evidence of effectiveness is not broad enough in scope to define best practice. The Joanna Briggs Institute (JBI) model of evidence-based health care considers diverse forms of evidence as defining evidence-based practice, including the context where the health care is provided, the preference of the person receiving care, and the health professional's clinical judgement, as well as the best available evidence. ${ }^{19}$ The JBI model considers the best available evidence as not only evidence of effects, but also evidence of feasibility (is it practical), evidence of appropriateness (is the intervention appropriate), and evidence of meaningfulness (how is it experienced by the person receiving care). For this thesis, I considered the question of maternal health strategies, and from evidence of effectiveness only, felt that more could be added in terms of evidence from text and expert opinion. My aim was to systematically consider this evidence of text and expert opinion, and derive recommendations that will impact and facilitate change in practice, realising the complexity of this issue.

Cambodia, Thailand, Malaysia and Sri Lanka were chosen as the focus for this thesis, as they are situated within a similar geographical context, and in order to manage the vast amount of information. Even though currently these countries differ as defined by the World Bank, ${ }^{8}$ Thailand, Malaysia and Sri Lanka have all managed to reduce maternal mortality, through a variety of strategies over the last few decades. Financial reasons alone are not entirely responsible for this improvement. Malaysia and Sri Lanka 
started making these improvements back in the 1950's, when they were classified as low-income countries. ${ }^{17}$ Therefore the examples from these three countries may have relevance for other low income countries today, and should not be disregarded as only due to increasing Gross National Product. Malaysia, Sri Lanka and Thailand are often mentioned in the literature as success stories in reducing maternal mortality, through a variety of different strategies, as illustrated in Figure 1. The one common theme in these three countries was the introduction of skilled attendants for the majority of women in childbirth. ${ }^{6}$

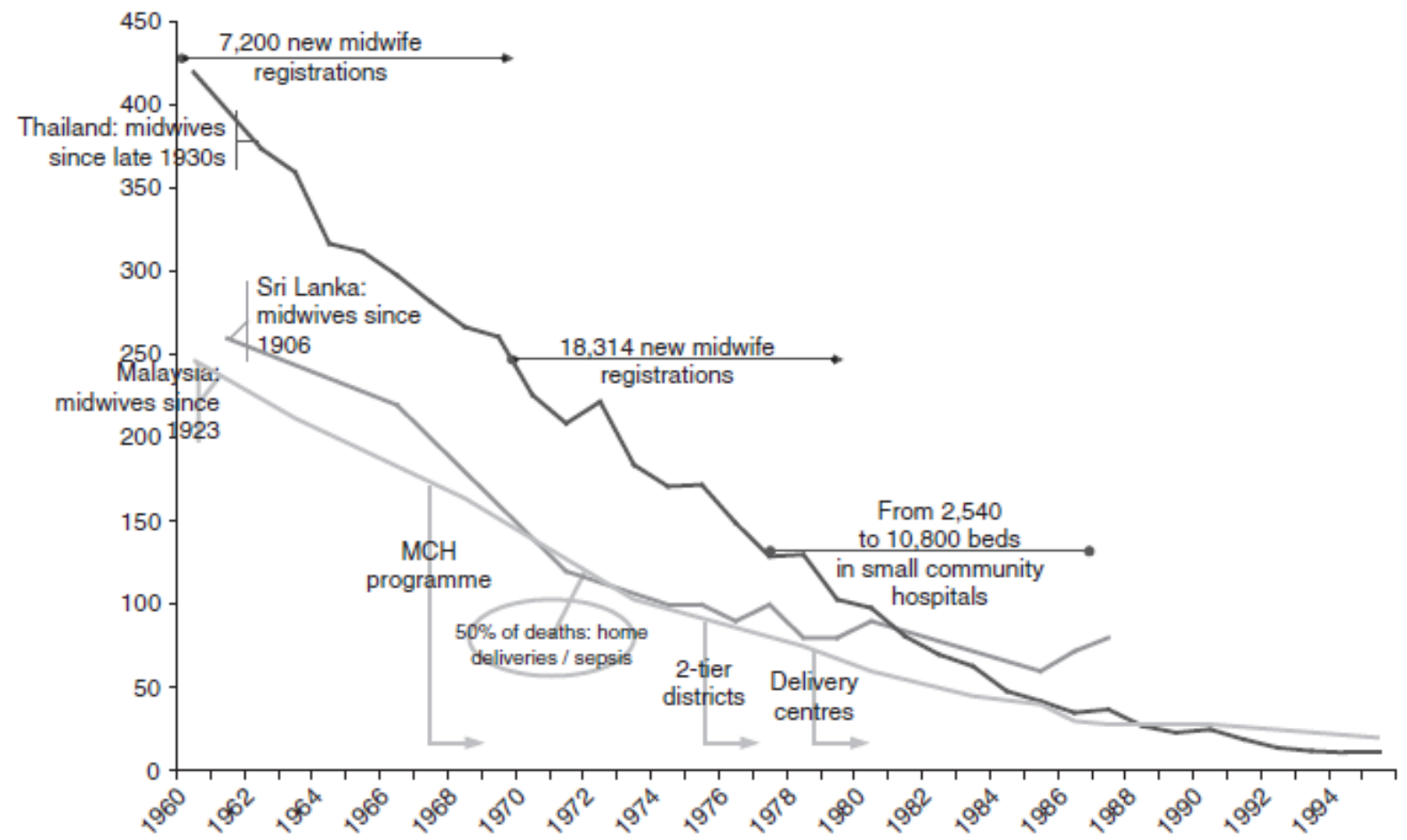

Figure 1 Material Mortality since the 1960's in Malaysia, Sri Lanka and Thailand ${ }^{12}$

Figure 1 illustrates the dramatic trend in declining maternal deaths in Malaysia, Sri Lanka and Thailand, with the introduction of midwifery education and registration, which increased the number of women giving birth with the assistance of skilled attendants. This also correlates with the increased number of women giving birth in community health centres / district hospitals, and the improved opportunity for referral when necessary.

There are many policy papers and reports from countries such as Cambodia, Thailand, Malaysia and Sri Lanka, around these issues of safer motherhood. There have also been large systematic reviews conducted looking at who is attending to birthing women, and 
the effectiveness they have had on birth outcomes. However, a search of the literature has not located a pooled synthesis of textual findings about the major (policies) factors surrounding maternity care in the above mentioned countries. The aim of this review was to systematically search and appraise all relevant articles of text and opinion, and policy papers in order to determine effective strategies to reduce maternal mortality in Cambodia, Thailand, Malaysia and Sri Lanka. This thesis explores not so much a gap of knowledge in existing literature, but using a varying process to affirm this knowledge and present it in an alternative mode. For this reason, I chose to undertake a systematic review of text and opinion as part of this thesis.

\section{Statement of the review question}

The primary objectives of this systematic review were to compare and evaluate the health policy positions across Cambodia, Thailand, Malaysia and Sri Lanka as they relate to maternal mortality and the provision of midwifery services. The specific questions this review sought to address were:

1. What are the strategies to reduce maternal mortality in Cambodia, Thailand, Malaysia and Sri Lanka?

2. Which strategies have had the greatest impact in relation to a change in maternity care practice within the countries of interest?

\section{Overview of the science of evidence synthesis}

The science of evidence synthesis involves analysing research evidence and opinion, and generally has three components of theory, methodology and the systematic review of evidence. ${ }^{20}$ Methods of synthesising evidence not only relate to quantitative research, but also apply to qualitative research and evidence generated from text and opinion. Systematic reviews are considered to be the highest level of evidence generation, as they aim to systematically locate all of the evidence about a clinical question, appraise it, extract data and present a summary of the findings. Systematic reviews place emphasis on methodological quality of the included studies, or the credibility of the text and opinion. With many topics specific to healthcare, quantitative data does not fully represent what can be regarded as the 'best available evidence,' especially when it relates to what is feasible, appropriate or meaningful in a given 
situation. Systematic reviews are important tools that help clinicians, researchers and policymakers alike to summarize the existing information in order to make evidencebased decisions. ${ }^{20}$ Systematic reviews are different from narrative or literature reviews, because they are based on protocols, hypothesis and selection criteria prepared before conducting the review and examining the data.

Evidence arising out of expert opinion and text is considered a valid form of evidence, especially in situations where no high quality evidence from research exists. Appropriate sources of evidence in this context may include any text such as a journal article, a government report or guideline with an informed and authoritative opinion about a topic. The validity of the text is assessed by examining what is being said, the source and its credibility and logic, and aims to establish if any motives are influencing the expressed opinion. ${ }^{20}$ Examining different texts also ensures that alternative opinions are uncovered. Extracting conclusions from these text, categorising and aggregating these categories to develop a meta-synthesis is an interpretative process that requires transparency. By following these three steps, the systematic review of text and opinion aims to provide transparency and rigour to this process. The critical appraisal of expert opinion aims to establish validity as it relates to the soundness of the text, whether it is logical and convincing, and the authority of the source. Two reviewers independently critically appraise data, by asking a series of questions addressed for each paper retrieved. (See Appendix I) The next step involves data extraction from the original paper, using an agreed format to minimise error, and to provide an historical record of decisions made about the data in relation to the specific review. (See Appendix II) A data extraction instrument is used to extract these conclusions. The third step involves categorising the conclusions from the data extraction and synthesising these categories, to establish the basis of similarity in meaning. The aim is for this synthesis to lead to the establishment of recommendations, that summarise the findings of individual studies into a product of practical value. 


\section{Discussion of the methodological basis}

In considering this thesis on maternal mortality, much of the literature I explored revolved around randomized research trials focusing on evidence of effectiveness of one specific intervention. Evidence from multidimensional, system-wide approaches appeared more difficult to evaluate, and the complexity of maternal health issues in relation to effectiveness became obvious. Evidence of effects, as in randomized controlled trials, present a challenge in determining a causal effect on complex health interventions, where it is not always possible to break down and isolate independent and dependent variables. Contextual factors such as poverty, stigma and discrimination influence performance, attrition and detection bias, yet these are factors which are fundamental to randomized controlled trials. Other forms of evidence may be more relevant, such as country case studies. ${ }^{17}$ This is when I decided to explore the approach of systematically reviewing text and opinion in regards to maternal mortality, and choosing four specific countries to be the focus of this review.

The Joanna Briggs Institute Narrative, Opinion and Text Assessment and Review Instrument (JBI-NOTARI) was used in this review to assist with critical appraisal, textual data extraction and the synthesis of the findings of textual reports. This approach was chosen to look beyond research papers of effectiveness around maternal mortality issues (especially when focusing on single interventions). My aim with using JBINOTARI was to explore non-research text, and to identify the key messages conveyed through the text, considering the author, and the historical, social and political perspectives. JBI-NOTARI is based on both content and discourse analysis, and uses the techniques of both approaches. This includes a wide range of approaches, stemming from diverse theoretical backgrounds. Content analysis incorporates the reading and rereading of the text to identify the meaning of the words, and the creation of statements that accurately portray the meaning of the content. Discourse analysis refers to expressing oneself using words to describe, interpret, analyse and critique meanings behind words, and also in establishing the 'authority' of the text. ${ }^{21}$ 
JBI-NOTARI is a module of SUMARI: System for the Unified Management, Assessment and Review of Information, the Joanna Briggs Institutes software for the systematic review of literature. SUMARI includes the Comprehensive Review Management System (known as JBI-CReMS), which guides you through the systematic review process, and is designed to take the data extracted and stored in NOTARI, and allow that data to be manipulated and generated into an ongoing, editable report. CReMS links to four analytical modules of JBI-SUMARI, one of which is JBINOTARI.

The data synthesis of the textual data was performed using the JBI-NOTARI software package. The process of meta-synthesis embodied in this program involves the aggregation or synthesis of conclusions made in relation to the strategies that have decreased maternal mortality. The aim of this process is to generate a set of statements that represent aggregation through assembling the conclusions rated according to their credibility and categorising these conclusions on the basis of similarity in meaning. These categories are then subjected to a meta-synthesis in order to produce a comprehensive set of synthesised findings that are used as a basis for evidence-based practice. The meta-synthesis of textual data developed in JBI-NOTARI involved categorising the conclusions and synthesising these categories. This program permits the reviewer to exercise some degree of judgement. However, synthesis involved both the aggregation of categories and the use of interpretive techniques to summarise the findings of individual studies into a product of practical value. Accepting the wide range of research approaches utilised within the health field to generate knowledge for practice, the methodologies within JBI-NOTARI were utilised to review all forms of expert opinion and text. ${ }^{21}$ 


\section{Definition of terms}

When researching literature around maternal mortality issues, it is important to define the commonly used terms, in order to establish an understanding of what these terms represent.

\section{Maternal Mortality}

Maternal mortality is defined as "the death of a woman while pregnant or within 42 days of termination of pregnancy, irrespective of the duration or site of the pregnancy or its management, but not from accidental causes." 22

\section{Skilled Birth Attendant}

Skilled care at birth is defined as "the essential care for childbirth and the immediate postpartum period that every woman and her newborn need. It includes: a) routine care for all women and her newborn b) special care for those who need integrated interventions, and c) management of complications or pregnancy and childbirth and problems in newborns. Such care should be provided as a continuum at primary health care level by health care providers with midwifery skills (skilled attendants) and, when complications occur, at secondary health care level that requires additional health care providers with obstetric, anaesthetic and paediatric skills supported by appropriate services." 23

\section{Traditional Birth Attendant}

A traditional birth attendant is defined as "a traditional, independent (of the health system), non-formally trained and community-based providers of care during pregnancy, childbirth and the postnatal period." 5

Abbreviations:

MMR: maternal mortality rate

TBA: Traditional birth attendant

WHO: World Health Organization

ICM: International Confederation of Midwives

FIGO: Federation of Gynaecology and Obstetrics 
EmOC: Emergency Obstetric Care

MDG: Millennium Development Goal

JBI: The Joanna Briggs Institute

NOTARI: Narrative, Opinion and Text Assessment and Review Instrument

CReMS: Comprehensive Review Management System

SUMARI: System for the Unified Management, Assessment and Review of Information

Chapter 1 has established the background for the importance of this review, and to provide context for current strategies being used in Cambodia, Malaysia, Thailand and Sri Lanka to reduce maternal mortality. It has also outlined the methodological basis for undertaking a systematic review as part of this thesis, and a brief explanation of JBINOTARI. The following chapter will discuss further the methods to undertake the review. 


\section{Chapter 2: Methods}

This chapter will explain the methodology used to undertake the systematic review of evidence in relation to this thesis, using JBI-NOTARI. Strategies to decrease maternal mortality were the focus of the review, reviewing text derived from sources other than research, namely narrative, opinion or other textual form.

The primary objectives of this systematic review were to compare and evaluate the health policy positions across Cambodia, Thailand, Malaysia and Sri Lanka as they relate to maternal mortality and the provision of midwifery services. The specific questions this review sought to address were:

1. What are the strategies to reduce maternal mortality in Cambodia, Thailand, Malaysia and Sri Lanka?

2. Which strategies have had the greatest impact in relation to a change in maternity care practice within the countries of interest?

\section{Inclusion criteria}

\section{Types of participants}

The review considered studies that included:

Pregnant and birthing women who received care from a skilled birth attendant.

Types of strategies / phenomena of interest

The review considered studies that described:

1. The health system / service delivery structures and underlying policy.

2. The maternity care provided by a skilled birth attendant.

Types of outcomes

The primary outcomes of interest in this review were: 
Impact on maternal mortality rates.

Secondary outcomes of interest to this review included:

a) Changes to health system structures related to pregnancy and childbirth (including resources / finances)

b) Change in cultural practices related to pregnancy and birth

c) Empowerment of women and their position in society (and what impact this has had with respect to their choice of pregnancy and birth care).

\section{Types of papers}

This review considered government reports, expert opinion, discussion papers, position papers, and other forms of text, published in the English language. Technical reports, statistical reports and epidemiological reports were excluded.

\section{Review methods}

\section{Search strategy}

The search strategy aimed to find both published and unpublished studies. A three-step search strategy was utilised in each component of this review. An initial limited search of MEDLINE and CINAHL was undertaken followed by analysis of the text words contained in the title and abstract, and of the index terms used to describe the article. A second search using all identified keywords and index terms was undertaken across all included databases. Thirdly, the reference list of all identified reports and articles was searched for additional studies.

The databases were searched from 2000 up until June 2010, to reflect the approximate timing when traditional birth attendant training was being phased out, and before skilled birth attendant training as an official programme was being promoted.

The databases searched included:

MEDLINE

CINAHL

EMBASE

Cochrane Central Register of Controlled Trials 
Health Technology Assessment (HTA) Database

Scopus

ISI Web of Knowledge

LILACS

Mednar database

Pan American Health Organisation (PAHO)

World Health Organisation (WHO)

The search for unpublished studies included:

ProQuest dissertations and theses, Index to theses, Australian digital theses program digital dissertations, and the Networked digital library of theses and dissertations (NDLTD).

The Internet was also searched for reports of projects within the following organisations such as United Nations, World Bank and USAID.

Initial keywords:

skilled birth attendant(s), midwifery, midwife, midwives, lay midwives, nurse midwives, nurses, doctors, maternal mortality rate, survival (rates), safety, training, train, education, upskill, safer motherhood, Cambodia, Thailand, Malaysia, Sri Lanka.

\section{Assessment of methodological quality / critical appraisal}

Textual papers selected for retrieval were assessed by two independent reviewers for authenticity prior to inclusion in the review using standardised critical appraisal instruments from the Joanna Briggs Institute Narrative, Opinion and Text Assessment and Review Instrument (JBI-NOTARI) (Appendix I). Critical appraisal was important to establish validity, in this context referring to the logic of the opinion and its ability to be convincing, and to have authority as a source of opinion. A transparent process was used in appraising this textual data, and focused on a) assessing the opinion, b) identifying the credibility of the source of the opinion, c) endeavouring to establish the motives underlining the opinion, and d) locating alternative opinions that supported or questioned the statement. ${ }^{21}$ Any disagreements that arose between the reviewers were resolved through discussion, or with a third reviewer. 


\section{Data extraction}

Textual data was extracted from papers included in the review using the standardised data extraction tool from JBI-NOTARI (Appendix II).The data extracted included specific details about the strategies, populations, and data of significance to the review question and specific objectives. In particular, conclusions were transferred from each included paper, to minimise error, provide an historical record of how decisions were made to include conclusions, and to become the basis for extraction and synthesis. Each individual paper was read, and re-read, to extract and state the meaning of the author(s). This conclusion was backed by an 'illustration' taken from the paper, and entered into JBI-NOTARI. The approach was methodical, on a paper by paper basis, and after the initial extraction, I re-read and checked each paper again, with a deeper understanding of maternal mortality issues. This verification of each conclusion affirmed the meaning within the text. To categorise the validity of narrative, opinion and text, three levels of credibility were assigned to each conclusion. Unequivocal refers to evidence that is beyond reasonable doubt, including conclusions that are not open to challenge. Credible evidence is an opinion that appears reasonable given the current data presented in the paper, and unsupported evidence is when conclusions are reached that are not supported by the data. ${ }^{21}$ It was important that each conclusion had a level of credibility assigned to it during the data extraction phase, to ensure transparency of the resulting syntheses.

\section{Data synthesis}

Textual papers were pooled using the Narrative, Opinion and Text Assessment and Review Instrument (JBI-NOTARI). As described in the introduction, this involved the aggregation or synthesis of like conclusions to generate a set of statements that represented that aggregation. After extracting the conclusions, I allocated each conclusion into groups of categories, which reflected similar themes. I then considered the full list of categories, and grouped them according to similar themes. After lengthy deliberation, this process produced a comprehensive set of synthesised findings that could then be used as a basis for evidence-based recommendations.

Synthesis involved both the aggregation of categories, and the use of interpretive techniques to summarise the findings of individual studies into a product of practical value. It was not intended to reanalyse the data, but to compare and communicate the 
meaning of the categorised conclusions, based on their similarity of meaning. These synthesised findings are presented in the results section, listed with conclusions (and levels of credibility), linked to the category, and also to the synthesised finding, to document my rationale behind this data synthesis.

This chapter has presented the methods for undertaking this systematic review, and the following chapter will present the results. 


\section{Chapter 3: Results}

Chapter 3 reports the results of the systematic review, describing the studies, both included and excluded, and the conclusions extracted, with levels of credibility. The results of the synthesis are reported by presenting each synthesised finding, listing the categories and displaying each conclusion (and illustration) linked with the generated category and synthesised finding. Each synthesised finding is also presented in a visual NOTARI View, which details the relationships between the conclusions, categories and synthesised findings.

\section{Description of studies}

An extensive search for studies for inclusion in this review was conducted between June to September 2010. A research librarian was consulted in the initial stages of planning, and the search strategy is detailed in Appendix III. The search yielded a provisional sample of 1488 citations. The titles were screened and those that were obviously not relevant were eliminated. Abstracts of the 136 remaining papers were reviewed, and those meeting the inclusion criteria were examined in entirety to determine eligibility. Fifty eight of these papers were duplicates and therefore eliminated.

Seventy eight papers were read in full, with forty five being excluded because they either contained empirical data concerning maternal mortality, or were not fully textual in nature. The high number of excluded papers puzzled me initially. When reading the abstract in the search phase, many of these paper's abstracts didn't mention empirical methods, but came across as a textual paper only. When I read them in full, it quickly became apparent that they were a mixture of research data and text and opinion, and therefore were excluded on this basis. This was discussed in length with my secondary reviewer, and with some papers, a third reviewer was consulted. A table of excluded studies, including the reasons for exclusion are set out in Appendix V. 
A total of 33 papers were included in this review, and all were textual papers. All of the included papers presented various strategies to decrease maternal mortality in either Cambodia, Thailand, Malaysia and / or Sri Lanka.

- 9 papers focused on Sri Lanka only

- 6 papers focused on Cambodia only

- 1 paper focused on Thailand only

- 2 papers focused on Malaysia only

- 10 papers mentioned both Sri Lanka and Malaysia

- 3 papers mentioned both Sri Lanka and Thailand

- 2 papers mentioned Sri Lanka, Thailand and Malaysia 


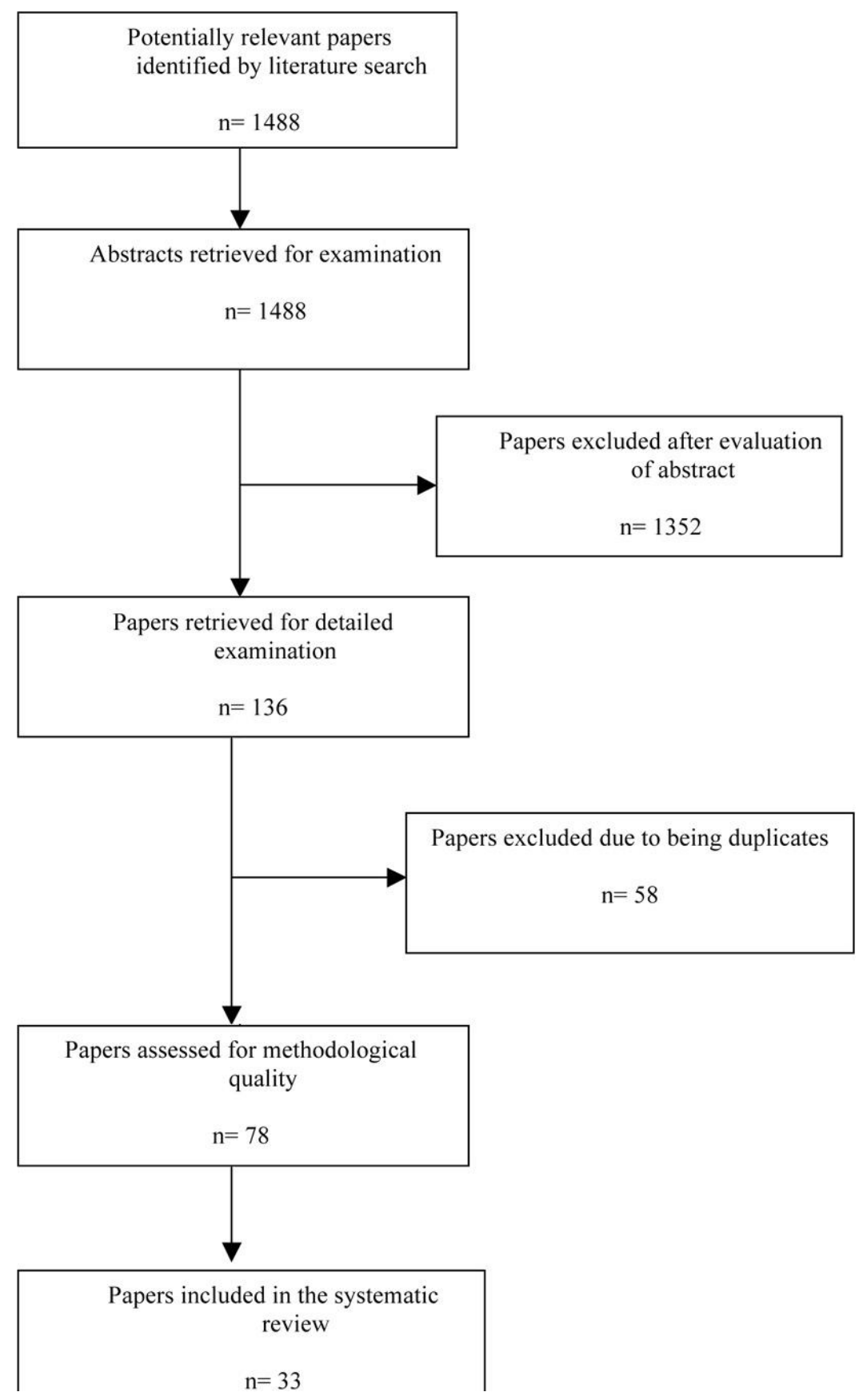

Figure 2 Search Retrieval Flow Diagram

The included papers were textual reports from many different sources, but all were the opinions of experts in the area of maternal health. Strategies that were reported were generally multi-dimensional approaches to decreasing maternal mortality, and therefore cannot be listed in a single intervention list of characteristics. (See included studies in Appendix IV) 


\section{Categorisation and synthesis of findings}

From the 33 included papers, 138 conclusions were extracted and analysed using the Joanna Briggs Institute Narrative, Opinion and Text Assessment and Review Instrument (JBI-NOTARI). Conclusions were drawn from the papers and supported by illustrations from the publications. All 138 of the conclusions were grouped into 31 categories on the basis of similarity and these were subjected to in-depth analysis and review to generate 9 synthesised findings. The synthesised findings are summarised below, and then displayed in full tables, incorporating all of the conclusions and categories into the various syntheses.

The results of the synthesis included a description of the categories used to support the final synthesised findings. In the synthesised findings I have refrained from mentioning specific countries, as strategies from one particular country could be explored for use in another country, given that context and local culture remains embedded in the extracted conclusions. Conclusions presented in the tables have been assigned the following levels of credibility: $\mathrm{U}=$ unequivocal, $\mathrm{C}=$ credible, $\mathrm{S}=$ unsupported (as outlined in the Methods chapter). 


\section{Review findings / results}

The results of the synthesis are reported by presenting each synthesised finding, listing the categories and displaying each conclusion (and illustration) linked with the generated category and synthesised finding. Each synthesised finding is also presented in a visual NOTARI View, which details the relationships between the conclusions, categories and synthesised findings. Levels of credibility are also assigned to each conclusion.

\section{Synthesis 1: The professionalization of midwifery, and provision of skilled attendance at birth is essential for decreasing maternal mortality}

A total of five categories from 24 conclusions were developed and synthesised into the key learning that professionalization of midwifery, and provision of skilled attendance at birth is essential for decreasing maternal mortality. The categories in this group relate to valuing maternal health staff through quality education, and providing a supportive and enabling environment in which to work, and the evidence appears to be unequivocal. (Figure 3) 
SYNTHESIS 1

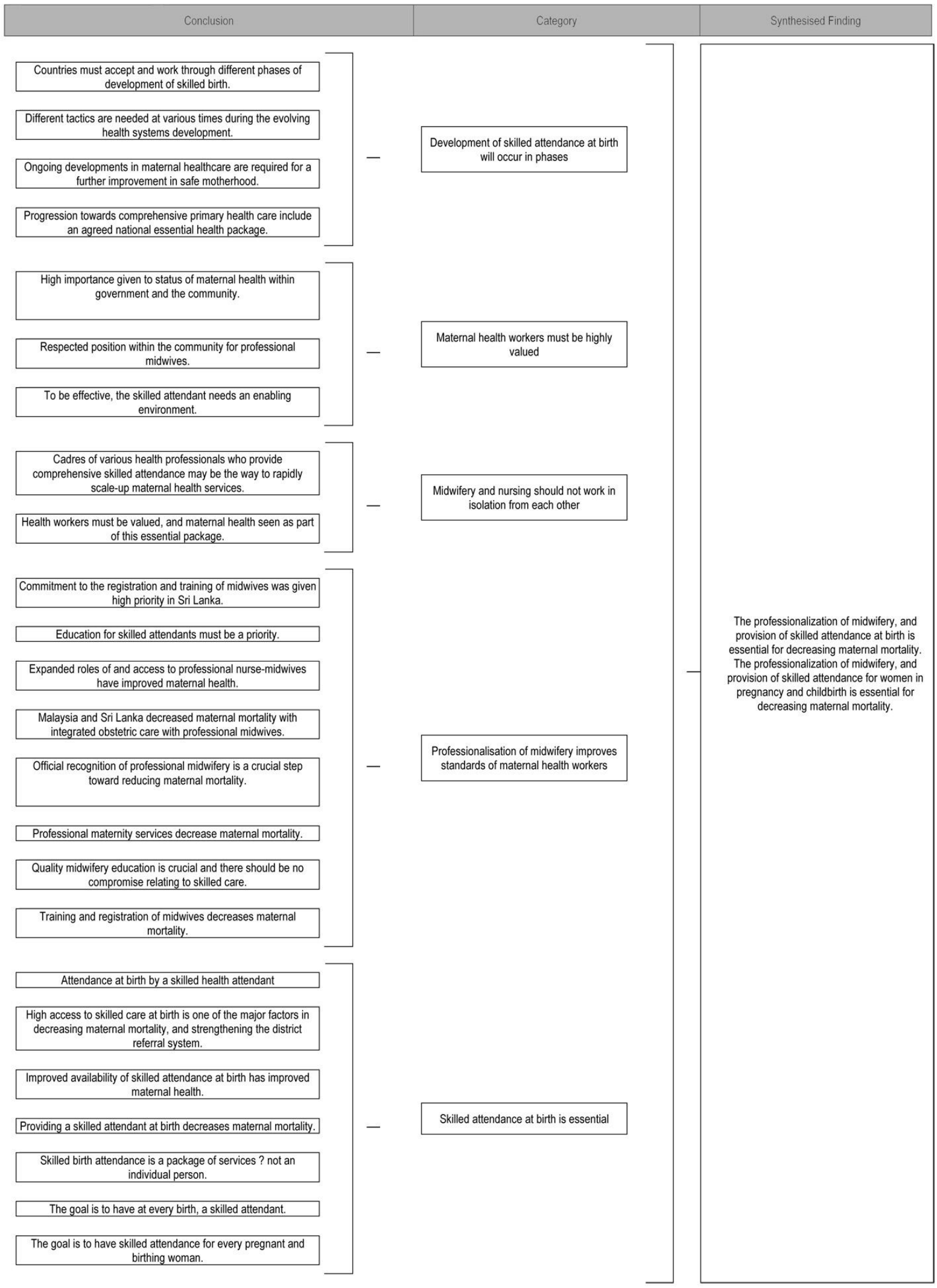

Figure 3 NOTARI view of Synthesis 1 


\section{Conclusion 1: Countries must accept and work through different phases of development of skilled birth. (Unequivocal)}

"Other challenges include acceptability of skilled attendants in and by the community, assisting them to stay in the community they serve, deployment in remote areas with a very small population and development of an adequate and appropriate reward system including career development schemes." 23 (page 26)

\section{Conclusion 2: Different tactics are needed at various times during the evolving health systems development. (Unequivocal)}

"The critical elements in the successive phases can be characterized as (a) establishing solid foundations for effective maternity care, (b) increasing access to such care, and (c) subsequently ensuring appropriate utilization of available services through improved quality." 24 (page 13)

\section{Conclusion 3: Ongoing developments in maternal healthcare are required for a further improvement in safe motherhood. (Credible)}

"In terms of developments in healthcare, recent activities such as the organization of the maternal death audit, advanced training for care providers, introduction of a two-way referral pregnancy record, have provided for a further improvement in safe motherhood." ${ }^{25}$ (page 122)

\section{Conclusion 4: Progression towards comprehensive primary health care include an} agreed national essential health package. (Unequivocal)

"Key strategies in these countries are an agreed national essential health package with defined priorities with links to the not-for-profit sector, non-governmental organisations, and other service providers in the system. The three stages of primary health care identified here (selective, in transition between selective and comprehensive, and comprehensive) fit with other analyses of phased health-system development." 26 (page 958) 


\section{Conclusion 5: High importance given to status of maternal health within government and the community. (Unequivocal)}

"Sri Lanka remains a remarkable exception as a result of the large and sustained investments it has made in providing primary health care and education to its population. This is especially reflected in the status of maternal health, with almost $94 \%$ of births in Sri Lanka by skilled health workers." 11 (page 818)

\section{Conclusion 6: Respected position within the community for professional midwives.} (Credible)

"Professional midwives have been relatively inexpensive, yet they have been the cornerstone for the expansion of extensive health systems to rural communities. They have provided accessible and culturally acceptable maternity services in hospitals and communities, gained sustained respect from the communities they serve, and are described with affection and admiration by managers and policymakers in each country." 17 (page 305)

\section{Conclusion 7: To be effective, the skilled attendant needs an enabling environment. (Unequivocal)}

"For not only must the skilled attendant be appropriately educated, but she needs an enabling environment like a fish needs water. This includes a legislative structure such as systems of communication and transport, equipment and supplies that can make or break the opportunity for the skilled attendant to promote safer childbirth." 27 (page 168)

\section{Conclusion 8: Cadres of various health professionals who provide comprehensive} skilled attendance may be the way to rapidly scale-up maternal health services. (Credible)

"New forms of health workers are being considered, such as comprehensive nurses competent to perform all basic nursing and midwifery skills at the village or district level. Cadres of workers trained and deployed to reduce maternal mortality must be planned in the context of a functioning health system and referral system and with specific linkage to other health professionals." 2 (page 330) 
Conclusion 9: Health workers must be valued, and maternal health seen as part of this essential package. (Credible)

"Midwifery and nursing should not be fields in isolation from each other or from other cadres of workers with frontline primary health care responsibility. These fields and their members must be understood by all policymakers interested in poverty reduction." 2 (page 328)

Conclusion 10: Commitment to the registration and training of midwives was given high priority in Sri Lanka. (Unequivocal)

"Registration of midwives, midwifery education, ante- and post-natal, infant and maternal welfare clinics, school medical services which included free treatment, and even a school meals service, all emerged in the interwar period." ${ }^{28}$ (page 267)

\section{Conclusion 11: Education for skilled attendants must be a priority. (Unequivocal)}

"The Thai government gave priority to training midwives and replacing TBAs with certified midwives." ${ }^{27}$ (page 168)

Conclusion 12: Expanded roles of and access to professional nurse-midwives have improved maternal health. (Unequivocal)

"In Thailand and Sri Lanka, specifically in poor and undeserved areas; modest but significant investments in improved maternal health services; expanded roles of and access to professional nurse-midwives; and ongoing political support and commitment." 22 (page 316)

\section{Conclusion 13: Malaysia and Sri Lanka decreased maternal mortality with integrated obstetric care with professional midwives. (Unequivocal)}

"Removing financial barriers to care was a key element in their success and skilled attendance reached more than 80 per cent of the population in the 1990s. To support competent and widely accepted rural midwives throughout the country, a network of accessible hospitals was developed.” 292007 (page 558) 


\section{Conclusion 14: Official recognition of professional midwifery is a crucial step toward reducing maternal mortality. (Unequivocal)}

"An outstanding feature of both countries is the long-standing professional status of midwifery. The early and massive efforts in competency-based training and placement of midwives in rural areas provided a means of reaching out to rural communities and resulted in the midwives being the frontline primary health care worker." ${ }^{24}$ (page 16)

\section{Conclusion 15: Professional maternity services decrease maternal mortality.} (Unequivocal)

"Before the 1970s most Malaysian women delivered at home with untrained birth attendants, and maternal mortality rates were 320 per 100,000 (in 1957). By the mid1980s, most births were at home, with 95 per cent attended by a trained midwife and maternal mortality had fallen to 43 per $100,000 .{ }^{3}$ (page 10)

\section{Conclusion 16: Quality midwifery education is crucial and there should be no compromise relating to skilled care. (Unequivocal)}

"Strengthening of training institutions in midwifery is a major issue, and mechanisms should be in place to ensure quality of training. (page 5) Sri Lanka has made midwifery an attractive and well-respected profession since the early period of its efforts to reduce MMR. Both Sri Lanka and Thailand had introduced a strong licensing and accreditation system in order to ensure that midwives, who were licensed were truly competent." 23 (page 31)

\section{Conclusion 17: Training and registration of midwives decreases maternal mortality. (Unequivocal)}

"Training in midwifery and the registration of midwives were introduced the same year as the establishment of the maternity hospital." ${ }^{25}$ (page 115)

\section{Conclusion 18: Attendance at birth by a skilled health attendant. (Unequivocal)}

"Almost 94\% of births in Sri Lanka are attended by skilled health workers." ${ }^{11}$ (page 818) 
Conclusion 19: High access to skilled care at birth is one of the major factors in decreasing maternal mortality, and strengthening the district referral system. (Unequivocal)

"One of the key factors that contributes to success in this regard is the availability of skilled attendants at community level with a referral back-up, providing emergency obstetric care and special care for newborns with problems, in a functioning health system." ${ }^{23}$ (page 2)

Conclusion 20: Improved availability of skilled attendance at birth has improved maternal health. (Unequivocal)

"This was a key strategy adopted through both expansion of the health unit system which provided assistance from trained midwives in home-based deliveries and by increasing the availability of facilities for institutional deliveries." ${ }^{30}$ (page 90)

\section{Conclusion 21: Providing a skilled attendant at birth decreases maternal mortality. (Unequivocal)}

"The Thailand experience in particular shows how providing skilled attendants, in this case midwives, resulted in dramatically reduced maternal and newborn mortality." 6 (page 41)

\section{Conclusion 22: Skilled birth attendance is a package of services not an individual person. (Unequivocal)}

"The network of basic health services had been put in place, and the systems focussed on improving access by removing geographic and/or economic barriers to the use of skilled attendance, not merely skilled attendants." ${ }^{17}$ (page 311 )

\section{Conclusion 23: The goal is to have at every birth, a skilled attendant. (Credible)}

"Maternal health workers rely on health workers to assist in achieving the goal of having, at every birth, no matter the location, an attendant with the capacity to provide basic emergency obstetric care." ${ }^{15}$ (page 50) 


\section{Conclusion 24: The goal is to have skilled attendance for every pregnant and birthing woman. (Credible)}

“All components of pregnancy and delivery care are provided by the more intensively trained maternal health workers, while lesser-trained workers still contribute to overall coverage by providing a crucial subset of interventions. This model creates the flexibility necessary to provide community based service delivery." ${ }^{15}$ (page 54)

The high status of maternal health, especially in a country like Sri Lanka, has seen the professional midwife become the cornerstone for providing primary health care to the community. Midwives are well respected members of the community, cost-effective and are highly valued. ${ }^{17}$ For this reason, 94\% of women giving birth in Sri Lanka are attended by a skilled birth attendant. ${ }^{11}$ These changes will not occur overnight. Development of skilled attendance will happen in phases, and at times different tactics will be required as the health system evolves. ${ }^{24}$ Professional skilled attendants will need to be accepted by the community, and earn their trust. They will need to provide high quality care to women and families. There will be challenges in providing the skilled attendants with a well-equipped and well staffed health facility, and a strong referral system, to keep them motivated and wanting to stay within that community, especially when it is rural. The professionalization of midwifery also demands quality midwifery education, not only for students in initial stages of training, but also ongoing education for staff, wherever they may be working. Commitment from management for staff to attend regular education days, and to take further training is essential. ${ }^{23}$ The concept of a skilled birth attendant who works within an 'enabling environment,' who has all the necessary structures to be able to promote safe childbirth. ${ }^{27}$ Overall, the professionalization of midwifery helps us to understand that skilled birth attendance is not provided by an individual person, but is a comprehensive package of services. ${ }^{17}$ 


\section{Synthesis 2: Free and equitable health care is the ideal, but countries must determine contextual and localised financing strategies}

A total of three categories from 18 conclusions were developed and synthesised into the key learning that all countries ideally should aim to provide free and equitable health care, but they must determine contextual and localised financing strategies to promote maternal health. Adequate financial resources must be a priority, but financing strategies will differ according to local context and appropriateness, and the stage of development within the individual health setting. What has worked in one location may not be suitable in another setting. This evidence appears to be credible. (Figure 4) 
SYNTHESIS 2

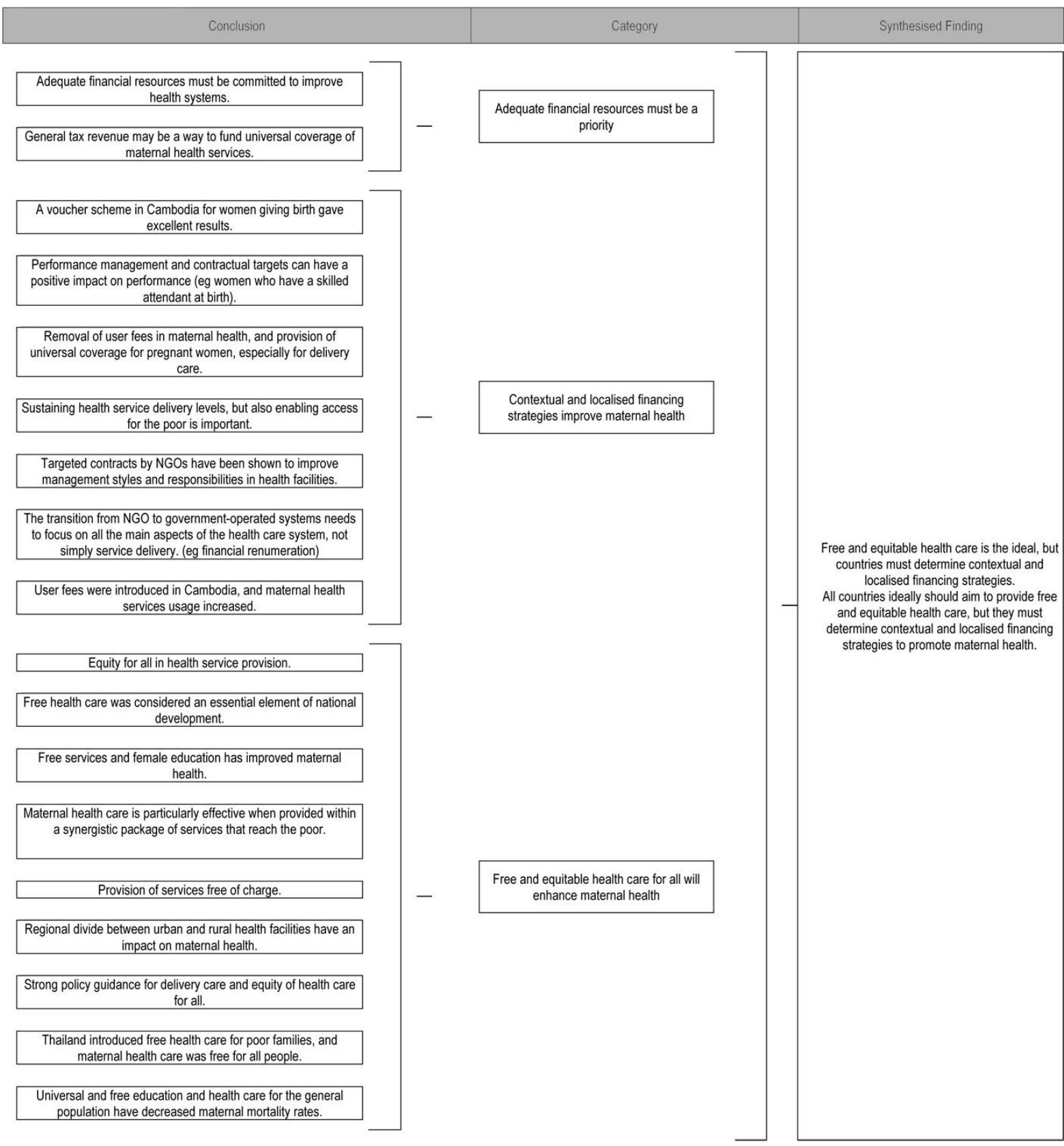

Figure 4 NOTARI view of Synthesis 2 
Conclusion 1: Adequate financial resources must be committed to improve health systems. (Unequivocal)

"Adequate financing for expanding access to and improving quality of skilled care at birth should be available. A mechanism for global pooling of funds for maternal and child health should be established. Special attention should be given to the poor and the disadvantaged, as well as underserved areas in countries." ${ }^{23}$ (page 6)

\section{Conclusion 2: General tax revenue may be a way to fund universal coverage of} maternal health services. (Unequivocal)

"In Sri Lanka and Malaysia, general tax revenue funds universal coverage of maternal health services, and achieve equitable service coverage." 31 (page 1459)

\section{Conclusion 3: A voucher scheme in Cambodia for women giving birth gave excellent results. (Unequivocal)}

"In the case of safe motherhood, vouchers cover, for instance, antenatal care (ANC) visits, transport to facilities, delivery fees and post-partum consultations for women and newborns." 18 (page 904)

\section{Conclusion 4: Performance management and contractual targets can have a} positive impact on performance (eg women who have a skilled attendant at birth). (Credible)

"Performance management, of both health care providers and administrators, can play a crucial role in the gradual handover of responsibilities. (page 197) Targets for each indicator were set by the contractor who also undertook the evaluation of the respective performance by the contracted facilities. Each target was worth a certain proportion of the amount that the facility could earn and the final financial remuneration was based on the sum of the individual scores for the contractual targets." 32 (page 202) 
Conclusion 5: Removal of user fees in maternal health, and provision of universal coverage for pregnant women, especially for delivery care. (Credible)

"Use of maternal health services is highly sensitive to the official fees charged." 31 (page 1459)

Conclusion 6: Sustaining health service delivery levels, but also enabling access for the poor is important. (Credible)

"User fees in tandem with health equity funds to enable financial access to health services for the poor are a useful means to progressively phase out the amount spent on staff performance bonuses while concurrently increasing salaries, and as such improving the likelihood of sustaining service delivery levels." 32 (page 206)

\section{Conclusion 7: Targeted contracts by NGOs have been shown to improve} management styles and responsibilities in health facilities. (Credible)

"NGOs, however, have been quite successful in delivering services in remote areas. The target related to deliveries in health facilities was fully met." 33 (page 8)

\section{Conclusion 8: The transition from NGO to government-operated systems needs to} focus on all the main aspects of the health care system, not simply service delivery. (eg financial renumeration) (Credible)

"The transition from NGO contracting to a government-operated health system, while maintaining the same level of service delivery, is feasible provided certain key factors are addressed. In Cambodia, the transition was achieved by focusing on all the main aspects of the health care system, not simply service delivery, and ensuring acceptable financial remuneration for staff of contracted health facilities through performance subsidies and user fee revenue." 32 (page 197)

\section{Conclusion 9: User fees were introduced in Cambodia, and maternal health} services usage increased. (Credible)

"In Cambodia, user fees were set at less than pre-existing unofficial charges...... an exemption scheme was also introduced." 31 (page 1459) 


\section{Conclusion 10: Equity for all in health service provision. (Unequivocal)}

"Access to all" had been the driving force in health care reforrn in Malaysia and Sri Lanka; safe motherhood had benefited along with other health programs, most likely because the midwife was the backbone of these broad health initiatives." ${ }^{34}$ (page 2)

\section{Conclusion 11: Free health care was considered an essential element of national development. (Unequivocal)}

"The governments of Malaysia and Sri Lanka implemented specific, sustained human development strategies in health, education, and nutrition, regarding free health care for the poor as an essential element of national development." ${ }^{17}$ (page 303)

\section{Conclusion 12: Free services and female education has improved maternal health.} (Unequivocal)

"The commitment of the health sector to provide services free of charge supported by non-health inputs, especially female education, has enabled Sri Lanka to make gains in maternal health." 30 (page 85 )

\section{Conclusion 13: Maternal health care is particularly effective when provided within} a synergistic package of services that reach the poor. (Unequivocal)

"The governments of Malaysia and Sri Lanka consistently implemented human development programs that reached underprivileged groups, such as the rural poor (both countries), disadvantaged ethnic groups and less developed states (Malaysia), and plantation workers (Sri Lanka).” ${ }^{24}$ (page 5)

\section{Conclusion 14: Provision of services free of charge. (Unequivocal)}

"Provision of services free of charge to the consumer was a key decision that facilitated equity and accessibility of services by all socio-economic groups." 35 (page 127) 


\section{Conclusion 15: Regional divide between urban and rural health facilities have an}

impact on maternal health. (Unequivocal)

"Persistently high maternal mortality rates are indicative of fundamental inequities in the health system, providing clear evidence of the low use, or capacity for use, of health centre and hospital referral facilities by women. The DHS data correlating education status and rural residence with lower facility utilization reinforce the finding that socioeconomic factors including gender, place, income and education are significant barriers to health service access." 36 (page 111)

\section{Conclusion 16: Strong policy guidance for delivery care and equity of health care for all. (Unequivocal)}

"Services were free to the consumer, thus eliminating one financial barrier. In Malaysia and Sri Lanka, transport to the referral facilities was also provided, eliminating a second financial barrier." 34 (page 24)

\section{Conclusion 17: Thailand introduced free health care for poor families, and maternal health care was free for all people. (Unequivocal)}

"In 1975 the poorest families were exempted from payments for health services, .... maternal, newborn, and child health care and immunisation were provided free of charge from the 1970s." ${ }^{26}$ (page 956)

\section{Conclusion 18: Universal and free education and health care for the general population have decreased maternal mortality rates. (Unequivocal)}

"Sri Lanka's achievements in providing universal and free education and health care to the general population are reflected in good social indicators of the poor and the poor fare considerably better in some key non-income dimensions of poverty than in most other developing countries." ${ }^{37}$ (page 17) 
Many of the included papers reported that Sri Lanka, Malaysia and Thailand all had a similar financial approach to providing free and equitable health care, funded by general tax revenue on the whole. ${ }^{24,31}$ This had been a strong commitment by these governments many years previously, and had clearly enhanced maternal health. Detailed economic analysis is outside the scope of this review, but obviously countries must determine contextual and localised financing strategies for their own setting. Cambodia, with its relatively recent history of social upheaval, reported other financing strategies, including voucher schemes, ${ }^{18}$ user fees ${ }^{31}$ and performance management and contractual targets. ${ }^{32}$ They have had mixed involvement from government and nongovernmental organizations, attempting to hasten the process of decreasing maternal mortality (and indeed other health indicators). These different financing strategies in Cambodia have yielded mixed results, and will require reassessment in the future as they strive to improve maternal health.

\section{Synthesis 3: Strengthening health systems with a package of comprehensive services is important}

A total of three categories from 19 conclusions were developed and synthesised into the key learning that approaching maternal health comprehensively, highlighting a package of services is of greater benefit than single stand-alone interventions. Evidence suggests this finding is unequivocal. Multi-dimensional approaches especially aimed at strengthening maternal health systems will also help to achieve wider health service improvement. (Figure 5) 


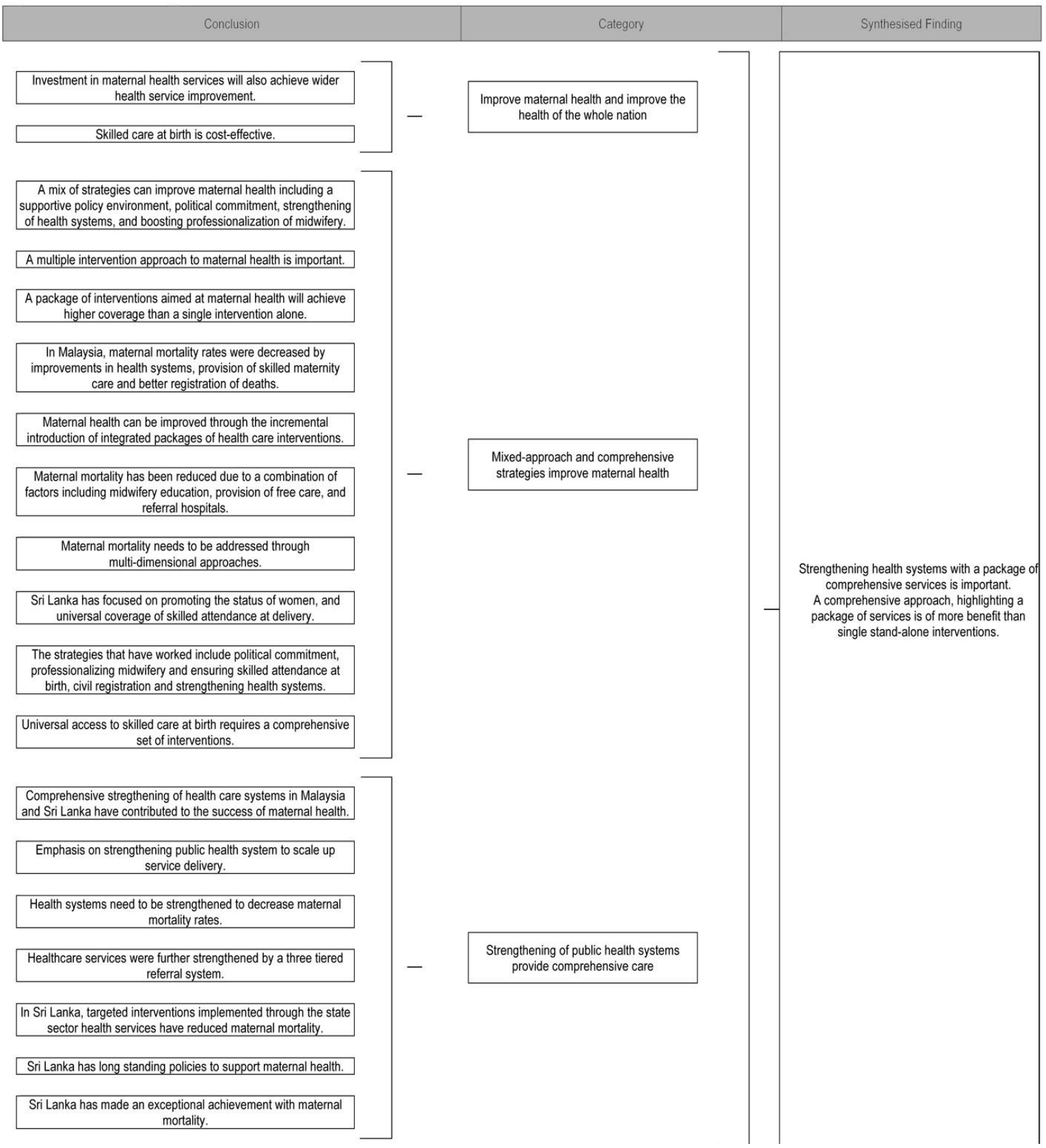

Figure 5 NOTARI view of Synthesis 3

\section{Conclusion 1: Investment in maternal health services will also achieve wider} health service improvement. (Unequivocal)

"Addressing maternal health therefore contributes to global and national efforts to alleviate poverty, and will also achieve wider health service improvement." 31 (page 1458) 


\section{Conclusion 2: Skilled care at birth is cost-effective. (Unequivocal)}

"Providing women with appropriate skilled care, especially at and around the time of birth, has the potential of reducing the incidence of morbidity." 6 (page 47)

\section{Conclusion 3: A mix of strategies can improve maternal health including a} supportive policy environment, political commitment, strengthening of health systems, and boosting professionalization of midwifery. (Unequivocal)

“Thailand, Malaysia, and Sri Lanka have all improved maternal health substantially through a mix of strategies including a supportive policy environment, political commitment, strengthening of health systems, and boosting professionalization of midwifery." 7 (page 282)

Conclusion 4: A multiple intervention approach to maternal health is important. (Unequivocal)

"Almost all interventions identified in the literature have mixed demand and supply side components - there were not an isolated intervention." ${ }^{18}$ (page 906)

\section{Conclusion 5: A package of interventions aimed at maternal health will achieve} higher coverage than a single intervention alone. (Unequivocal)

"A health centre intrapartum-care strategy involves midwives as the main providers, but with other attendants working with them in a team. Care involves preventive best practices, avoidance of iatrogenic procedures, and first-line management of complications." ${ }^{38}$ (page 1285)

\section{Conclusion 6: In Malaysia, maternal mortality rates were decreased by} improvements in health systems, provision of skilled maternity care and better registration of deaths. (Unequivocal)

"In Malaysia, the factors related to this decrease in maternal mortality are believed to be improvements in health systems, provision of skilled maternity care and better registration of deaths." ${ }^{39}$ (page 240 ) 


\section{Conclusion 7: Maternal health can be improved through the incremental}

introduction of integrated packages of health care interventions. (Unequivocal)

"In Malaysia and Sri Lanka, maternal and newborn mortality have been rapidly reduced since the $1950 \mathrm{~s}$, by a stepwise approach that has targeted especially underprivileged groups. In both countries, multisectoral strategies have combined improvements in maternal health care with efforts to improve water and sanitation, communication, and schooling, especially for girls." ${ }^{40}$ (page 996)

\section{Conclusion 8: Maternal mortality has been reduced due to a combination of factors including midwifery education, provision of free care, and referral hospitals. (Unequivocal)}

"Thailand, Malaysia and Sri Lanka have also seen declines in maternal mortality due to long-term investment in midwifery training and referral hospitals; free care and a supportive system with regulation, control, and supervision of the medical and midwifery profession; and information to confirm progress." ${ }^{14}$ (page 1192)

\section{Conclusion 9: Maternal mortality needs to be addressed through multi- dimensional approaches. (Unequivocal)}

"In regards to maternal health, this includes policy issues related to human resource development, health sector financing, attention to equity, legal issues and attention to prevailing societal norms and customs for community involvement." 23 (page 1)

\section{Conclusion 10: Sri Lanka has focused on promoting the status of women, and universal coverage of skilled attendance at delivery. (Unequivocal)}

"Firstly, Sri Lanka can boast a fall in MMR from 2200/100 000 in 1920 to 70/100 000 in 1997. This has been attributed to three main factors, namely: the relatively high status of women in society, focused investments in maternal health and a policy to attain universal coverage of skilled attendance at delivery." ${ }^{27}$ (page 168) 


\section{Conclusion 11: The strategies that have worked include political commitment, professionalizing midwifery and ensuring skilled attendance at birth, civil registration and strengthening health systems. (Unequivocal)}

"The strategies used in Malaysia and Sri Lanka over the past half century include maintaining a supportive policy environment and political commitment; professionalizing midwifery and ensuring skilled attendance during childbirth; strengthening health systems; introducing civil registration; and improving access to and quality of care through rural midwives with closely linked backup emergency obstetric services." 34 (page v)

\section{Conclusion 12: Universal access to skilled care at birth requires a comprehensive set of interventions. (Unequivocal)}

"One of the reasons for the slow progress in improving maternal and newborn health is the adoption of a single action response, rather than a comprehensive approach. For example, investing in emergency obstetric care facilities without attention to the other components of skilled care at birth." ${ }^{23}$ (page 27)

\section{Conclusion 13: Comprehensive strengthening of health care systems in Malaysia and Sri Lanka have contributed to the success of maternal health. (Unequivocal)}

"In Malaysia and Sri Lanka, four key components contributed to the success of both national programs: comprehensive strengthening of human development programs (ie. Infrastructure, education, sanitation and health systems) specifically in poor and undeserved areas; modest but significant investments in improved maternal health services; expanded roles of and access to professional nurse-midwives; and ongoing political support and commitment." 22 (page 316)

Conclusion 14: Emphasis on strengthening public health system to scale up service delivery. (Unequivocal)

"Sri Lanka and Malaysia have a public health service with a large network of public services, and have funded them to a standard that has maintained public confidence. In these countries, the private sector has grown to take up demand from the better off, 
offering more convenient and more pleasant outpatient care, but has not taken up a major role for inpatient provision." 3 (page 10)

\section{Conclusion 15: Health systems need to be strengthened to decrease maternal mortality rates. (Unequivocal)}

"Critical analyses highlight the need to strengthen health systems. This requires skilled birth attendants providing care during childbirth, backed by basic and comprehensive essential obstetric care services." ${ }^{17}$ (page 299)

\section{Conclusion 16: Healthcare services were further strengthened by a three tiered} referral system. (Unequivocal)

"The healthcare services were further strengthened on a three tiered basis so that a referral system was established between the primary, secondary and tertiary care units." ${ }^{25}$ (page 115)

\section{Conclusion 17: In Sri Lanka, targeted interventions implemented through the} state sector health services have reduced maternal mortality. (Unequivocal)

"The availability of a comprehensive health care package aimed at married women of the reproductive age group through a field-based service delivery system that is labour intensive and relatively cost effective, supported by a widespread network of institutional facilities, is the key factor in improving maternal health." ${ }^{35}$ (page 128)

\section{Conclusion 18: Sri Lanka has long standing policies to support maternal health.} (Unequivocal)

"Sri Lanka's investments in health have been proportionately greater than in the other countries and egalitarian, protecting the poor from the costs of inpatient services and keeping levels of private spending relatively lower, especially for reproductive health." 41 (page 25) 


\section{Conclusion 19: Sri Lanka has made an exceptional achievement with maternal mortality. (Unequivocal)}

"This achievement is the result of the extended availability of antenatal care and institutional delivery services that has been an integral part of the state health care system for more than half a century." ${ }^{37}$ (page 17)

Mixed approach and comprehensive strategies will have a greater impact on maternal health, and if maternal health is improved, the whole country will also achieve wider health benefits. ${ }^{31}$ The provision of skilled attendance at birth also impacts on not only mortality, but also levels of morbidity, which also has an overall impact on the health of a nation. If a woman is unwell, it impacts not only on herself, but also the health and welfare of her family, and to a lesser extent, her community. ${ }^{6}$ Many of these papers reported that a combination of factors were responsible for reducing maternal mortality, including political commitment, supportive policies, strengthening of health systems and professionalizing midwifery. ${ }^{7,34}$ A common theme emerging was that a package of interventions aimed to improve maternal health was much more likely to succeed than a single intervention alone. ${ }^{38}$ 


\section{Synthesis 4: Political commitment at all levels of maternal health policy development}

A total of three categories drawn from 10 conclusions were developed and synthesised into the key learning that political will and commitment is required at all levels when determining maternal health policies, and it appears to be mostly unequivocal evidence. Countries must determine policies with their local context in mind, but political will must ensure policies promote maternal health at all levels of policy development. (Figure 6)

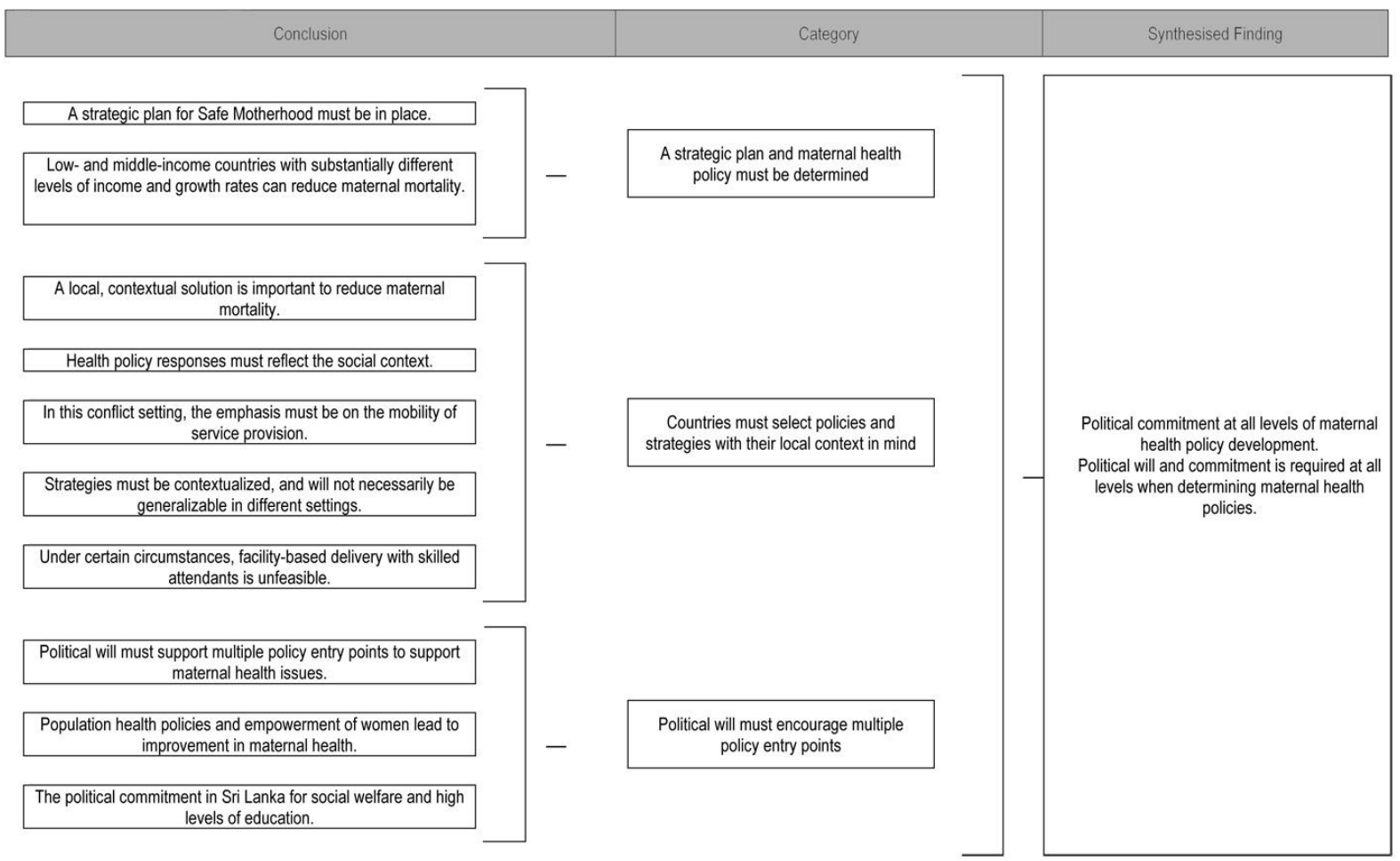

Figure 6 NOTARI view of Synthesis 4

\section{Conclusion 1: A strategic plan for Safe Motherhood must be in place.}

\section{(Unequivocal)}

"National Policies and Strategies on Safe Motherhood 1997, including the four pillars of Safe Motherhood (family planning, ANC, clean labour and delivery and essential obstetric care), are part of the strategic plan for Cambodia." ${ }^{42}$ (page 12) 


\section{Conclusion 2: Low- and middle-income countries with substantially different}

levels of income and growth rates can reduce maternal mortality. (Unequivocal)

"Sri Lanka has obtained better results than its peers for a lower health expenditure per capita, and Malaysia has attained the same or better maternal mortality outcomes at a much lower level of health expenditures per capita. This finding is consistent with other evidence: it is not the level of expenditure, but the specific interventions, that make the difference in lowering maternal mortality." ${ }^{24}$ (page 5)

\section{Conclusion 3: A local, contextual solution is important to reduce maternal mortality. (Unequivocal)}

"Countries need to assess their current status and select policy options that are feasible and most likely to provide immediate impact within their own context.' ${ }^{17}$ (page 310 )

\section{Conclusion 4: Health policy responses must reflect the social context. (Credible)}

The case of Cambodia illustrates that policy responses such as health service contracting, public-private collaborations and equity funds, although not universal solutions for health system strengthening, can still be considered as highly adaptive policy responses in a social context." ${ }^{36}$ (page 114)

Conclusion 5: In this conflict setting, the emphasis must be on the mobility of service provision. (Credible)

"Continuity of care and delivery of services under such conditions can only be achieved within a structure that emphasises mobility of service provision to the population, rather than centralised services that must be accessed by the population." ${ }^{15}$ (page 54)

Conclusion 6: Strategies must be contextualized, and will not necessarily be generalizable in different settings. (Unequivocal)

"The choice of an intervention depends on the context and whatever the intensity of the work performed, it never solves the problem on its own." 18 (page 907) 


\section{Conclusion 7: Under certain circumstances, facility-based delivery with skilled attendants is unfeasible. (Credible)}

"In eastern Burma, continuing conflict and lack of functioning health systems render the emphasis on facility-based delivery with skilled attendants unfeasible. Along the Thailand/Burma border, local organisations have implemented an innovative pilot, the Mobile Obstetric Maternal Health Workers (MOM) Project, establishing a three-tiered collaborative network of community-based reproductive health workers." ${ }^{15}$ (page 44)

\section{Conclusion 8: Political will must support multiple policy entry points to support maternal health issues. (Unequivocal)}

"Multiple entry points to policy should be supported, including support of parliamentary committees, female representation in parliaments, and female leadership in human resource development. In order to support nurses and midwives, enabling legislation must recognize and support them as professionals and a legal infrastructure must buttress their practice. Top management posts for skilled attendants should be created." 2 (page 327)

\section{Conclusion 9: Population health policies and empowerment of women lead to improvement in maternal health. (Unequivocal)}

"National Population Policy 2003 - these policies recognize the central role of reproductive health services, empowerment of women and the link between poverty and rapid population growth." 42 (page 13)

\section{Conclusion 10: The political commitment in Sri Lanka for social welfare and high levels of education. (Unequivocal)}

"High degree of commitment to social welfare and an expensive social welfare package implemented continuously since independence. These measures resulted in widespread access to healthcare and high levels of education of both men and women." ${ }^{25}$ (page 114) 
The World Health Organization, or international gatherings such as the Millennium Declaration can propose excellent strategies, but without each individual country determining and committing to maternal health policies, and without the political will on all levels, it will not be implemented. ${ }^{42}$ Individual countries may share successful strategies for maternal health, but must assess their own current situation and select policy options that are feasible, and most likely to have the greatest impact within their local context. Not all policies will have a 'one size fits all' approach, and maternal health policies should not be expected to do so. ${ }^{18}$ Political will must also encourage multiple policy entry points to impact fully on maternal health, with female representation in parliament, female leadership in health management and education, and midwifery professionals advocating for all birthing women and skilled birth attendants. $^{2}$

\section{Synthesis 5: Appropriate task-shifting where strong referral links exist may be required}

A total of three categories from 19 conclusions were developed and synthesised into the key learning that task-shifting for health workers where appropriate, especially when strong referral systems are in place, may enhance maternal health. Evidence for this finding appears credible. Task-shifting can increase the coverage of maternal health interventions, but strong referral systems must be in place between all levels of health care workers, for this strategy to work effectively. (Figure 7) 


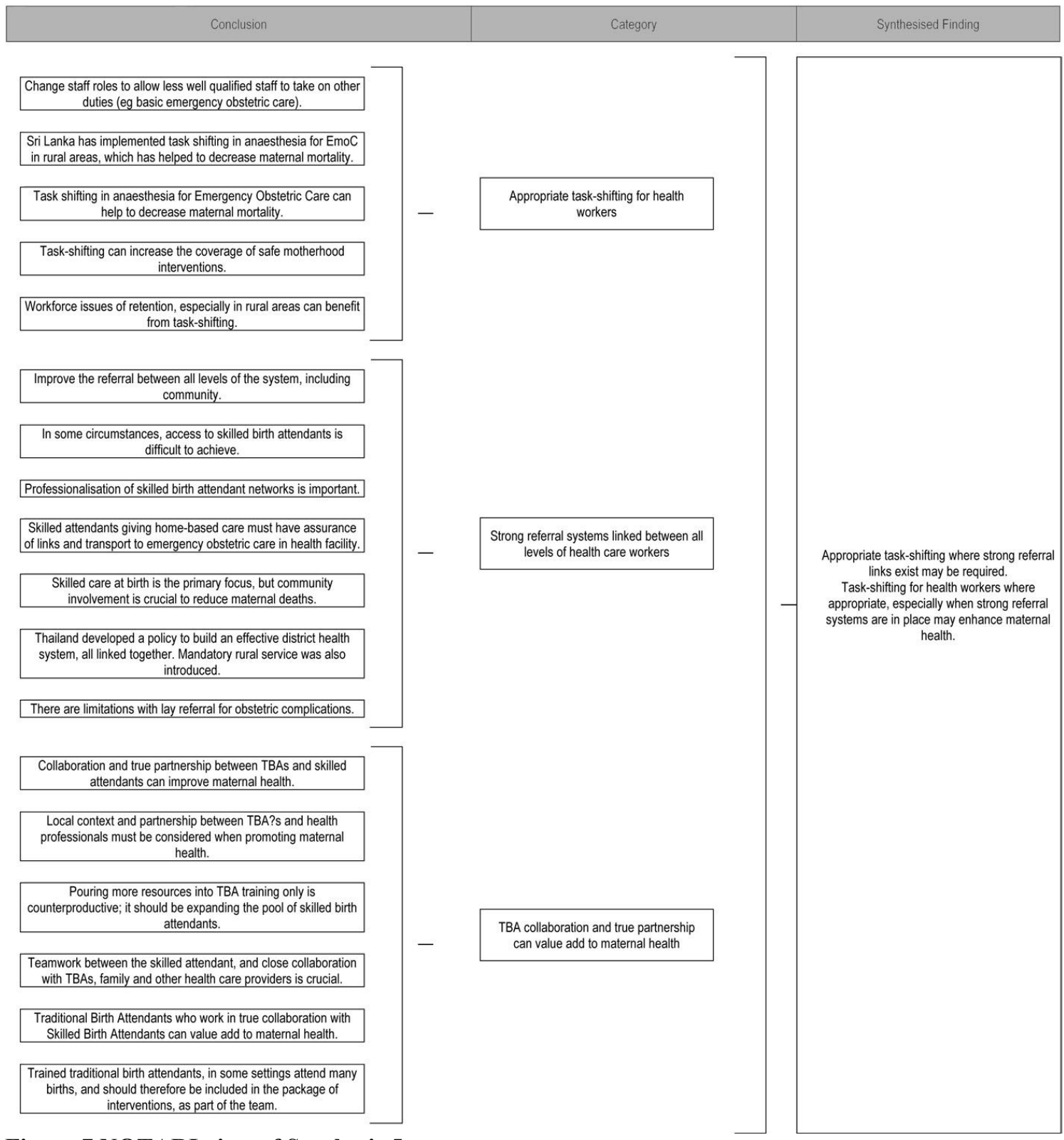

Figure 7 NOTARI view of Synthesis 5

\section{Conclusion 1: Change staff roles to allow less well qualified staff to take on other duties (eg basic emergency obstetric care). (Credible)}

"Another option is to change roles so that less well qualified staff take on duties that were previously reserved for doctors, for example, nurses and assistant nurse midwives have been trained to provide basic emergency obstetric care, post abortion care and anaesthesia. This has been shown to be successful, enabling them to provide life-saving services in remote areas where there is no doctor, and support doctors in surgical obstetrics." 3 (page 17) 
Conclusion 2: Sri Lanka has implemented task shifting in anaesthesia for EmoC in rural areas, which has helped to decrease maternal mortality. (Credible)

"Sri Lanka is the only South Asian country that has been successful in reducing maternal mortality, primarily through increasing the availability of skilled birth attendance and EmOC. This relies on trained medical officers in emergency situations in smaller rural hospitals, where anaesthetists are not available." ${ }^{43}$ (page 25)

\section{Conclusion 3: Task shifting in anaesthesia for Emergency Obstetric Care can help} to decrease maternal mortality. (Credible)

"Structured task shifting programmes in anaesthesia for Emergency Obstetric Care must be scaled up in South Asia in order to provide the full range of services necessary to reduce maternal deaths." ${ }^{43}$ (page 29)

\section{Conclusion 4: Task-shifting can increase the coverage of safe motherhood interventions. (Credible)}

"Developing countries facing human resource shortages have consistently found safe motherhood goals such as universal skilled attendance at birth hard to meet. Taskshifting, or the delegation of clinical tasks from higher-level healthcare providers to mid- or lower-level healthcare providers is therefore necessary to increase the coverage of safe motherhood interventions in high-mortality, low resource settings." 22 (page 318)

\section{Conclusion 5: Workforce issues of retention, especially in rural areas can benefit from task-shifting. (Credible)}

“There are several benefits in using mid-level providers to perform anaesthesia for EmOC. The training cost and training period for mid-level providers are lower than those of anaesthetists. Additionally, the retention rate of mid-level providers in rural areas is higher than specialists, including anaesthetists. This can increase the availability of EmOC in rural areas and reduce the need for referrals to other centres." 43 (page 22) 
Conclusion 6: Improve the referral between all levels of the system, including community. (Credible)

"Developing and implementing approaches to working more extensively with volunteer health workers, and addressing the transition between use of the traditional birth attendant and skilled attendant. Ensure the WHO recommendations for the

minimum numbers of Comprehensive and basic Obstetric Facilities are applied." 42 (page 15)

Conclusion 7: In some circumstances, access to skilled birth attendants is difficult to achieve. (Credible)

“The MOM Project has also had to provide maternal health care under circumstances where there is no foreseeable access to skilled birth attendants, as defined by the WHO, whose definition explicitly excludes non-accredited individuals, even if they are able to provide interventions that improve pregnancy outcomes." 15 (page 46)

Conclusion 8: Professionalization of skilled birth attendant networks is important. (Unequivocal)

"Countries must officially accredit midwives and other delivery care professionals, have clear policies on which kind of health provider can provide particular services, disseminate clear clinical protocol, and consider delegation/upskilling for the shortterm." 2 (page 329)

\section{Conclusion 9: Skilled attendants giving home-based care must have assurance of} links and transport to emergency obstetric care in health facility. (Unequivocal)

"Home-based care without assurance of links and transport to emergency obstetric care in facilities will also limit the effectiveness of this strategy and could compromise community confidence in the midwife." 38 (page 1292) 


\section{Conclusion 10: Skilled care at birth is the primary focus, but community involvement is crucial to reduce maternal deaths. (Unequivocal)}

"Community involvement in taking care of pregnant women and newborns, and in timely referral of pregnant women and their newborns when complications and problems arise." 23 (page 5)

\section{Conclusion 11: Thailand developed a policy to build an effective district health} system, all linked together. Mandatory rural service was also introduced. (Unequivocal)

"In Thailand in the 1980s, government policy supported development of the District Health System. By the 1990s, each district, typically with a population of 50,000, was served by a district hospital of 30-120 beds operated by a team of qualified health professionals, linked to subdistrict health centres serving a population of 5000 and staffed by three to four paramedics and providing better geographical access to services especially for the rural poor. To help address the human resource gap, mandatory rural service was instituted in 1971." ${ }^{26}$ (page 956)

\section{Conclusion 12: There are limitations with lay referral for obstetric complications.} (Unequivocal)

"Delays in reaching care are often summarized as the 'three delays' - delay in recognizing complications, delay in reaching care and delay in receiving appropriate care at the health facility." 6 (page 44 )

\section{Conclusion 13: A health policy turn-around determined that traditional birth} attendants were not effective at reducing maternal mortality rates. (Credible)

"It appears that, by focusing on the attendant's capacity to respond to obstetric emergencies, policy makers ignored other skills and expertise of the TBA. The decision to withdraw support for TBA training and reallocate it to the promotion of skilled attendants training was made on the evidence that worldwide maternal mortality rates were not falling." 12 (page 308) 
Conclusion 14: Collaboration and true partnership between TBAs and skilled attendants can improve maternal health. (Credible)

"This successful model (in Malaysia) is based on collaboration and true partnership in which there is mutual and genuine respect for each other's skills and practices." ${ }^{12}$ (page 310)

Conclusion 15: Local context and partnership between TBAs and health professionals must be considered when promoting maternal health. (Credible)

"In some cases, the TBA trainers, many of them professional midwives, dismissed the importance of local customs and practices, seeing them as barriers to improved maternal health. Rarely were partnerships encouraged." ${ }^{12}$ (page 308)

Conclusion 16: Pouring more resources into TBA training only is counterproductive; it should be expanding the pool of skilled birth attendants. (Unequivocal)

"The best way of using a community resource like the TBA's is to treat them as key informants and encourage them to refer pregnant women to health centres." 7 (page 282)

Conclusion 17: Teamwork between the skilled attendant, and close collaboration with TBAs, family and other health care providers is crucial. (Credible)

"These lay care-givers play an important social and cultural role, and often control and facilitate access to skilled attendants and referral care." ${ }^{6}$ (page 46)

Conclusion 18: Traditional Birth Attendants who work in true collaboration with Skilled Birth Attendants can value add to maternal health. (Credible)

"World Health Report 2005 proposes that where TBAs are well integrated into the community and are well respected, efforts can be made to redefine their role to become support workers or health promoters." 23 (page 25) 


\section{Conclusion 19: Trained traditional birth attendants, in some settings attend many births, and should therefore be included in the package of interventions, as part of the team. (Credible)}

"Trained traditional birth attendants without the support of skilled back-up services do not reduce the maternal mortality ratio. However they may identify early signs of complications during labour and delivery, and refer women for treatment." 38 (page 1293)

The shortage of appropriately qualified staff has always impacted on the quality of maternal health services, and task-shifting has been one approach adopted by countries to overcome this. Task-shifting is when clinical tasks are delegated from high-level health care staff, with appropriate training, to mid or low-level health care staff. ${ }^{22}$ It has been especially well utilized in the provision of emergency obstetric care, post abortion care and anaesthesia. This changing in staff roles appears to have worked well in rural areas where there isn't a doctor to provide these services, or as a support to assist when a surgical obstetric service was required. ${ }^{3}$ Task-shifting is not an appropriate method if there is not an adequate referral system in place. If a skilled birth attendant is providing services without the assurance of referral links and transport to emergency back-up obstetric care, this will limit the impact this strategy can have. ${ }^{38}$ It will also undermine the confidence of the skilled birth attendant, and the community she works within. One paper reported that in Thailand, priority was given to building up the district hospital system. ${ }^{26}$ Each health district was served by a district hospital of $30-120$ beds, staffed with qualified health professionals, and then linked to the subdistrict health centres staffed by less qualified health staff. With this model, effective referral occurred where necessary in a timely manner, and people could easily access services. Another area that concerns task-shifting is Traditional Birth Attendants. There was a global health policy turn-around in the 1990's that determined that training Traditional Birth Attendants was counterproductive and not effective in reducing maternal mortality rates. ${ }^{12}$ Training for TBA's was ceased, and in many regions they were no longer considered as a player in the maternal health field. Many papers reported on the benefit of TBA's, and in many cultures if they are valued and respected within their communities, they can continue to play an important role. Task-shifting in this case means that their role can be redefined, 
and the focus moved to support, health promotion, and facilitating referral to a skilled

birth attendant. ${ }^{6,7,23}$ In Malaysia, TBA's have been an integral part of the maternal health strategy, and between midwives and TBA's there is a mutual and genuine respect based on collaboration and true partnership, in a desire to improve maternal health. ${ }^{12}$

\section{Synthesis 6: Access issues for women to quality services in any location is of high priority}

A total of five categories from 18 conclusions were developed and synthesised into the key learning that issues of accessing maternal health care include availability to quality staff, and physical and economic issues of access, whatever the location. These findings are mostly unequivocal. Many factors need to be addressed when looking at access issues, especially where cultural issues may act as a barrier. (Figure 8) 


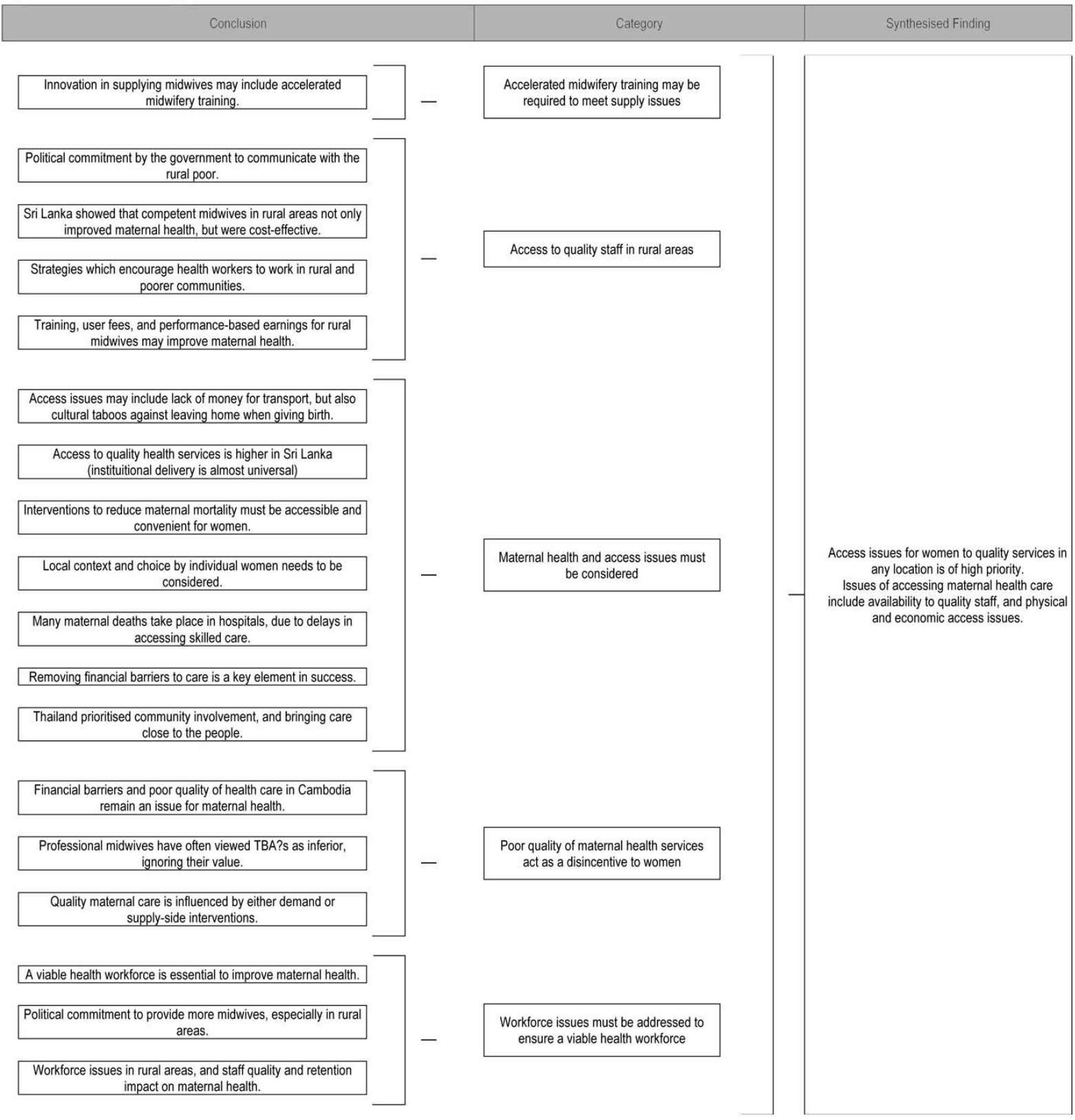

Figure 8 NOTARI view of Synthesis 6

\section{Conclusion 1: Innovation in supplying midwives may include accelerated midwifery training. (Credible)}

"This increase in skilled attendance is the next frontier for progress in these countries and might require innovation to achieve supply (eg, accelerated midwifery training) and demand (eg, conditional cash transfers for facility births and transport subsidies)." 26 (page 955) 
Conclusion 2: Political commitment by the government to communicate with the rural poor. (Unequivocal)

"Both countries demonstrated an early commitment to maternal and child health through sustained financial, managerial, and political support. The countries were politically stable, and their health care systems provided strong linkages and feedback between the rural poor and the ruling political establishment, reinforcing rapid and integrated rural development." 17 (page 305)

\section{Conclusion 3: Sri Lanka showed that competent midwives in rural areas not only} improved maternal health, but were cost-effective. (Unequivocal)

"The experience of Sri Lanka is instructive, in that improvement of rural health centres staffed by competent midwives reduced the need for beds in urban referral hospitals with large cost savings, and reduced family opportunity costs with care being near to home." ${ }^{26}$ (page 958)

\section{Conclusion 4: Strategies which encourage health workers to work in rural and poorer communities. (Unequivocal)}

"Countries have tried different ways to get trained health workers to work in areas where the poor live, with initiatives such as hardship allowances for remote postings, permitting private practice (e.g. Sri Lanka, Malaysia) and making rural postings as prerequisites for promotion." 3 (page 17)

\section{Conclusion 5: Training, user fees, and performance-based earnings for rural} midwives may improve maternal health. (Credible)

"Most government health workers prefer being in cities. There are not enough midwives in rural areas where most Cambodians live. And then there is a lack of motivation because of very poor salaries." 7 (page 282) 


\section{Conclusion 6: Access issues may include lack of money for transport, but also}

cultural taboos against leaving home when giving birth. (Unequivocal)

"Skilled birth attendance remains low and for most of these countries has changed little in the past decade, indicating a mix of constraints from absence of midwives and access issues to cultural taboos against leaving home around the time of birth." ${ }^{26}$ (page 955)

\section{Conclusion 7: Access to quality health services is higher in Sri Lanka (instituitional delivery is almost universal). (Unequivocal)}

"Access to quality health services is high and evenly distributed, and instituitional delivery is almost universal." ${ }^{41}$ (page 19)

\section{Conclusion 8: Interventions to reduce maternal mortality must be accessible and convenient for women. (Unequivocal)}

"Women's socioeconomic status is clearly a major factor in why some women seek care and others do not. Services must come to them. If cost is not the primary barrier, mobility may prevent healthcare utilization, such as when it is not customary for a woman to travel unaccompanied beyond her village." 22 (page 321)

\section{Conclusion 9: Local context and choice by individual women needs to be considered. (Credible)}

"Expanded access to skilled birth attendance has been achieved either by providing services for home births, for basic facility births, or by gradually concentrating all births in hospitals with full services. The evidence does not indicate that any one of these options is more effective than the others." ${ }^{17}$ (page 311 )

\section{Conclusion 10: Many maternal deaths take place in hospitals, due to delays in accessing skilled care. (Unequivocal)}

"Delay due to such difficulties is known as the second delay which contributes to deaths; the first delay being in the recognition by women and families of the need to seek care, and the third being the delay in receiving effective interventions." ${ }^{14}$ (page 1196) 


\section{Conclusion 11: Removing financial barriers to care is a key element in success.} (Unequivocal)

"Care for sudden, life-threatening conditions, such as serious complications during childbirth, is often denied to poor families. Informal fees for acute maternal conditions can be high, even ruinous to the family, and can be effective deterrents to the seeking of care. Where transportation schemes for obstetric emergencies have not been organized, physical access is often limited due to cost and access to transportation." ${ }^{24}$ (page 10)

\section{Conclusion 12: Thailand prioritised community involvement, and bringing care close to the people. (Unequivocal)}

"In Thailand, community volunteers play an important part, promoting behaviour change and providing selected maternal, newborn, and child health, nutrition services, and promoting immunisation." ${ }^{26}$ (page 956)

\section{Conclusion 13: Financial barriers and poor quality of health care in Cambodia remain an issue for maternal health. (Unequivocal)}

"There are considerable financial barriers to essential services, limited physical access and poor quality of health care, offering low-value for money, result in a low proportion of the people using government provided health services." 33 (page 2)

\section{Conclusion 14: Professional midwives have often viewed TBAs as inferior, ignoring their value. (Credible)}

"Professional midwives ....often harbor the same discriminatory attitudes to traditional practices and practitioners. If TBAs know the mothers are going to be poorly treated, they can be reluctant to refer them, and if they do refer, the women often refuse to go." 12 (page 309)

\section{Conclusion 15: Quality maternal care is influenced by either demand or supply-} side interventions. (Unequivocal)

\footnotetext{
"To promote the uptake of quality care, there are two possible approaches: influencing the demand and / or the supply of care." ${ }^{18}$ (page 901)
} 
Conclusion 16: A viable health workforce is essential to improve maternal health. (Unequivocal)

"The question of human resources for health has received long overdue attention from the international public health community. A viable health workforce is the key to a strong health system that is necessary for reaching the MDGs." 2 (page 319)

\section{Conclusion 17: Political commitment to provide more midwives, especially in rural areas. (Unequivocal)}

"For maternal services, delivery by trained health professionals increased about 2 times: $22.4 \%$ in 2003 to $46 \%$ in 2007. In late 2007, the Royal Government of Cambodia has issued a policy for supporting midwives for safe delivery at public health sector level." (page 6) "Increased access to skilled attendants for deliveries with particular focus on rural areas." ${ }^{42}$ (page 15)

\section{Conclusion 18: Workforce issues in rural areas, and staff quality and retention impact on maternal health. (Unequivocal)}

"On a regional basis, Cambodia has a very low staff to population ratio of 1:1000, half the World Health Organization (WHO) recommended rate of 2:1000.” ${ }^{36}$ (page 110)

Access issues incorporate many various factors, from supplying adequate, high quality trained health staff, especially in rural areas, health facilities that are accessible for women, (especially in some cultures where there is taboo surrounding leaving your home at the time to give birth), and financial costs for transport to health facilities. In some cultures, women have no say as to accessing these services, even if they are available, as husbands and/or mother-in-laws hold all the decision making power, and finances. ${ }^{26}$ Services must be easily accessible for women. ${ }^{22}$ In low-income countries, if it is not convenient for women to access health services, they will have to choose between spending time and money to travel to the health service, as well as taking them away from their normal daily tasks (working to grow food and collect water, etc). In 
Thailand, this need was recognized, and priority was given to involving maternal community workers who could bring the health care close to the people. ${ }^{26}$ Human resources and workforce issues to increase access to quality skilled birth attendants, especially in rural areas is a major concern, and not only for low-income countries. If improving maternal health is the key goal, then accessing quality skilled staff is essential, wherever you live. ${ }^{36}$ Cambodia simply does not have enough midwives, and health policy makers have recognised this as a major problem. ${ }^{42}$ Efforts to address this supply issue have discussed the need to accelerate midwifery training, to increase numbers appropriately. ${ }^{26}$ Other methods involved rural midwives receiving performance-based earnings, to make it attractive for them to work there, and as an incentive to keep them there. ${ }^{7}$ These issues are complex though, and there were reports of women not using the available maternal health services, as the professional midwives were unkind to the women, and if they were accompanied by a traditional birth attendant, they were ignored and felt inferior to the hospital staff. ${ }^{12}$

\section{Synthesis 7: Empowerment of women will actively promote maternal health}

A total of three categories drawn from 14 conclusions were developed and synthesised into the key learning that strategies that focus on empowering women will in turn actively promote maternal health. These findings were unequivocal. The status of women within a society influences the importance placed on maternal health. (Figure 9) 


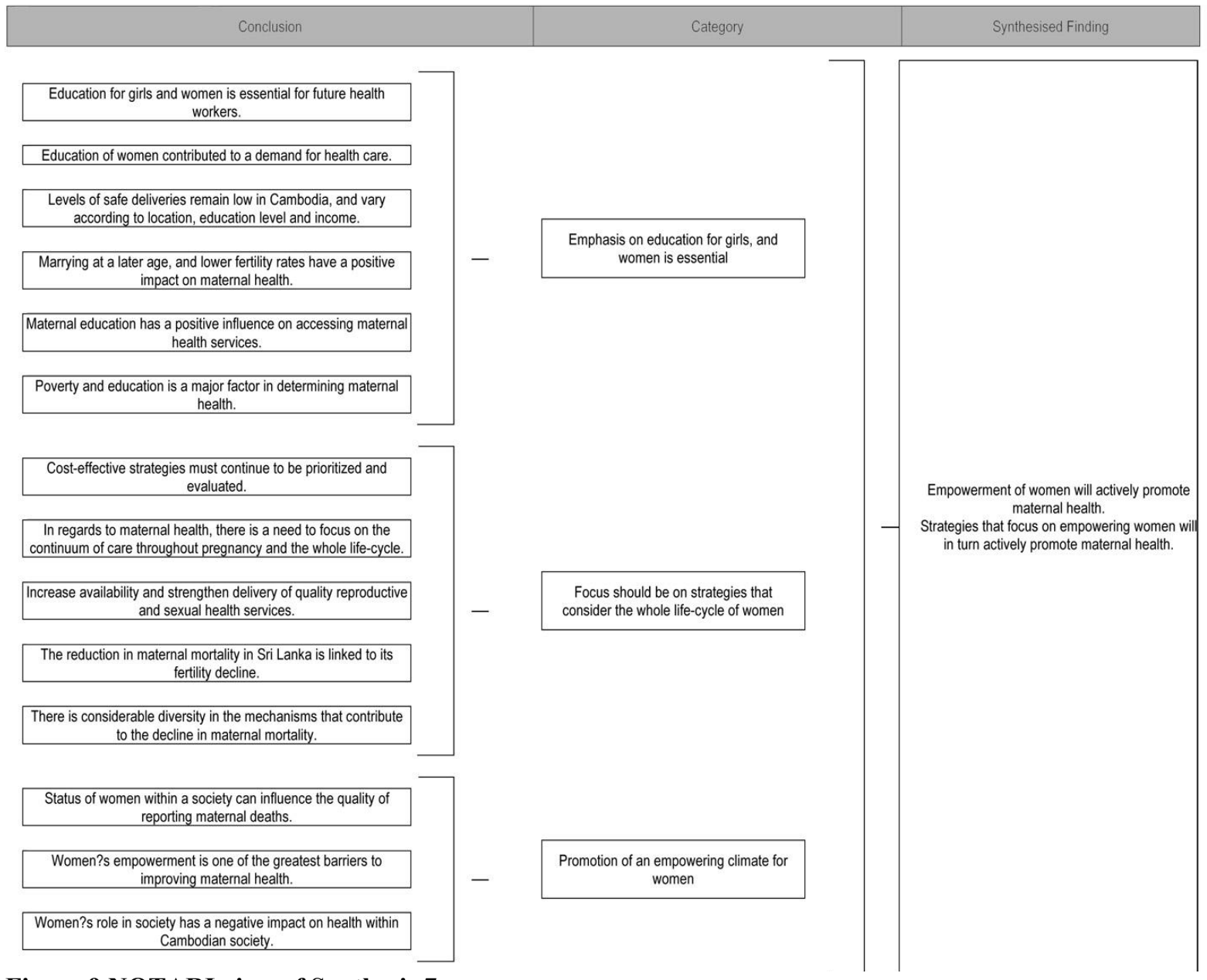

Figure 9 NOTARI view of Synthesis 7

\section{Conclusion 1: Education for girls and women is essential for future health workers. (Unequivocal)}

"Ministries of health, along with education and other ministries involved in workforce planning must determine whether the numbers of professionals trained in pregnancy and delivery care needed to reach the population are even possible given the numbers of secondary school graduates." ${ }^{2}$ (page 329 )

\section{Conclusion 2: Education of women contributed to a demand for health care.} (Unequivocal)

"Other non-health interventions, especially education of women, contributed to a demand for health care and to the betterment of health status in general." ${ }^{35}$ (page 128) 
Conclusion 3: Levels of safe deliveries remain low in Cambodia, and vary according to location, education level and income. (Unequivocal)

"While improving, overall levels of safe deliveries in Cambodia remain low and findings vary significantly by geographic location, education level and income." 33 (page 2)

Conclusion 4: Marrying at a later age, and lower fertility rates have a positive impact on maternal health. (Unequivocal)

"In Sri Lanka women marry at a later age, and have a low fertility rate." ${ }^{41}$ (page 4)

Conclusion 5: Maternal education has a positive influence on accessing maternal health services. (Unequivocal)

"Maternal education, economic status and husband's education play strong positive and independent roles in determining the use of maternal health services." ${ }^{41}$ (page 18)

\section{Conclusion 6: Poverty and education is a major factor in determining maternal} health. (Unequivocal)

“....suggesting that poverty (as it is strongly related to education status) is a major factor in determining accessibility to health services and, consequently, health outcomes for poorer communities." ${ }^{36}$ (page 109)

\section{Conclusion 7: Cost-effective strategies must continue to be prioritized and} evaluated. (Credible)

"Others also suggest that strategies to reduce maternal mortality in resource-poor settings should focus on reducing the risk-pool by decreasing fertility through contraceptive use and the provision of safe abortion, followed by a focus on the main cause of maternal mortality: PPH." ${ }^{22}$ (page 319 ) 
Conclusion 8: In regards to maternal health, there is a need to focus on the continuum of care throughout pregnancy and the whole life-cycle. (Unequivocal)

"Issues such as the need for family planning, improvement of nutrition status, prevention of unwanted pregnancies and teenage pregnancies, prevention and management of unsafe abortion, as well as prevention and management of common diseases in pregnant women, such as malaria and anaemia should be addressed adequately." 23 (page 4)

Conclusion 9: Increase availability and strengthen delivery of quality reproductive and sexual health services. (Unequivocal)

"Strategies in Cambodia include: increasing availability of trained staff, ensuring availability of quality reproductive health commodities, introducing or expanding key services (contents of the essential service package), and establishing and strengthening partnerships and linkages." 42 (page 14)

\section{Conclusion 10: The reduction in maternal mortality in Sri Lanka is linked to its} fertility decline. (Unequivocal)

"During the downward trend in fertility which commenced in the mid-1950s, the initial decline was mainly due to the rise in age at marriage of females. Since 1975 an increasing proportion of the fertility decline was due to the decline in marital fertility." 25 (page 117)

\section{Conclusion 11: There is considerable diversity in the mechanisms that contribute} to the decline in maternal mortality. (Unequivocal)

"Case studies show considerable diversity in the mechanisms that contribute to the decline in maternal mortality; these encompass policies such as liberalisation of abortion laws, control of infectious diseases, ensuring access to hospital care, and the provision of midwifery care." ${ }^{14}$ (page 1193) 


\section{Conclusion 12: Status of women within a society can influence the quality of reporting maternal deaths. (Unequivocal)}

"Quality of reporting maternal deaths is a barometer of commitment to and responsibility for action in terms of the health of women." 39 (page 237)

\section{Conclusion 13: Women's empowerment is one of the greatest barriers to improving maternal health. (Unequivocal)}

"Skilled attendants as health professionals, at both the individual provider/client interaction level, but also at a collective level, have an important opportunity to begin to influence and promote an empowering climate for women." 6 (page 53)

\section{Conclusion 14: Women's role in society has a negative impact on health within} Cambodian society. (Unequivocal)

“In many cases, women's bargaining power within the household about decisions about her health is weak and there is a need to both raise awareness and empower women in making informed decisions affecting her (and her family's) health needs." ${ }^{33}$ (page 4)

Many papers discussed the role of empowerment of women. In Sri Lanka, education for girls has been given high priority, which has had an influence on marrying at a later age, which generally lowers the fertility rate. All of these factors positively contribute to maternal health. ${ }^{41}$ Education for girls and women also impacts on the number of secondary school students who are able to progress to midwifery or medical studies, ensuring the future supply of skilled birth attendants. ${ }^{2}$ Education of women in a society will also increase the demand for skilled health care services, and women and families will know that this is the safest way for them to birth their baby, and access this care. ${ }^{35}$ Empowerment through education will also raise awareness of wider issues surrounding maternal health. Skilled birth attendance is essential, but other factors including nutrition for girls and women, knowledge about family planning, prevention and management of unsafe abortions, and other diseases such as anaemia and malaria are equally important throughout the woman's whole life-cycle. ${ }^{23}$ Empowerment of women within a society will impact on the individual health of women, but also at the 
collective level, when groups of women, both consumers and health professionals come together and make their voices heard. ${ }^{6}$ Women's empowerment is one of the greatest tools to improving maternal health.

\section{Synthesis 8: Data collection to evaluate maternal mortality will inform policy decisions}

A total of four categories from 13 conclusions were developed and synthesised, with mostly unequivocal evidence suggesting that monitoring and evaluation systems can strengthen and inform policy decisions in regard to maternal mortality issues. Improving health management information systems encourages data to be used to inform policy and strategy development. (Figure 10)

SYNTHESIS 8

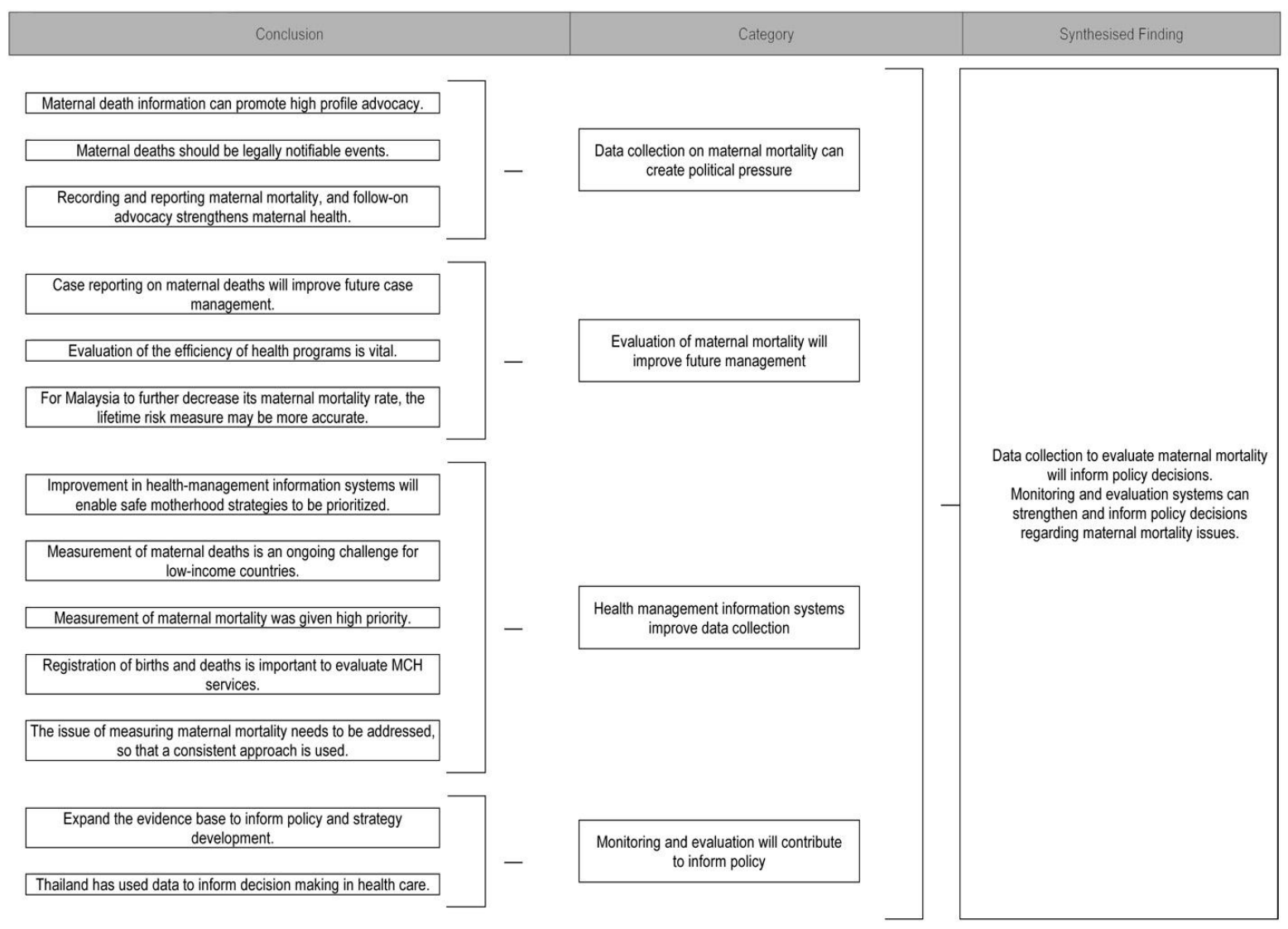

Figure 10 NOTARI view of Synthesis 8 


\section{Conclusion 1: Maternal death information can promote high profile advocacy.}

(Unequivocal)

"Politicians and leaders were continuously confronted with area-specific maternal mortality data. This proved to be a powerful lever for initiating and sustaining maternal health programs." ${ }^{17}$ (page 312 )

\section{Conclusion 2: Maternal deaths should be legally notifiable events. (Credible)}

"However, when the purpose relates to laws, such as when all maternal deaths are legally notifiable events, or to human rights standards which uphold the right of everyone to be free from avoidable death, then universality of reporting is implied." 39 (page 235)

\section{Conclusion 3: Recording and reporting maternal mortality, and follow-on advocacy strengthens maternal health. (Unequivocal)}

"Within the health system, both Malaysia and Sri Lanka instituted systems for areaspecific mortality data, and maternal death review that evolved as the health system developed." ${ }^{24}$ (page 19)

\section{Conclusion 4: Case reporting on maternal deaths will improve future case management. (Unequivocal)}

"Case reporting may be seen as part of quality assurance within health services, and death audits are now widely practiced across developed and developing countries." 39 (page 235)

\section{Conclusion 5: Evaluation of the efficiency of health programs is vital.} (Unequivocal)

"Evaluate efficiency of the district oriented program with low maternal mortality rates. Low levels may require an enhanced supporting system of the central Ministry of Health and/or restructuring of district health strategies. Monitor staff trained for quality assurance in maternal health care." 37 (page 27) 
Conclusion 6: For Malaysia to further decrease its maternal mortality rate, the lifetime risk measure may be more accurate. (Credible)

"Although there has been a significant decline in maternal mortality in Malaysia, the actual rates may be higher. With the confusion in the use of the terms ratio and rate, a proposed ideal measure is the lifetime risk (the probability of becoming pregnant and the probability of dying as a result of pregnancy)." ${ }^{44}$ (page 33)

\section{Conclusion 7: Improvement in health-management information systems will enable safe motherhood strategies to be prioritized. (Unequivocal)}

"Strengthening vital registration systems is a key priority of the WHO. The generation of reliable, continuously available, real-time demographic indicators would enable evidence-based prioritization of healthcare interventions and subsequent improved planning for resource allocation, monitoring and evaluation.” 22 (page 319)

\section{Conclusion 8: Measurement of maternal deaths is an ongoing challenge for low- income countries. (Unequivocal)}

"Capturing of maternal deaths is not straight forward, even in countries with advanced statistical systems, and much has been written about these measurement constraints. Rather, a mixed methods approach should be encouraged, seizing all opportunities to gather fit-for-purpose data, such as decennial censuses, indirect approaches, and adjusted routine facility-based data." ${ }^{14}$ (page 1197)

\section{Conclusion 9: Measurement of maternal mortality was given high priority. (Unequivocal)}

"Registration of births and deaths to be the responsibility of the Ministry of Health and undertaken by medical officers, changes in death certificates to include more information, every maternal death to be investigated." 28 (page 277) 


\section{Conclusion 10: Registration of births and deaths is important to evaluate $\mathrm{MCH}$}

services. (Unequivocal)

"Registration of births and deaths became compulsory.....the ready availability of statistics facilitated the evaluation of $\mathrm{MCH}$ services." 25 (page 115)

Conclusion 11: The issue of measuring maternal mortality needs to be addressed, so that a consistent approach is used. (Credible)

"Maternal Mortality Ratio is also an underestimate due to poor vital registration of maternal deaths. Many deaths go unregistered and uncertified. Although some countries have a good registration system, the poor classification of death makes the validity of the maternal mortality rate questionable." ${ }^{44}$ (page 32 )

\section{Conclusion 12: Expand the evidence base to inform policy and strategy development. (Unequivocal)}

"Monitoring and evaluation is a part of national monitoring and evaluation within Joint Annual Performance Review of maternal health programs." ${ }^{42}$ (page 14)

\section{Conclusion 13: Thailand has used data to inform decision making in health care.} (Unequivocal)

"Use of data for public health decision making has been an important ingredient." 26 (page 956)

Tracking of progress towards MDG 5 is problematic when you don't have clear measurements in place to collect maternal mortality data. ${ }^{39}$ Putting these data collection systems in place is a priority for all countries, to evaluate maternal mortality which will in turn inform policy decisions. Recording and reporting on maternal deaths can be a powerful tool to confront politicians and other community leaders, to give high profile that something needs to be done. ${ }^{17}$ Different methods of data collection are needed that are consistent, including vital registration systems, but creativity is also required to capture data, such as census information collection and other indirect 
approaches. ${ }^{14}$ Data collection assists in evaluation, and many countries now practice case reporting on maternal deaths, as a means of improving future case management and quality assurance. ${ }^{39}$ Thailand, Sri Lanka and Malaysia have all used maternal mortality data for public health decision making, to inform the direction of future policies for maternal health. ${ }^{26}$ From a local context, this ensures priority is given to the local issues that require local strategies, and from a national perspective, this helps to support what is actually happening around the country, with relevant feedback from the district areas.

\section{Synthesis 9: Countries struggling to decrease maternal mortality require global assistance}

A total of two categories drawn from 3 conclusions were developed and synthesised into a key learning that countries will benefit from sharing information together about successful strategies, and receiving assistance and support from global neighbours when requested. These findings were mostly unequivocal. Maternal health issues have been influenced by a lack of cohesion when determining priorities, but this global support is required for countries struggling to decrease maternal mortality. (Figure 11)

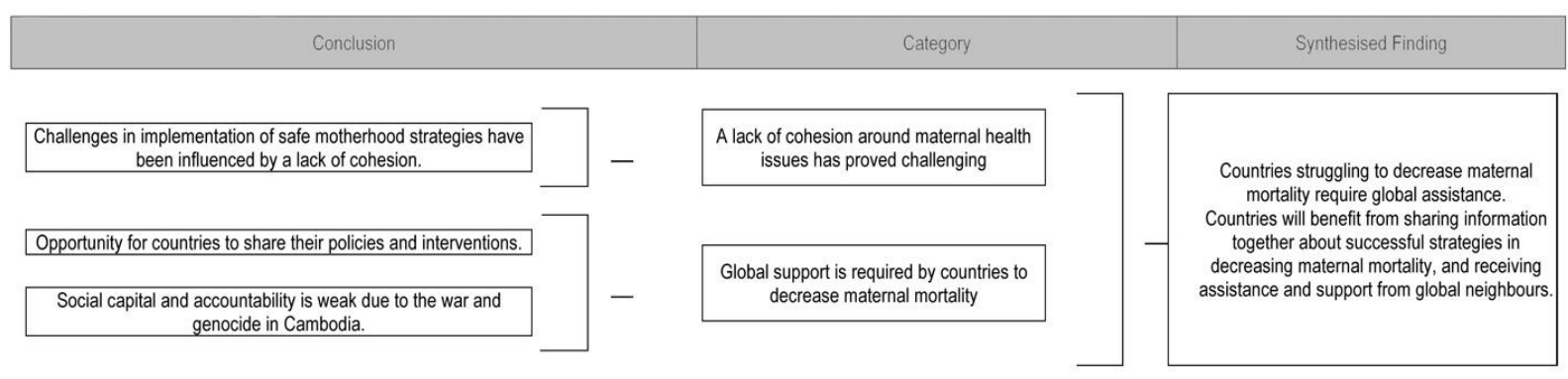

Figure 11 NOTARI view of Synthesis 9 


\section{Conclusion 1: Challenges in implementation of safe motherhood strategies have been influenced by a lack of cohesion. (Unequivocal)}

"Fierce debate over the effectiveness and prioritization of interventions has crippled global progress in the reduction of maternal mortality. There is a lack of cohesion among safe motherhood advocates, which is not so much related to 'what works', but mainly relates to what should be prioritized (taking feasibility into account)....." 22 (page 321)

\section{Conclusion 2: Opportunity for countries to share their policies and interventions.} (Credible)

"All countries expressed their commitment to achieve the MDGs related to maternal and newborn health and shared their policies and interventions carried out in this regard." 23 (page 4)

\section{Conclusion 3: Social capital and accountability is weak due to the war and genocide in Cambodia. (Unequivocal)}

"Accountability of public institutions and public servants is weak and institutional mechanisms to promote transparency are still in their infancy (in Cambodia). Social capital in Cambodia has been severely fractured by war and genocide." ${ }^{33}$ (page 6)

It is easy for individuals, and countries alike, to feel overwhelmed when considering maternal health issues. Troubled by a lack of cohesion, even amongst global experts, safe motherhood networks know what needs to happen, but the problem lies in what is practical and feasible. ${ }^{22}$ Establishing priorities is a challenge, and especially for individual countries that need to make their own contextualized decisions. Global support can be helpful in encouraging networking and opportunities for countries within similar regions and settings to share their policies and successful strategies. ${ }^{23}$ The experience of countries such as Sri Lanka, Thailand and Malaysia can be of benefit to a country like Cambodia, as they are further along in their journey of reducing maternal mortality. Cambodia has also experienced a lack of social cohesion following the war and genocide of the 1970's, so the experience of these other countries may be a helpful example for them. ${ }^{33}$ 


\section{Chapter 4: Discussion and Conclusion}

\section{General discussion}

Issues related to maternal mortality have been extensively researched and reported on. Despite this, the actual translation of research into practice has been frustratingly slow. Undertaking this Master's thesis has provided me with an opportunity to delve into the literature, try to understand a very complex area, and extract and synthesise textual data using JBI NOTARI. In this chapter I will recommend implications for practice, relating to these strategies which have been used in Cambodia, Thailand, Malaysia and Sri Lanka to reduce maternal mortality, some more successfully than others. Issues of generalizability of the evidence for other countries could be questioned, but upon reflection I would consider it appropriate as long as the strategies were considered within the local context of each country.

Before considering practical strategies which reduce maternal mortality, I would like to further explore the international perspectives of maternal health policy. After more than twenty years with a focus on safe motherhood, the Inter-Agency Group for Safe Motherhood (IAG) has had disappointing results, in terms of attracting political support and developing strong leadership potential. ${ }^{16}$ There has been a lack of cohesion amongst experts on maternal health, in regards to agreeing on certain strategies and prioritization, which has hampered the progress in terms of the global debate. ${ }^{22}$ On the world stage in other key areas, an easily recognised leader has emerged, but not in the case of safe motherhood. This lack of an ambassador may have negatively impacted on the capacity to move the issue forwards. A strong leader could have united groups together, assisting with policy decision issues and engaging the political force in each country. ${ }^{16}$ There have been other attempts to unite the global community, such as the formation in 2009 of the White Ribbon Alliance in support of maternal health, but they have never reached the desired impact. Even the term 'Safe Motherhood' was disliked by some feminist groups, and others have argued that because the target group are poor, powerless women, many men in positions of power have not been willing to actively engage in the issues. ${ }^{16}$ The announcement of the Millennium Development Goals, and 
the inclusion at number 5 to 'improve maternal health,' has been the opportunity that the international supporters have required to draw attention and demand action on this issue. $^{14}$

Another issue within the global community is the difficulty to separate the mother-child dyad, and whether they even should be separated. For this review, I have concentrated solely on maternal health, but can you really focus only on the woman, and not pay attention to the baby? On the global stage, there have been partnerships between the safe motherhood and child survival groups, with the hope that a synergistic approach would benefit both groups. But in reality, it would appear that competition for funding, and other issues of contention have created problems for these groups to work effectively together. ${ }^{16}$ The shame in this situation also reflects in the knowledge that a maternal life saved will directly impact on the lives of her children. Children who have lost their mother have a three to ten times higher chance of dying themselves. ${ }^{31}$ The difficulties in reducing maternal mortality through one single intervention sometimes make it not as 'popular' in terms of gaining support from politician's. Child health interventions such as immunisations are easier to implement and evaluate, not requiring the complex, multi-dimensional strategies that maternal health requires, as also determined by this review. (see Figure 5) For countries such as Sri Lanka and Thailand, the progression from selective primary health care, with single interventions such as growth monitoring, breastfeeding, oral rehydration and immunisation was a good starting point, but then they had to move towards delivering a wider range of interventions, transitioning to comprehensive services. Building an effective district health system, with provision of skilled attendance at birth was crucial to reducing maternal mortality. ${ }^{26}$

Research focusing on issues of maternal mortality tend to consider clinical factors primarily, instead of analysing the situation within an economical, political and social framework. ${ }^{45}$ It is not enough to look only at health factors related to maternal mortality, but must also incorporate these macrostructural components, and how they can be analysed together. ${ }^{16}$ Maternal mortality issues are not only related to a problem of resources, but needs to be more about imaginative planning and prioritization by policy makers and health workers. The factors that shape these issues are complex, and 
this review has helped me to understand and streamline this information about the various strategies.

The evidence from this review is overwhelming in support of skilled attendance for every woman at birth. (see Figure 3) This is mostly achieved through a health facility where skilled health care staff are available. But what about situations where this is practically not possible? An interesting project along the Thai-Burma border discusses this issue, where it is not possible to have a fixed health care facility due to conflict within this particular setting. Many of this community are refugees, constantly being forced to move locations. The Mobile Obstetric Maternal Health Workers (MOM) Program has been established to provide a three-tier network of community-based workers. ${ }^{15}$ This innovative program provides training for first-tier Maternal Health workers, second-tier Community Health workers, and third-tier Traditional Birth Attendants. They have differing levels of expertise, but ensure a referral link to provide good maternal care. Each tier of health worker is aware of their responsibility for each intervention, and when to refer. There is a strong emphasis on community support, good communication, adequate supervision and mentoring, and monitoring and evaluation of outcomes. Even within this extremely challenging environment, this project has shown that it is feasible to try a slightly different approach to provide skilled attendance at birth, even when it can't be delivered in the usual context of a fixed health care facility. This is a good example of a project adjusted to the local context, where alternative strategies need to be explored.

Another strategy explored through this review concerned the availability of skilled birth attendants, and how for many countries such as Cambodia, these skilled health workers are simply not available. ${ }^{42}$ By increasing the supply of skilled birth attendants through strategies such as accelerated midwifery training, a thoughtful approach must be taken. ${ }^{26}$ In theory this is an innovative strategy, but care must be taken to provide high quality training to ensure the quality of the trained staff. Clinical expertise requires adequate support and supervision by experienced clinician's, to mentor new midwives within an enabling environment. If poorly trained staff are then sent to a rural area without adequate support and assistance, not only will the individual staff member lack confidence and motivation, but most importantly, the women within the community will not trust them either, and will not seek them out for care. 
Another interesting trend in high-income countries currently is the education of midwives as direct-entry, without previous nurse training. The reasoning behind this approach is that women giving birth are not unwell, so a nursing background isn't required to be a midwife. In the context of this review, I have some problems with this approach. To strengthen health systems in many of these countries that struggle with high maternal mortality rates, professional education for nurse-midwives who can handle basic complications at birth would seem to be essential. ${ }^{22}$ Many of these women may also have pre-existing issues such as anaemia or other nutritional deficiencies, or present with other health related issues of poverty (such as TB or HIV infection). Within the context of these low-income countries, skilled birth attendants require extra tools in their toolkit, to quickly identify any complications or give required treatments. A comprehensive approach is more likely to be achieved with a nurse-midwife, to capture whatever issues arise, from a broad primary health care perspective (such as nutrition, hygiene, family planning, childhood illnesses, skilled birth attendance, etc.). In many settings, the role of the midwife and the nurse is interchangeable, extending across the woman's lifespan well beyond pregnancy and childbirth. ${ }^{2}$ This will be an important issue in the future, for individual countries to determine the required context for their local midwifery and/or nursing education, and what is appropriate for their needs.

The evidence from this review is credible as to the role of the Traditional Birth Attendant within this skilled attendance framework (see Figure 7). Their role must be clearly defined, and an emphasis placed on a supportive role, health promotion, and facilitating referral to a skilled birth attendant. This can only work within a system with strong referral links, and a good relationship within the community between birthing women, the Traditional Birth Attendant and the Skilled Birth Attendant. ${ }^{12}$ This issue remains controversial for many, with task-shifting to less qualified staff strongly opposed by certain groups. Some from less-resourced countries ask the question of those from well-resourced countries whether they would entrust their daughter, wife or sister to a Traditional Birth Attendant? This is a very challenging question, and once again highlights the need to contextualise for each setting, for what is appropriate in one setting may not be in another. 
The global partnership between countries with higher maternal mortality rates, and countries with lower rates, may also be useful to explore. As well as regional meetings between countries with strategy sharing, ${ }^{23}$ there are also examples of capacity building when a midwife from one country might work alongside the members of the Midwives Association in another country, as in Cambodia. The International Confederation of Midwives is holding its conference this year in South Africa, with MDG 5 as the key focus. They are encouraging all midwives to support and advocate for highlighting the plight of maternal health. Another recent project titled the South East Asia - Optimising Reproductive and Child Health in Developing Countries (SEA-ORCHID) was a project over five years, with a partnership between nine sites across four countries in South East Asia, and three sites across Australia. ${ }^{46}$ The project aimed to strengthen the capacity for evidence-based health care and research synthesis amongst health care workers, and to determine whether this led to an improvement in health outcomes for women and their babies. Projects of this nature, with collaboration between countries, form the basis for a genuine way forwards, to support and encourage the global goal to reduce maternal deaths.

From undertaking this study, my own personal understanding of what a skilled birth attendant is, has grown and developed. A skilled birth attendant is not a single health practitioner working to provide care for pregnant and birthing women, but a team / network of people providing skilled attendance at birth, within an enabling environment. ${ }^{27}$ There are many strategies that will improve maternal mortality, but all require an enabling environment to maximise their potential to provide skilled attendance. This skilled attendance can involve supportive health policies and provision for regulation of staff and a functioning health system. The health setting requires adequate staff (numbers and skill level), equipment and other necessary supplies. It must also be easily accessible for people, financially affordable, with available referral and transport systems, so there are no barriers for women to be able to access this skilled attendance. ${ }^{27}$

Midwives and other health care workers who provide skilled attendance at birth also require an enabling environment, working within a supportive team. Often their work environments, and the clinical situations they encounter daily, are hugely challenging, and being well supported and supervised within a team setting will encourage these 
clinicians who provide skilled attendance, to prevent 'burn-out' and a sense of professional isolation. Commitment by health management to provide suitable continuing education is also important in this regard.

Figure 12 Enabling Environment: 'Skilled attendance in childbirth' visually demonstrates the 9 essential factors from the synthesised findings which must be present to enhance maternal health. To maximise their potential, they must be encircled and empowered by an 'enabling environment.'

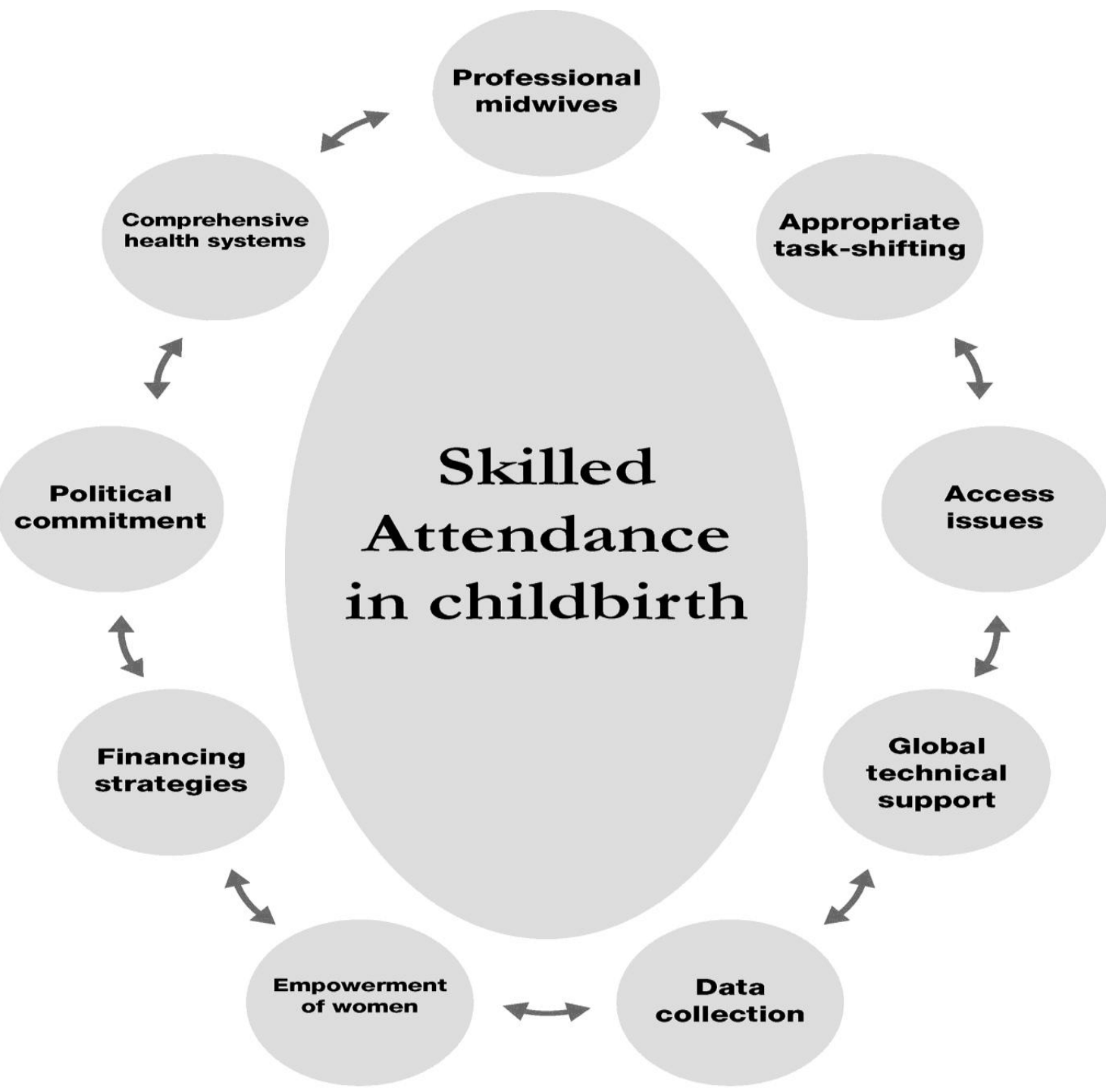

'ENABLING ENVIRONMENT'

Figure 12 Enabling Environment 
All governments, health professionals who work to provide skilled attendance, and women and communities must work together, with a shared commitment to tackle these issues of maternal mortality. This is a huge challenge, but is an issue that must be constantly worked on to improve these mostly preventable deaths.

\section{Assumptions, limitations and delimitations}

\section{Limitations:}

Even though a large volume of data was retrieved for this review, its limitations must be acknowledged. The use of a narrow set of search terms and the restriction to the English language means that some relevant text may have been missed, especially considering the four countries involved do not use English as their first language. Critical appraisal, categorising the conclusions and synthesising these categories has been attempted to be carried out as a transparent process with the use of JBI-NOTARI. Validity in this context has been sought relating to the soundness of the opinion in terms of its logic and its ability to convince, but as a reviewer there has been some judgement involved.

\section{Delimitations:}

Within the maternal health spectrum, the problem of separating the maternal and child dyad exists - can you really look at one without the other? For the purposes of this review, I focused only on maternal health in an attempt to contain the amount of data I had to review and manage. In terms of the real world, I very much am aware of the mother - child dyad, and the impact of the one on the other. 


\section{Implications for practice}

From the overall results of the review, nine recommendations can be made for practice, relating to strategies that will decrease maternal mortality (grades of recommendations are assigned for each). Recommendations are graded on the basis of both the level of evidence assigned to them, and their clinical relevance.

\section{Recommendation 1:}

The professionalization of midwifery, and provision of skilled attendance at birth is essential for decreasing maternal mortality. (Grade A)

This relates to maternal health workers being valued by their government and the community, receiving quality education and registration systems for midwives, and the expectation that every woman requires skilled attendance at birth.

\section{Recommendation 2:}

Free and equitable health care is the ideal, but countries must determine contextual and localised financing strategies. (Grade B)

This relates to issues of not only adequate financial resources, but also creative planning and prioritization of strategies.

\section{Recommendation 3:}

Approaching maternal health comprehensively, highlighting a package of services is of greater benefit than single stand-alone interventions. (Grade A) Factors including political commitment, supportive policies, strengthening of health systems and professionalizing midwifery are all important in decreasing maternal mortality.

\section{Recommendation 4:}

Political will and commitment is required at all levels when determining maternal health policies. (Grade A) 
This also relates to countries selecting policies and strategies with their local context in mind.

\section{Recommendation 5:}

Appropriate task-shifting for health workers, especially when strong referral systems are in place, may enhance maternal health. (Grade B)

This recommendation considers workforce issues while ensuring a quality, sustainable service.

\section{Recommendation 6:}

Access issues for women, to quality services in any location, is of high priority. (Grade A)

This will be dependent on removal of barriers such as financial, cultural and physical access such as transportation issues.

\section{Recommendation 7:}

Empowerment of women within a society will actively promote maternal health. (Grade A)

The emphasis is on education for girls and women, and the status of women within society.

\section{Recommendation 8:}

Data collection, monitoring and evaluation systems can strengthen and inform policy decisions in regard to maternal mortality issues. (Grade A) Giving priority to health information systems that improve data collection and evaluation of health programs will expand the evidence base and inform policy and strategy development. 


\section{Recommendation 9:}

Countries will benefit from sharing information together about successful strategies to reduce maternal mortality, and receiving assistance and support from global neighbours when requested. (Grade A)

These may be opportunities for regional country meetings, or through online learning support, through to capacity building (for example midwives associations).

\section{Implications for research}

Currently, there is much global debate and research around maternal mortality issues, especially as the target of reaching MDG 5 by 2015 quickly approaches. On one hand, there is the discussion that evidence is available about what needs to happen, but it isn't being translated into practice. The challenge for future research is to increase the collaboration with researchers from developing countries. Most research is being carried out about developing country issues, but by researchers within developed countries, with the best of intentions but skewed by their own perspectives. Researchers in developing countries must lead these research initiatives, with collaboration and support if requested. ${ }^{45}$ Organizations such as the Joanna Briggs Institute, working with their Collaborating Centres that are situated in these under-represented research locations are a wonderful opportunity to progress this further.

\section{Conclusions}

In regards to maternal mortality, there is no room for complacency. Innovative developments must be explored and researched to further improve maternal health. ${ }^{25}$ Creative thinking, and commitment to continually prioritise maternal health is crucial to keep it on the agenda of all concerned. Exciting projects such as the 'Saving Lives at Birth: a grand challenge for development' provide opportunities and funding for people around the world to consider alternatives in prevention and treatment options for maternal health. A world where women no longer fear pregnancy and childbirth must be our goal, and even though it would seem unattainable, it is indeed a worthy one. 


\section{References}

1. The World Bank. Global monitoring report 2009 - Goal 5: Improve Maternal Health. 2009.

2. Wirth M. Professionals with delivery skills: backbone of the health system and key to reaching the maternal health Millennium Development Goal. Croat Med J 2008;49(3):318-33.

3. Walford Veronica, Pearson Mark, Eliya Ravi Rannan, Tharaga. F. Future policy choices for the health sector in Asia. DFID: Health Resource Centre. 2006.

4. Hogan M, Foreman K, Naghavi M, Ahn S, Wang M, Makela S, et al. Maternal mortality for 181 countries, 1980 - 2008: a systematic analysis of progress towards Millennium Development Goal 5. The Lancet 2010;375:1609-23.

5. World Health Organization. Making pregnancy safer: the critical role of the skilled attendant. A joint statement by the WHO, ICM and FIGO. 2004.

6. de Bernis L, Sherratt D, AbouZhar C, Lerberghe W. Skilled attendants for pregnancy, childbirth and postnatal care. British Medical Bulletin 2003;67:39-57.

7. Chatterjee P. Cambodia tackles high maternal mortality. The Lancet 2005;366:28182.

8. The World Bank. World development indicators. 2010.

9. Costello A, Azad K, S B. An alternative strategy to reduce maternal mortality. The Lancet 2006;368:1477 - 79 .

10. Bryce J, Daelmans B, Dwivedi A, Fauveau V, Lawn J, Mason E. Countdown to 2015 for maternal, newborn, and child survival: the 2008 report on tracking coverage of interventions. The Lancet 2008;371:1247 - 58 .

11. Bhutta ZA, Gupta I, De'Silva H, Manandhar D, Awasthi S, Moazzem Hossain SM, et al. Maternal and child health: Is South Asia ready for change? BMJ. 2004;328(7443):816-19.

12. Kruske S, Barclay L. Effect of shifting policies on traditional birth attendant training. J Midwifery Womens Health 2004;49(4):306-11.

13. Filippi V, Ronsmans C, Campbell O, Graham W, Mills A, Borghi J, et al. Maternal health in poor countries: the broader context and a call to action. The Lancet 2006;368:954-6. 
14. Ronsmans C, Graham WJ. Maternal mortality: who, when, where, and why. The Lancet 2006;368(9542):1189 - 200.

15. Mullany LC, Lee CI, Paw P, Shwe Oo EK, Maung C, Kuiper H, et al. The MOM Project: delivering maternal health services among internally displaced populations in eastern Burma. Reprod Health Matters 2008;16(31):44-56.

16. Shiffman J, Smith S. Generation of political priority for global health initiatives: a framework and case study of maternal mortality. The Lancet 2007;370(9595):13709.

17. Liljestrand J, Pathmanathan I. Reducing maternal mortality: Can we derive policy guidance from developing country experiences? J Public Health Policy 2004;25(34):299-314.

18. De Brouwere V, Richard F, Witter S. Access to maternal and perinatal health services: Lessons from successful and less successful examples of improving access to safe delivery and care of the newborn. Trop Med Int Health 2010;15(8):901-09.

19. Pearson A, Wiechula, R., Court, A., Lockwood, C. . A reconsideration of what constitutes "evidence" in the healthcare professions. Nurs Sci Q 2007;20(1):85 - 88.

20. Pearson A, Field J, Jordan Z, editors. Evidence-based clinical practice in nursing and health care.: Blackwell Publishing, 2007.

21. Pearson A, Florence Z. NOTARI Users Manual. The Joanna Briggs Institute 2007; Version 4.0.

22. Prata N, Passano P, Sreenivas A, Gerdts CE. Maternal mortality in developing countries: challenges in scaling-up priority interventions. Womens Health (Lond Engl) 2010;6(2):311-27.

23. World Health Organization. Skilled care at every birth. Regional Office for SouthEast Asia. 2005.

24. Pathmanathan I, Liljestrand J, Martins J, Rajapaksa L, Lissner C, de Silva A, et al. Investing in maternal health: learning from Malaysia and Sri Lanka. The World Bank 2003.

25. Seneviratne HR, Rajapaksa LC. Safe motherhood in Sri Lanka: A 100-year march. Int J Gynecol Obstet 2000;70(1):113-24.

26. Rohde J, Cousens S, Chopra M, Tangcharoensathien V, Black R, Bhutta ZA, et al. 30 years after Alma-Ata: has primary health care worked in countries? The Lancet 2008;372(9642):950-61. 
27. Maclean GD. The challenge of preparing and enabling 'skilled attendants' to promote safer childbirth. Midwifery 2003;19(3):163-9.

28. Jones M. Infant and maternal health services in Ceylon, 1900-1948: imperialism or welfare? Soc Hist Med 2002;15(2):263-89.

29. De Brouwere V. The comparative study of maternal mortality over time: The role of the professionalisation of childbirth. Soc Hist Med 2007;20(3):541-62.

30. Fernando D, Jayatilleka A, Karunaratna V. Pregnancy--reducing maternal deaths and disability in Sri Lanka: national strategies. Br Med Bull 2003;67:85-98.

31. Borghi J, Ensor T, Somanathan A, Lissner C, Mills A. Mobilising financial resources for maternal health. The Lancet 2006;368(9545):1457-65.

32. Jacobs B, Thome JM, Overtoom R, Oeun Sam S, Indermuhle L, Price N. From public to private and back again: sustaining a high service-delivery level during transition of management authority: a Cambodia case study. Health Policy Plan 2010;25(3):197 - 208.

33. The World Bank. Cambodia: Second Health Sector Support Program. 2008.

34. Koblinsky M. Reducing maternal mortality: learning from Bolivia, China, Egypt, Honduras, Indonesia, Jamaica, and Zimbabwe. The World Bank 2003.

35. Fernando DN. Orienting health systems for maternal health - The Sri Lankan experience. Development 2005;48(4):127-36.

36. Grundy J, Khut QY, Oum S, Annear P, Ky V. Health system strengthening in Cambodia-a case study of health policy response to social transition. Health Policy 2009;92(2-3):107-15.

37. The World Bank. Sri Lanka: health sector development project 2004.

38. Campbell OM, Graham WJ. Strategies for reducing maternal mortality: getting on with what works. The Lancet 2006;368(9543):1284-99.

39. Graham WJ, Hussein J. Universal reporting of maternal mortality: an achievable goal? Int J Gynaecol Obstet 2006;94(3):234-42.

40. Ekman B, Pathmanathan I, Liljestrand J. Integrating health interventions for women, newborn babies, and children: a framework for action. The Lancet 2008;372(9642):990-1000.

41. Chatterjee M, Levine R, Rao-Seshadri S, Murthy N. Toward better reproductive health for poor women in South Asia: a summary for policymakers. World Bank Report 2007. 
42. Vandine O. Country report on caring and promoting health for mother and child toward healthy next generation in Cambodia. Ministry of Health 2008.

43. Mavalankar D, Sriram V. Provision of anaesthesia services for emergency obstetric care through task shifting in South Asia. Reprod Health Matters 2009;17(33):2131.

44. Hematram Y. Measuring maternal mortality in Malaysia. J University Malaya Medical Centre 2006;9(1):30-34.

45. Gil-Gonzalez D, Carrasco-Portino M, Ruiz MT. Knowledge gaps in scientific literature on maternal mortality: a systematic review. Bull World Health Org 2006;84(11):903 - 09.

46. McDonald S, Turner T, Chamberlain C, Lumbiganon P, Thinkhamrop J, Festin MR, et al. Building capacity for evidence generation, synthesis and implementation to improve the care of mothers and babies in South East Asia: methods and design of the SEA-ORCHID Project using a logical framework approach. BMC Med Res Methodol 2010;10:61. 


\section{Appendices}

\section{Appendix I: Critical appraisal instrument}

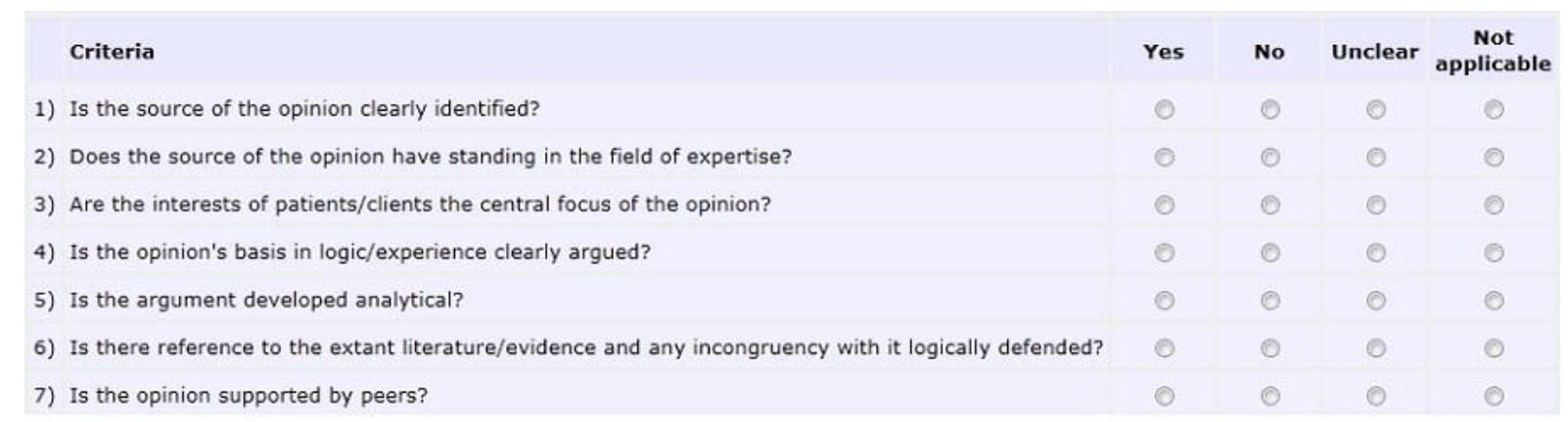

Figure 13 NOTARI critical appraisal instrument

Table 1 Final Assessment

\begin{tabular}{|c|c|c|c|c|c|c|c|}
\hline Citation & Q1 & Q2 & Q3 & Q4 & Q5 & Q6 & Q7 \\
\hline Bhutta, Z. A., I. Gupta, et al., 2004 & $\mathrm{Y}$ & $\mathrm{Y}$ & Y & Y & Y & Y & $\mathrm{Y}$ \\
\hline Borghi, J., T. Ensor, et al., 2006 & $\mathrm{Y}$ & $\mathrm{Y}$ & $\mathrm{Y}$ & Y & Y & Y & $\mathrm{Y}$ \\
\hline Campbell, O. M. \& W. J. Graham, 2006 & Y & Y & Y & Y & Y & $\mathrm{Y}$ & $\mathrm{Y}$ \\
\hline Chatterjee M, Levine R, et al., 2007 & Y & $\mathrm{Y}$ & Y & Y & Y & Y & $\mathrm{Y}$ \\
\hline Chatterjee, P., 2005 & Y & $\mathrm{U}$ & Y & Y & Y & $\mathrm{U}$ & Y \\
\hline $\begin{array}{l}\text { de Bernis, L., D. R. Sherratt, et al., } \\
2003\end{array}$ & Y & Y & Y & Y & Y & Y & Y \\
\hline De Brouwere, V., 2007 & $\mathrm{Y}$ & $\mathrm{U}$ & $\mathrm{U}$ & $\mathrm{Y}$ & Y & $\mathrm{Y}$ & $\mathrm{Y}$ \\
\hline $\begin{array}{l}\text { De Brouwere, V., F. Richard, et al., } \\
2010\end{array}$ & Y & $\mathrm{U}$ & Y & Y & Y & $\mathrm{Y}$ & $\mathrm{Y}$ \\
\hline $\begin{array}{l}\text { Ekman, B., I. Pathmanathan, et al., } \\
2008\end{array}$ & Y & $\mathrm{Y}$ & Y & Y & Y & $\mathrm{Y}$ & $\mathrm{Y}$ \\
\hline Fernando, D. N., 2005 & Y & $\mathrm{Y}$ & $\mathrm{Y}$ & $\mathrm{U}$ & $\mathrm{Y}$ & $\mathrm{Y}$ & $\mathrm{Y}$ \\
\hline $\begin{array}{l}\text { Fernando, D., A. Jayatilleka, et al., } \\
2003\end{array}$ & $\mathrm{Y}$ & Y & Y & Y & Y & Y & $\mathrm{Y}$ \\
\hline
\end{tabular}




\begin{tabular}{|c|c|c|c|c|c|c|c|}
\hline Graham, W. J. \& J. Hussein, 2006 & $\mathrm{Y}$ & $\mathrm{Y}$ & $\mathrm{Y}$ & $\mathrm{Y}$ & $\mathrm{Y}$ & $\mathrm{Y}$ & $\mathrm{Y}$ \\
\hline Grundy, J., Q. Y. Khut, et al., 2009 & $\mathrm{Y}$ & $\mathrm{Y}$ & $\mathrm{Y}$ & $\mathrm{Y}$ & $\mathrm{Y}$ & $\mathrm{Y}$ & $\mathrm{Y}$ \\
\hline Hematram, Y., 2006 & $\mathrm{Y}$ & $\mathrm{Y}$ & $\mathrm{Y}$ & Y & $\mathrm{Y}$ & $\mathrm{Y}$ & $\mathrm{Y}$ \\
\hline Jacobs B, Thome JM, et al., 2010 & Y & $\mathrm{Y}$ & Y & $\mathrm{U}$ & $\mathrm{Y}$ & $\mathrm{Y}$ & $\mathrm{N}$ \\
\hline Koblinsky M, 2003 & Y & $\mathrm{Y}$ & Y & $\mathrm{Y}$ & Y & $\mathrm{Y}$ & $\mathrm{Y}$ \\
\hline Kruske, S. \& L. Barclay, 2004 & $\mathrm{Y}$ & $\mathrm{Y}$ & $\mathrm{Y}$ & $\mathrm{Y}$ & $\mathrm{Y}$ & $\mathrm{Y}$ & $\mathrm{Y}$ \\
\hline Liljestrand, J. \& I. Pathmanathan, 2004 & $\mathrm{Y}$ & $\mathrm{Y}$ & $\mathrm{Y}$ & $\mathrm{Y}$ & $\mathrm{Y}$ & $\mathrm{Y}$ & $\mathrm{Y}$ \\
\hline Maclean, G. D., 2003 & Y & $\mathrm{Y}$ & $\mathrm{Y}$ & $\mathrm{Y}$ & $\mathrm{Y}$ & $\mathrm{Y}$ & $\mathrm{Y}$ \\
\hline Mavalankar, D. \& V. Sriram, 2009 & Y & Y & Y & Y & $\mathrm{Y}$ & Y & $\mathrm{Y}$ \\
\hline $\begin{array}{l}\text { Pathmanathan I, Liljestrand J, et al., } \\
2003\end{array}$ & Y & $\mathrm{Y}$ & Y & Y & $\mathrm{Y}$ & $\mathrm{Y}$ & Y \\
\hline $\begin{array}{l}\text { Seneviratne, H. R. \& L. C. Rajapaksa, } \\
2000\end{array}$ & $\mathrm{Y}$ & $\mathrm{Y}$ & Y & Y & Y & $\mathrm{Y}$ & Y \\
\hline The World Bank, 2004 & $\mathrm{Y}$ & $\mathrm{Y}$ & $\mathrm{Y}$ & $\mathrm{Y}$ & $\mathrm{Y}$ & $\mathrm{Y}$ & $\mathrm{Y}$ \\
\hline The World Bank, 2008 & Y & Y & $\mathrm{Y}$ & Y & Y & $\mathrm{Y}$ & $\mathrm{Y}$ \\
\hline Vandine, O., 2008 & $\mathrm{Y}$ & $\mathrm{Y}$ & Y & $\mathrm{Y}$ & Y & $\mathrm{Y}$ & $\mathrm{Y}$ \\
\hline $\begin{array}{l}\text { Walford Veronica, Pearson Mark, et al., } \\
2006\end{array}$ & Y & $\mathrm{Y}$ & Y & Y & $\mathrm{Y}$ & $\mathrm{Y}$ & $\mathrm{Y}$ \\
\hline Wirth, M., 2008 & $\mathrm{Y}$ & Y & $\mathrm{Y}$ & $\mathrm{Y}$ & Y & $\mathrm{Y}$ & $\mathrm{Y}$ \\
\hline World Health Organization, 2005 & $\mathrm{Y}$ & $\mathrm{Y}$ & $\mathrm{Y}$ & $\mathrm{Y}$ & $\mathrm{Y}$ & $\mathrm{Y}$ & $\mathrm{Y}$ \\
\hline Jones, M., 2002 & $\mathrm{Y}$ & $\mathrm{Y}$ & $\mathrm{Y}$ & $\mathrm{Y}$ & $\mathrm{Y}$ & $\mathrm{Y}$ & $\mathrm{Y}$ \\
\hline Rohde, J., S. Cousens, et al., 2008 & $\mathrm{Y}$ & $\mathrm{Y}$ & $\mathrm{Y}$ & $\mathrm{Y}$ & $\mathrm{Y}$ & $\mathrm{Y}$ & $\mathrm{Y}$ \\
\hline Ronsmans, C. \& W. J. Graham, 2006 & $\mathrm{Y}$ & Y & $\mathrm{Y}$ & $\mathrm{Y}$ & $\mathrm{Y}$ & $\mathrm{Y}$ & $\mathrm{Y}$ \\
\hline Prata N, Passano P, et al., 2010 & Y & Y & $\mathrm{Y}$ & Y & $\mathrm{Y}$ & $\mathrm{Y}$ & $\mathrm{Y}$ \\
\hline$\%$ & 100.0 & 90.63 & 96.88 & 93.75 & 100.0 & 96.88 & 96.88 \\
\hline
\end{tabular}




\section{Appendix II: Data extraction instrument}

\section{Extraction Details: Extraction - Name (2011)}

* denotes field which will appear in report appendix

Type of Text:

Those Represented: *

Stated Allegiance/Position:

Setting:

Geographical:

Cultural:

Logic of Argument: *

Data Analysis:

Authors Conclusion:

Reviewers Comments: *

Complete

Figure 14 NOTARI data extraction instrument 


\section{Appendix III: Detailed search strategy}

Initial search terms and concepts:

skilled birth

skilled birth attendant(s)

maternal mortality

midwives

midwifery

midwife

lay midwives

nurse midwives

education

training

safer motherhood

Cambodia

Thailand

Sri Lanka

Malaysia

Electronic databases searched: (from 2000 to June 2010)

MEDLINE

CINAHL

EMBASE

Cochrane Central Register of Controlled Trials

Health Technology Assessment (HTA) Database

Scopus

ISI Web of Knowledge

LILACS

Mednar database

Pan American Health Organisation (PAHO)

World Health Organisation (WHO)

Health Policy Monitor 
World Bank

United Nations

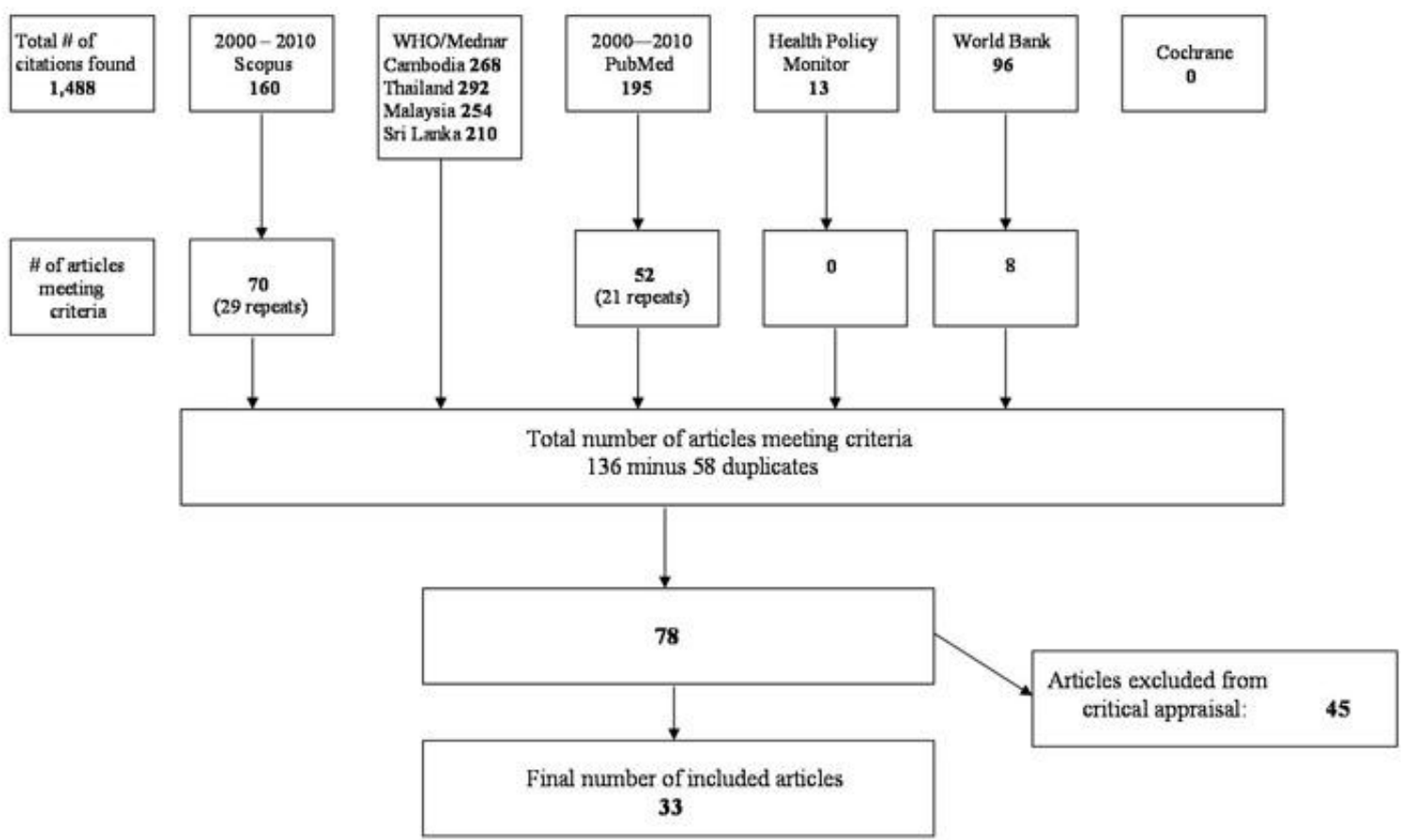

Figure 15 Search Diagram 


\section{Appendix IV: Included studies}

Table 2 Included studies

\begin{tabular}{|c|c|c|c|c|c|}
\hline Study & Methods & Participants & Intervention & Outcomes & Notes \\
\hline $\begin{array}{l}\text { Bhutta, Z. } \\
\text { A., I. Gupta, } \\
\text { et al., } 2004\end{array}$ & $\begin{array}{l}\text { Maternal and } \\
\text { child health } \\
\text { indicators in } \\
\text { South Asian } \\
\text { region }\end{array}$ & $\begin{array}{l}\text { Women in } \\
\text { South Asian } \\
\text { region }\end{array}$ & $\begin{array}{l}\text { Address issues } \\
\text { of female } \\
\text { illiteracy, } \\
\text { poverty, } \\
\text { malnutrition, } \\
\text { lack of } \\
\text { empowerment of } \\
\text { women and } \\
\text { skilled birth } \\
\text { attendants. }\end{array}$ & $\begin{array}{l}\text { Underlying } \\
\text { determinants } \\
\text { such as female } \\
\text { illiteracy, } \\
\text { poverty, } \\
\text { malnutrition and } \\
\text { lack of } \\
\text { empowerment of } \\
\text { women are } \\
\text { major barriers. } \\
\text { In Sri Lanka the } \\
\text { status of } \\
\text { maternal health, } \\
\text { where } 94 \% \text { of } \\
\text { births attended } \\
\text { by skilled health } \\
\text { workers. }\end{array}$ & $\begin{array}{l}\text { A good paper } \\
\text { by experts in } \\
\text { the South } \\
\text { Asian region. } \\
\text { Strategies } \\
\text { that are both } \\
\text { cost effective } \\
\text { and practical. }\end{array}$ \\
\hline $\begin{array}{l}\text { Borghi, J., T. } \\
\text { Ensor, et al., } \\
2006\end{array}$ & $\begin{array}{l}\text { The impact of } \\
\text { financial } \\
\text { resources }\end{array}$ & $\begin{array}{l}\text { maternal } \\
\text { health users in } \\
\text { low-income } \\
\text { countries }\end{array}$ & $\begin{array}{l}\text { Contextual and } \\
\text { localized } \\
\text { financing } \\
\text { strategies for } \\
\text { maternal health }\end{array}$ & $\begin{array}{l}\text { Donors / } \\
\text { governments } \\
\text { need to increase } \\
\text { financial } \\
\text { contributions for } \\
\text { maternal health }\end{array}$ & $\begin{array}{l}\text { Contextual } \\
\text { and localized } \\
\text { financing } \\
\text { strategies } \\
\text { will improve } \\
\text { maternal } \\
\text { health }\end{array}$ \\
\hline $\begin{array}{l}\text { Campbell, O. } \\
\text { M. and W. J. } \\
\text { Graham, } \\
2006\end{array}$ & $\begin{array}{l}\text { Focus on a } \\
\text { 'package' of } \\
\text { strategies }\end{array}$ & $\begin{array}{l}\text { Users of } \\
\text { maternal } \\
\text { health in low- } \\
\text { income } \\
\text { countries }\end{array}$ & $\begin{array}{l}\text { A health-centre } \\
\text { intrapartum-care } \\
\text { strategy }\end{array}$ & $\begin{array}{l}\text { A package of } \\
\text { interventions } \\
\text { aimed at } \\
\text { maternal health } \\
\text { will achieve } \\
\text { higher coverage } \\
\text { than a single } \\
\text { intervention } \\
\text { alone. }\end{array}$ & $\begin{array}{l}\text { Six key } \\
\text { messages } \\
\text { about what } \\
\text { strategies } \\
\text { will decrease } \\
\text { maternal } \\
\text { mortality. }\end{array}$ \\
\hline $\begin{array}{l}\text { Chatterjee } \\
\text { M, Levine R, } \\
\text { et al., } 2007\end{array}$ & $\begin{array}{l}\text { Access to } \\
\text { quality health } \\
\text { services - the } \\
\text { essential } \\
\text { package for } \\
\text { maternal } \\
\text { health }\end{array}$ & $\begin{array}{l}\text { Women of } \\
\text { reproductive } \\
\text { years in } 5 \\
\text { countries in } \\
\text { South Asia }\end{array}$ & $\begin{array}{l}\text { Skilled } \\
\text { attendance at } \\
\text { delivery whether } \\
\text { at home or at a } \\
\text { health facility } \\
\text { and a well } \\
\text { functioning } \\
\text { referral system }\end{array}$ & $\begin{array}{l}\text { Sri Lanka's long } \\
\text { standing policies } \\
\text { for maternal and } \\
\text { child have } \\
\text { decreased } \\
\text { maternal } \\
\text { mortality }\end{array}$ & $\begin{array}{l}\text { Access to } \\
\text { quality health } \\
\text { services is } \\
\text { higher in Sri } \\
\text { Lanka }\end{array}$ \\
\hline
\end{tabular}




\begin{tabular}{|c|c|c|c|c|c|}
\hline $\begin{array}{l}\text { Chatterjee, } \\
\text { P., } 2005\end{array}$ & $\begin{array}{l}\text { More } \\
\text { resources } \\
\text { towards } \\
\text { midwifery } \\
\text { education }\end{array}$ & $\begin{array}{l}\text { Skilled village } \\
\text { midwives in } \\
\text { rural } \\
\text { Cambodia }\end{array}$ & $\begin{array}{l}\text { Midwives } \\
\text { receiving } \\
\text { training in } \\
\text { emergency } \\
\text { delivery skills } \\
\text { and performance } \\
\text { based earnings }\end{array}$ & $\begin{array}{l}\text { Training, user } \\
\text { fees, and } \\
\text { performance- } \\
\text { based earnings } \\
\text { for rural } \\
\text { midwives may } \\
\text { improve } \\
\text { maternal health. }\end{array}$ & $\begin{array}{l}\text { Has not been } \\
\text { shown if it } \\
\text { does improve } \\
\text { maternal } \\
\text { health }\end{array}$ \\
\hline $\begin{array}{l}\text { De } \\
\text { Brouwere, } \\
\text { V., } 2007\end{array}$ & $\begin{array}{l}\text { Integrated } \\
\text { obstetric care }\end{array}$ & $\begin{array}{l}\text { Midwives and } \\
\text { medical } \\
\text { profession }\end{array}$ & $\begin{array}{l}\text { Professionalizati } \\
\text { on od midwives }\end{array}$ & $\begin{array}{l}\text { Maternal } \\
\text { mortality fell } \\
\text { with the } \\
\text { professionalizati } \\
\text { on of midwives }\end{array}$ & $\begin{array}{l}\text { Historically, } \\
\text { ongoing } \\
\text { challenge } \\
\text { between } \\
\text { midwives } \\
\text { and medical } \\
\text { profession }\end{array}$ \\
\hline $\begin{array}{l}\text { De } \\
\text { Brouwere, } \\
\text { V., F. } \\
\text { Richard, et } \\
\text { al., } 2010\end{array}$ & $\begin{array}{l}\text { A voucher } \\
\text { scheme in } \\
\text { Cambodia for } \\
\text { women } \\
\text { giving birth } \\
\text { gave } \\
\text { excellent } \\
\text { results }\end{array}$ & $\begin{array}{l}\text { Women } \\
\text { giving birth in } \\
\text { low income } \\
\text { settings }\end{array}$ & $\begin{array}{l}\text { A multiple } \\
\text { intervention } \\
\text { approach to } \\
\text { maternal health } \\
\text { is important. }\end{array}$ & $\begin{array}{l}\text { An intervention } \\
\text { package that has } \\
\text { proved to have a } \\
\text { positive effect in } \\
\text { one setting may } \\
\text { have very } \\
\text { different effects } \\
\text { in other settings. }\end{array}$ & $\begin{array}{l}\text { Strategies } \\
\text { must be } \\
\text { contextualize } \\
\text { d, and will } \\
\text { not } \\
\text { necessarily } \\
\text { be } \\
\text { generalizable } \\
\text { in different } \\
\text { settings }\end{array}$ \\
\hline $\begin{array}{l}\text { Ekman, B., I. } \\
\text { Pathmanatha } \\
\text { n, et al., } \\
2008\end{array}$ & $\begin{array}{l}\text { A stepwise } \\
\text { approach that } \\
\text { has targeted } \\
\text { especially } \\
\text { underprivileg } \\
\text { ed people. }\end{array}$ & $\begin{array}{l}\text { Women } \\
\text { giving birth in } \\
\text { low-income } \\
\text { countries }\end{array}$ & $\begin{array}{l}\text { Multisectoral } \\
\text { strategies have } \\
\text { combined } \\
\text { improvements in } \\
\text { maternal health } \\
\text { with water and } \\
\text { sanitation } \\
\text { improvements, } \\
\text { and education } \\
\text { for girls. }\end{array}$ & $\begin{array}{l}\text { Maternal health } \\
\text { can be improved } \\
\text { through the } \\
\text { incremental } \\
\text { introduction of } \\
\text { integrated } \\
\text { packages of } \\
\text { health-care } \\
\text { interventions. }\end{array}$ & $\begin{array}{l}\text { That a } \\
\text { multisectoria } \\
\text { approach } \\
\text { works }\end{array}$ \\
\hline $\begin{array}{l}\text { Fernando, D. } \\
\text { N., } 2005\end{array}$ & $\begin{array}{l}\text { Provision of } \\
\text { services free } \\
\text { of charge. }\end{array}$ & $\begin{array}{l}\text { Sri Lankan } \\
\text { women }\end{array}$ & $\begin{array}{l}\text { In Sri Lanka, } \\
\text { targeted } \\
\text { interventions } \\
\text { implemented } \\
\text { through the state } \\
\text { sector health } \\
\text { services have } \\
\text { reduced maternal } \\
\text { mortality. }\end{array}$ & $\begin{array}{l}\text { In Sri Lanka, the } \\
\text { maternal } \\
\text { mortality has } \\
\text { been reduced by } \\
\text { certain reforms. }\end{array}$ & $\begin{array}{l}\text { The history } \\
\text { of reforms in } \\
\text { Sri Lanka }\end{array}$ \\
\hline $\begin{array}{l}\text { Fernando, } \\
\text { D., A. } \\
\text { Jayatilleka, } \\
\text { et al., } 2003\end{array}$ & $\begin{array}{l}\text { Commitment } \\
\text { by health } \\
\text { sector }\end{array}$ & $\begin{array}{l}\text { Sri Lanka } \\
\text { women and } \\
\text { families }\end{array}$ & $\begin{array}{l}\text { Provision of } \\
\text { health services } \\
\text { free of charge. }\end{array}$ & $\begin{array}{l}\text { Free services } \\
\text { and female } \\
\text { education has } \\
\text { improved } \\
\text { maternal health. }\end{array}$ & $\begin{array}{l}\text { Commitment } \\
\text { by health } \\
\text { sector in Sri } \\
\text { Lanka has } \\
\text { improved } \\
\text { maternal } \\
\text { health. }\end{array}$ \\
\hline
\end{tabular}




\begin{tabular}{|c|c|c|c|c|c|}
\hline $\begin{array}{l}\text { Graham, W. } \\
\text { J. and J. } \\
\text { Hussein, } \\
2006\end{array}$ & $\begin{array}{l}\text { Case } \\
\text { reporting of } \\
\text { maternal } \\
\text { deaths }\end{array}$ & $\begin{array}{l}\text { Women who } \\
\text { have died in } \\
\text { childbirth }\end{array}$ & $\begin{array}{l}\text { Maternal deaths } \\
\text { should be legally } \\
\text { notifiable events } \\
\text { and quality of } \\
\text { reporting }\end{array}$ & $\begin{array}{l}\text { This paper aims } \\
\text { to highlight the } \\
\text { importance of } \\
\text { aspiring to } \\
\text { achieve } \\
\text { universal } \\
\text { reporting of } \\
\text { maternal deaths } \\
\text { as a part of } \\
\text { taking } \\
\text { responsibility for } \\
\text { these avoidable } \\
\text { tragedies. }\end{array}$ & $\begin{array}{l}\text { This } \\
\text { questions the } \\
\text { political will } \\
\text { to give } \\
\text { resources to } \\
\text { accurately } \\
\text { record } \\
\text { maternal } \\
\text { deaths. }\end{array}$ \\
\hline $\begin{array}{l}\text { Grundy, J., } \\
\text { Q. Y. Khut, } \\
\text { et al., } 2009\end{array}$ & $\begin{array}{l}\text { Health policy } \\
\text { responses }\end{array}$ & $\begin{array}{l}\text { Cambodia? } \\
\text { health policy } \\
\text { development }\end{array}$ & $\begin{array}{l}\text { Health service } \\
\text { contracting, } \\
\text { public-private } \\
\text { collaborations } \\
\text { and equity funds }\end{array}$ & $\begin{array}{l}\text { Despite the } \\
\text { internationally } \\
\text { recognized } \\
\text { health policy } \\
\text { flexibility and } \\
\text { innovation } \\
\text { demonstrated in } \\
\text { Cambodia, } \\
\text { policy response } \\
\text { still lags well } \\
\text { behind the } \\
\text { reality of social } \\
\text { transition. }\end{array}$ & $\begin{array}{l}\text { Decades of } \\
\text { civil conflict } \\
\text { in Cambodia } \\
\text { have resulted } \\
\text { in a } \\
\text { struggling } \\
\text { health } \\
\text { system, } \\
\text { especially in } \\
\text { maternal } \\
\text { health. }\end{array}$ \\
\hline $\begin{array}{l}\text { Hematram, } \\
\text { Y., } 2006\end{array}$ & $\begin{array}{l}\text { Measuring } \\
\text { maternal } \\
\text { mortality }\end{array}$ & $\begin{array}{l}\text { Maternal } \\
\text { deaths in } \\
\text { Malaysia }\end{array}$ & $\begin{array}{l}\text { A consistent } \\
\text { approach to } \\
\text { registration of } \\
\text { maternal deaths. }\end{array}$ & $\begin{array}{l}\text { Use of the } \\
\text { lifetime risk } \\
\text { measure may } \\
\text { help to further } \\
\text { reduce MMR. }\end{array}$ & $\begin{array}{l}\text { Malaysia has } \\
\text { improved } \\
\text { MMR ? can } \\
\text { they improve } \\
\text { further? }\end{array}$ \\
\hline $\begin{array}{l}\text { Jacobs B, } \\
\text { Thome JM, } \\
\text { et al., } 2010\end{array}$ & $\begin{array}{l}\text { Performance } \\
\text { management } \\
\text { and } \\
\text { contractual } \\
\text { targets }\end{array}$ & $\begin{array}{l}\text { Health } \\
\text { services } \\
\text { provided to } \\
\text { people in } \\
\text { Cambodia }\end{array}$ & $\begin{array}{l}\text { Need to focus on } \\
\text { the main aspects } \\
\text { of the health care } \\
\text { system }\end{array}$ & $\begin{array}{l}\text { The transition } \\
\text { from NGO } \\
\text { contracting to a } \\
\text { government- } \\
\text { operated health } \\
\text { system is } \\
\text { feasible. }\end{array}$ & $\begin{array}{l}\text { This is one } \\
\text { means to } \\
\text { improve } \\
\text { essential } \\
\text { health } \\
\text { services in } \\
\text { Cambodia }\end{array}$ \\
\hline $\begin{array}{l}\text { Jones, M., } \\
2002\end{array}$ & $\begin{array}{l}\text { Registration } \\
\text { and education } \\
\text { of midwives }\end{array}$ & $\begin{array}{l}\text { Women and } \\
\text { children in Sri } \\
\text { Lanka }\end{array}$ & $\begin{array}{l}\text { Registration of } \\
\text { births and deaths }\end{array}$ & $\begin{array}{l}\text { Ceylon was } \\
\text { under colonial } \\
\text { rule from } \\
\text { Britain, but it } \\
\text { was their ability } \\
\text { to improve } \\
\text { health and } \\
\text { welfare that they } \\
\text { should be } \\
\text { judged. }\end{array}$ & $\begin{array}{l}\text { Under } \\
\text { colonial rule, } \\
\text { but health } \\
\text { was } \\
\text { improved }\end{array}$ \\
\hline
\end{tabular}




\begin{tabular}{|c|c|c|c|c|c|}
\hline $\begin{array}{l}\text { Koblinsky } \\
\text { M, } 2003\end{array}$ & $\begin{array}{l}\text { Free and } \\
\text { equitable } \\
\text { health care }\end{array}$ & $\begin{array}{l}\text { Countries with } \\
\text { success at } \\
\text { reducing } \\
\text { MMR }\end{array}$ & $\begin{array}{l}\text { Professionalizing } \\
\text { midwifery, } \\
\text { strengthening } \\
\text { health systems } \\
\text { and civil } \\
\text { registration. }\end{array}$ & $\begin{array}{l}\text { Looking at the } \\
\text { strategies that } \\
\text { have reduced } \\
\text { MMR. }\end{array}$ & $\begin{array}{l}\text { Strong policy } \\
\text { guidance is } \\
\text { important. }\end{array}$ \\
\hline $\begin{array}{l}\text { Kruske, S. } \\
\text { and L. } \\
\text { Barclay, } \\
2004\end{array}$ & $\begin{array}{l}\text { Traditional } \\
\text { birth } \\
\text { attendant } \\
\text { training was } \\
\text { not seen to be } \\
\text { effective - } \\
\text { focus solely } \\
\text { on training } \\
\text { skilled birth } \\
\text { attendants. }\end{array}$ & $\begin{array}{l}\text { Traditional } \\
\text { birth } \\
\text { attendants }\end{array}$ & $\begin{array}{l}\text { Local context } \\
\text { and partnership } \\
\text { between TBA?s } \\
\text { and health } \\
\text { professionals }\end{array}$ & $\begin{array}{l}\text { Collaboration } \\
\text { and true } \\
\text { partnership is the } \\
\text { way forwards. }\end{array}$ & $\begin{array}{l}\text { TBA?s } \\
\text { viewed } \\
\text { highly by the } \\
\text { community - } \\
\text { mutual } \\
\text { respect and } \\
\text { trust. }\end{array}$ \\
\hline $\begin{array}{l}\text { Liljestrand, } \\
\text { J. and I. } \\
\text { Pathmanatha } \\
\text { n, } 2004\end{array}$ & $\begin{array}{l}\text { Health } \\
\text { systems must } \\
\text { be } \\
\text { strengthened }\end{array}$ & $\begin{array}{l}\text { Country case } \\
\text { studies from } \\
\text { Malaysia and } \\
\text { Sri Lanka }\end{array}$ & $\begin{array}{l}\text { Free health care, } \\
\text { professional } \\
\text { midwives and } \\
\text { political } \\
\text { commitment }\end{array}$ & $\begin{array}{l}\text { Skilled birth } \\
\text { attendance is a } \\
\text { package of } \\
\text { services? not an } \\
\text { individual } \\
\text { person. }\end{array}$ & $\begin{array}{l}\text { Started in } \\
1950 ? \mathrm{~s} \text { when } \\
\text { both } \\
\text { countries } \\
\text { were } \\
\text { considered } \\
\text { poor } \\
\text { ?developing? } \\
\text { countries. }\end{array}$ \\
\hline $\begin{array}{l}\text { Maclean, G. } \\
\text { D., } 2003\end{array}$ & $\begin{array}{l}\text { Improve } \\
\text { status of } \\
\text { women } \\
\text { within society }\end{array}$ & $\begin{array}{l}\text { Women } \\
\text { giving birth in } \\
\text { a variety of } \\
\text { locations }\end{array}$ & $\begin{array}{l}\text { Universal } \\
\text { coverage of } \\
\text { skilled } \\
\text { attendance at } \\
\text { birth }\end{array}$ & $\begin{array}{l}\text { Skilled } \\
\text { attendants need } \\
\text { an enabling } \\
\text { environment }\end{array}$ & $\begin{array}{l}\text { Looks at the } \\
\text { strategies } \\
\text { that have } \\
\text { worked to } \\
\text { reduce MMR }\end{array}$ \\
\hline $\begin{array}{l}\text { Mavalankar, } \\
\text { D. and V. } \\
\text { Sriram, } 2009\end{array}$ & $\begin{array}{l}\text { Structured } \\
\text { task shifting } \\
\text { programmes } \\
\text { in anaesthesia } \\
\text { for } \\
\text { Emergency } \\
\text { Obstetric } \\
\text { Care }\end{array}$ & $\begin{array}{l}\text { Those } \\
\text { involved in } \\
\text { task-shifting } \\
\text { in a South } \\
\text { Asian setting }\end{array}$ & $\begin{array}{l}\text { Trained medical } \\
\text { officers giving } \\
\text { anaesthetics for } \\
\text { Emergency } \\
\text { Obstetric Care } \\
\text { (instead of } \\
\text { anaesthetists) }\end{array}$ & $\begin{array}{l}\text { Sri Lanka has } \\
\text { implemented } \\
\text { task shifting in } \\
\text { anaesthesia for } \\
\text { EmoC in rural } \\
\text { areas, which has } \\
\text { helped to } \\
\text { decrease } \\
\text { maternal } \\
\text { mortality. }\end{array}$ & $\begin{array}{l}\text { Task-shifting } \\
\text { in } \\
\text { anaesthetics } \\
\text { for EmOC } \\
\text { can be a } \\
\text { good option. }\end{array}$ \\
\hline $\begin{array}{l}\text { Mullany, L. } \\
\text { C., C. I. Lee, } \\
\text { et al., } 2008\end{array}$ & $\begin{array}{l}\text { Different } \\
\text { levels of } \\
\text { health } \\
\text { workers } \\
\text { provide a } \\
\text { subset of } \\
\text { interventions } \\
\text { to pregnant } \\
\text { and birthing } \\
\text { women. }\end{array}$ & $\begin{array}{l}\text { Women along } \\
\text { the Thailand- } \\
\text { Burma border }\end{array}$ & $\begin{array}{l}\text { The MOM } \\
\text { project aims to } \\
\text { provide maternal } \\
\text { health care under } \\
\text { circumstances } \\
\text { where there is no } \\
\text { foreseeable } \\
\text { access to skilled } \\
\text { birth attendants } \\
\text { as defined by } \\
\text { WHO. }\end{array}$ & $\begin{array}{l}\text { This paper } \\
\text { provides } \\
\text { important } \\
\text { insights into the } \\
\text { feasibility and } \\
\text { effectiveness of } \\
\text { this approach } \\
\text { and strategies in } \\
\text { conflict settings. }\end{array}$ & $\begin{array}{l}\text { Excellent } \\
\text { paper: also } \\
\text { talks about } \\
\text { monitoring } \\
\text { and } \\
\text { evaluation. }\end{array}$ \\
\hline
\end{tabular}




\begin{tabular}{|c|c|c|c|c|c|}
\hline $\begin{array}{l}\text { Pathmanatha } \\
\text { n I, } \\
\text { Liljestrand J, } \\
\text { et al., } 2003\end{array}$ & $\begin{array}{l}\text { Professional } \\
\text { midwifery } \\
\text { services and } \\
\text { reporting } \\
\text { maternal } \\
\text { mortality } \\
\text { data. }\end{array}$ & $\begin{array}{l}\text { Malaysia and } \\
\text { Sri Lanka }\end{array}$ & $\begin{array}{l}\text { Establishing } \\
\text { solid foundations } \\
\text { for effective } \\
\text { maternity care }\end{array}$ & $\begin{array}{l}\text { Maternal health } \\
\text { care is } \\
\text { particularly } \\
\text { effective when } \\
\text { within a } \\
\text { synergistic } \\
\text { package of } \\
\text { services that } \\
\text { reach the poor. }\end{array}$ & $\begin{array}{l}\text { They have } \\
\text { achieved } \\
\text { remarkable } \\
\text { reduction in } \\
\text { MMR }\end{array}$ \\
\hline $\begin{array}{l}\text { Prata N, } \\
\text { Passano P, et } \\
\text { al., } 2010\end{array}$ & $\begin{array}{l}\text { Comprehensi } \\
\text { ve } \\
\text { strengthening } \\
\text { of maternal } \\
\text { health } \\
\text { services }\end{array}$ & $\begin{array}{l}\text { Those people } \\
\text { affected by } \\
\text { maternal } \\
\text { mortality in } \\
\text { developing } \\
\text { countries. }\end{array}$ & $\begin{array}{l}\text { Expanded roles } \\
\text { for professional } \\
\text { midwives, and } \\
\text { ongoing political } \\
\text { support. }\end{array}$ & $\begin{array}{l}\text { Strategies to } \\
\text { decrease MMR } \\
\text { need to include } \\
\text { political } \\
\text { commitment at } \\
\text { all levels, } \\
\text { investment in } \\
\text { high-yield and } \\
\text { cost-effective } \\
\text { interventions } \\
\text { and } \\
\text { redistribution of } \\
\text { clinical tasks to } \\
\text { the appropriate } \\
\text { level of } \\
\text { healthcare } \\
\text { providers. }\end{array}$ & $\begin{array}{l}\text { The } \\
\text { experience of } \\
\text { pregnancy } \\
\text { and birth is } \\
\text { feared among } \\
\text { many women } \\
\text { in developing } \\
\text { regions of the } \\
\text { world. }\end{array}$ \\
\hline $\begin{array}{l}\text { Rohde, J., S. } \\
\text { Cousens, et } \\
\text { al., } 2008\end{array}$ & $\begin{array}{l}\text { Accelerated } \\
\text { midwifery } \\
\text { training, } \\
\text { transport } \\
\text { subsidies }\end{array}$ & $\begin{array}{l}\text { Thirty low } \\
\text { and middle- } \\
\text { income } \\
\text { countries with } \\
\text { the highest } \\
\text { decrease of } \\
\text { maternal } \\
\text { mortality. }\end{array}$ & $\begin{array}{l}\text { Build an } \\
\text { effective district } \\
\text { health system, } \\
\text { and mandatory } \\
\text { rural service. }\end{array}$ & $\begin{array}{l}\text { Lessons learned } \\
\text { from all these } \\
\text { countries include } \\
\text { a nationally } \\
\text { agreed package } \\
\text { for health care, } \\
\text { and commitment } \\
\text { of all involved. }\end{array}$ & $\begin{array}{l}\text { Some } \\
\text { countries } \\
\text { have been } \\
\text { able to scale } \\
\text { up primary } \\
\text { health care, } \\
\text { progressing } \\
\text { to } \\
\text { comprehensi } \\
\text { ve primary } \\
\text { health care. }\end{array}$ \\
\hline $\begin{array}{l}\text { Ronsmans, } \\
\text { C. and W. J. } \\
\text { Graham, } \\
2006\end{array}$ & $\begin{array}{l}\text { Long-term } \\
\text { investment in } \\
\text { midwifery, } \\
\text { free care and } \\
\text { a regulated } \\
\text { hospital } \\
\text { system. }\end{array}$ & $\begin{array}{l}\text { Pregnant and } \\
\text { birthing } \\
\text { women in } \\
\text { developing } \\
\text { countries }\end{array}$ & $\begin{array}{l}\text { Measurement of } \\
\text { maternal } \\
\text { mortality. }\end{array}$ & $\begin{array}{l}\text { The Millennium } \\
\text { Declaration is } \\
\text { the first time that } \\
\text { maternal } \\
\text { mortality has } \\
\text { been given the } \\
\text { attention it } \\
\text { deserves. }\end{array}$ & $\begin{array}{l}\text { Mixed } \\
\text { methods } \\
\text { approach to } \\
\text { data } \\
\text { collection } \\
\text { should be } \\
\text { encouraged. }\end{array}$ \\
\hline
\end{tabular}




\begin{tabular}{|c|c|c|c|c|c|}
\hline $\begin{array}{l}\text { Seneviratne, } \\
\text { H. R. and L. } \\
\text { C. } \\
\text { Rajapaksa, } \\
2000\end{array}$ & $\begin{array}{l}\text { High levels of } \\
\text { education for } \\
\text { all }\end{array}$ & $\begin{array}{l}\text { Women } \\
\text { giving birth in } \\
\text { Sri Lanka }\end{array}$ & $\begin{array}{l}\text { Activities that } \\
\text { promote health } \\
\text { and social } \\
\text { development }\end{array}$ & $\begin{array}{l}\text { MCH services } \\
\text { were closely } \\
\text { linked to } \\
\text { improvements in } \\
\text { the healthcare } \\
\text { infrastructure } \\
\text { and social } \\
\text { development. }\end{array}$ & $\begin{array}{l}\text { Safe } \\
\text { motherhood } \\
\text { in Sri Lanka } \\
\text { has been } \\
\text { achieved by a } \\
\text { series of } \\
\text { activities for } \\
\text { health and } \\
\text { social } \\
\text { development. }\end{array}$ \\
\hline $\begin{array}{l}\text { The World } \\
\text { Bank, } 2004\end{array}$ & $\begin{array}{l}\text { Support to } \\
\text { district health } \\
\text { authorities to } \\
\text { improve } \\
\text { service } \\
\text { delivery and } \\
\text { outreach. }\end{array}$ & $\begin{array}{l}\text { People of Sri } \\
\text { Lanka }\end{array}$ & $\begin{array}{l}\text { Universal and } \\
\text { free education }\end{array}$ & $\begin{array}{l}\text { The overall } \\
\text { objective was to } \\
\text { address equity, } \\
\text { quality and } \\
\text { efficiency of the } \\
\text { health sector. }\end{array}$ & $\begin{array}{l}\text { Evaluation } \\
\text { and } \\
\text { monitoring } \\
\text { of programs } \\
\text { is important. }\end{array}$ \\
\hline $\begin{array}{l}\text { The World } \\
\text { Bank, } 2008\end{array}$ & $\begin{array}{l}\text { Barriers } \\
\text { include social } \\
\text { position of } \\
\text { women }\end{array}$ & $\begin{array}{l}\text { People of } \\
\text { Cambodia }\end{array}$ & $\begin{array}{l}\text { Targeted } \\
\text { contracts }\end{array}$ & $\begin{array}{l}\text { Targeted } \\
\text { contracts by } \\
\text { NGOs have been } \\
\text { shown to } \\
\text { improve } \\
\text { management } \\
\text { styles and } \\
\text { responsibilities } \\
\text { in health } \\
\text { facilities. }\end{array}$ & $\begin{array}{l}\text { Social capital } \\
\text { and } \\
\text { Accountabilit } \\
\text {-y is weak } \\
\text { due to the } \\
\text { war and } \\
\text { genocide in } \\
\text { Cambodia. }\end{array}$ \\
\hline $\begin{array}{l}\text { Vandine, O., } \\
2008\end{array}$ & $\begin{array}{l}\text { Increase } \\
\text { midwives, } \\
\text { better health } \\
\text { referral and } \\
\text { better } \\
\text { reporting }\end{array}$ & $\begin{array}{l}\text { Pregnant and } \\
\text { birthing } \\
\text { women in } \\
\text { Cambodia }\end{array}$ & $\begin{array}{l}\text { A } \\
\text { comprehensive } \\
\text { package of } \\
\text { health services }\end{array}$ & $\begin{array}{l}\text { Commitment of } \\
\text { the Cambodian } \\
\text { government to } \\
\text { provide more } \\
\text { midwives, } \\
\text { strengthening } \\
\text { health referral } \\
\text { systems, and } \\
\text { monitoring and } \\
\text { evaluation. }\end{array}$ & $\begin{array}{l}\text { The } \\
\text { provision of } \\
\text { the package } \\
\text { of services is } \\
\text { important. }\end{array}$ \\
\hline $\begin{array}{l}\text { Walford } \\
\text { Veronica, } \\
\text { Pearson } \\
\text { Mark, et al., } \\
2006\end{array}$ & $\begin{array}{l}\text { Health } \\
\text { financing and } \\
\text { midwifery } \\
\text { services }\end{array}$ & $\begin{array}{l}\text { Focus on } 13 \\
\text { Asian } \\
\text { countries }\end{array}$ & $\begin{array}{l}\text { Contextual } \\
\text { health financing }\end{array}$ & $\begin{array}{l}\text { Asian countries } \\
\text { and the agencies } \\
\text { may want to } \\
\text { look at how best } \\
\text { to coordinate } \\
\text { their } \\
\text { collaboration } \\
\text { and exchange in } \\
\text { the field of } \\
\text { health. }\end{array}$ & $\begin{array}{l}\text { Countries } \\
\text { must look at } \\
\text { their } \\
\text { individual } \\
\text { context, and } \\
\text { what will } \\
\text { work for } \\
\text { them. }\end{array}$ \\
\hline
\end{tabular}




\begin{tabular}{|c|c|c|c|c|c|}
\hline $\begin{array}{l}\text { Wirth, M., } \\
2008\end{array}$ & $\begin{array}{l}\text { An argument } \\
\text { for the equity } \\
\text { and efficiency } \\
\text { of nurses, } \\
\text { midwives }\end{array}$ & $\begin{array}{l}\text { Nurse/midwiv } \\
\text { es in low- } \\
\text { income } \\
\text { countries }\end{array}$ & $\begin{array}{l}\text { Scaling-up of } \\
\text { delivery care }\end{array}$ & $\begin{array}{l}\text { A massive } \\
\text { scaling-up of } \\
\text { delivery care } \\
\text { professionals } \\
\text { must be sparked } \\
\text { immediately and } \\
\text { creatively. }\end{array}$ & $\begin{array}{l}\text { Excellent } \\
\text { paper } \\
\text { looking at the } \\
\text { complex } \\
\text { bigger } \\
\text { picture } \\
\text { surrounding } \\
\text { maternal } \\
\text { health. }\end{array}$ \\
\hline $\begin{array}{l}\text { World } \\
\text { Health } \\
\text { Organization } \\
2005\end{array}$ & $\begin{array}{l}\text { Developing } \\
\text { midwifery, } \\
\text { increasing } \\
\text { finances, } \\
\text { strengthening } \\
\text { health } \\
\text { systems, } \\
\text { working with } \\
\text { communities. }\end{array}$ & $\begin{array}{l}\text { South East } \\
\text { Asia Region }\end{array}$ & $\begin{array}{l}\text { Multi- } \\
\text { dimensional } \\
\text { approaches }\end{array}$ & $\begin{array}{l}\text { Maternal } \\
\text { mortality needs } \\
\text { to be addressed } \\
\text { through multi- } \\
\text { dimensional } \\
\text { approaches. }\end{array}$ & $\begin{array}{l}\text { Countries } \\
\text { need support } \\
\text { to share } \\
\text { ideas, and } \\
\text { assistance } \\
\text { from } \\
\text { organisations } \\
\text { like WHO. }\end{array}$ \\
\hline $\begin{array}{l}\text { de Bernis, } \\
\text { L., D. R. } \\
\text { Sherratt, et } \\
\text { al., } 2003\end{array}$ & $\begin{array}{l}\text { Increased } \\
\text { access to a } \\
\text { skilled } \\
\text { attendant }\end{array}$ & $\begin{array}{l}\text { Pregnant and } \\
\text { birthing } \\
\text { women in a } \\
\text { variety of } \\
\text { low-income } \\
\text { countries }\end{array}$ & $\begin{array}{l}\text { A skilled } \\
\text { attendant must } \\
\text { attend the } \\
\text { majority of } \\
\text { births }\end{array}$ & $\begin{array}{l}\text { Maternal } \\
\text { mortality } \\
\text { decreases when } \\
\text { an increase } \\
\text { number of } \\
\text { women and } \\
\text { families seeking } \\
\text { skilled care at } \\
\text { birth }\end{array}$ & $\begin{array}{l}\text { Increased } \\
\text { access to a } \\
\text { skilled } \\
\text { attendant at } \\
\text { birth is most } \\
\text { important }\end{array}$ \\
\hline
\end{tabular}




\section{Appendix V: Excluded studies}

1. Achanna, K. S., A. M. Zaleha, et al., Perioperative mortality review in relation to pregnancy-related deaths. Med J Malaysia 2006:61;3.

Reason for Exclusion: Is a clinical audit, not text and opinion.

2. Ali, A. and P. Howden-Chapman, Maternity services and the role of the traditional birth attendant, bidan kampung, in rural Malaysia. J Public Health Management Practice 2007:13;3.

Reason for Exclusion: Not a textual paper.

3. Belton, S., Borders of fertility: Unplanned pregnancy and unsafe abortion in Burmese women migrating to Thailand. Health Care Women Int 2007:28.

Reason for Exclusion: Not a textual paper.

4. Carmichael, R., Cambodia: alarming maternal deaths require a mix of solutions. Reason for Exclusion: This report is from a global news blog site.

5. Carroli, G., C. Rooney, et al., How effective is antenatal care in preventing maternal mortality and serious morbidity? An overview of the evidence. Paediatr Perinat Epidemiol 2001:15;1.

Reason for Exclusion: Not a textual paper.

6. Chandy, H., M. Steinholt, et al., Delivery life support: a preliminary report on the chain of survival for complicated deliveries in rural Cambodia. Nurs Health Sci 2007:9.

Reason for Exclusion: Not a textual paper.

7. Chandy, H., Y. V. Heng, et al., Comparing two survey methods for estimating maternal and perinatal mortality in rural Cambodia. Women Birth 2008:21.

Reason for Exclusion: Not a textual paper.

8. Chatterjee S, Deville L, et al., Papua New Guinea and Sri Lanka: scaling up health interventions. Asian Development Bank 2004.

Reason for Exclusion: The focus of this paper is health policy - not much mention of skilled birth issues.

9. Darmstadt, G. L., A. C. Lee, et al., 60 Million non-facility births: who can deliver in community settings to reduce intrapartum-related deaths? Int J Gynaecol Obstet 2009:107.

Reason for Exclusion: Not a textual paper. 
10. Gunathunga, W. and D. N. Fernando, Assessment of community maternal care performance of public health midwives of a province in Sri Lanka: A multi-method approach. Dept Comm Med, Faculty of Medicine, University of Colombo, Sri Lanka 2000:31;2.

Reason for Exclusion: Descriptive, cross-sectional research paper: not textual.

11. Hill, K., K. Thomas, et al., Estimates of maternal mortality worldwide between 1990 and 2005: an assessment of available data. The Lancet 2007;370.

Reason for Exclusion: Paper is about data not interventions or policy.

12. Ir, P., D. Horemans, et al., Using targeted vouchers and health equity funds to improve access to skilled birth attendants for poor women: a case study in three rural health districts in Cambodia. BMC Pregnancy \& Childbirth 2010;10:1.

Reason for Exclusion: Mixed methods research study, not opinion.

13. Jayachandran, S., A. Lleras-Muney, Life expectancy and human capital investments: Evidence from maternal mortality declines. Q J Econ 2009;Feb.

Reason for Exclusion: Outcome of interest is literacy and education rates.

14. Jayasekara, R. S. and T. Schultz. Health status, trends, and issues in Sri Lanka. Nurs Health Sci 2007;9.

Reason for Exclusion: Focus is on general health trends, not maternal health: not an opinion piece.

15. Kalaichandran, A., D. Zakus. The obstetric pathology of poverty: maternal mortality in Kep province, Cambodia. World Health Popul 2007;April.

Reason for Exclusion: Research paper - structured questionnaire not opinion.

16. Khan, K. S., D. Wojdyla, et al. WHO analysis of causes of maternal death: a systematic review. The Lancet 2006;367.

Reason for Exclusion: A systematic review: not text and opinion.

17. Kottegoda, S., K. Samuel, et al. Reproductive health concerns in six conflictaffected areas of Sri Lanka. Reprod Health Matters 2008;16:31.

Reason for Exclusion: Evaluates data but no focus on maternal mortality.

18. Koum, K., S. Tiv, et al. Maternal death cases in the top referral hospital in Cambodia. J Obstet Gynaecol Res 2002;28:1.

Reason for Exclusion: This is a hospital-based retrospective, descriptive study.

19. Kruk, M. E., M. R. Prescott, et al. Equity of skilled birth attendant utilization in developing countries: financing and policy determinants. Am J Public Health 2008;98:1. 
Reason for Exclusion: Research paper not opinion.

20. Kruk, M. E., S. Galea, et al. Health care financing and utilization of maternal health services in developing countries. Health Policy Plan 2007;22.

Reason for Exclusion: Research paper not opinion.

21. Kunaviktikul, W. Nursing and nursing education in Thailand: The past, the present, and the future. Nurs Health Sci 2006;8.

Reason for Exclusion: Not discussing strategies for interventions.

22. Liabsuetrakul, T., K. Peeyananjarassri, et al. Emergency obstetric care in the southernmost provinces of Thailand. Int J Qual Health Care 2007;19:4.

Reason for Exclusion: Research paper not opinion.

23. Liamputtong, P., S. Yimyam, et al. Traditional beliefs about pregnancy and child birth among women from Chiang Mai, Northern Thailand. Midwifery 2005;21.

Reason for Exclusion: Grounded Theory paper: not opinion.

24. Lukumar, P., A. Pathmeswaran. Factors associated with home deliveries in Thampalakamam, Trincomalee. Ceylon Med J 2006;51:2.

Reason for Exclusion: Case control study, not text and opinion.

25. Lumbiganon, P., M. Laopaiboon, et al. Method of delivery and pregnancy outcomes in Asia: the WHO global survey on maternal and perinatal health 2007-08. The Lancet 2010;375.

Reason for Exclusion: Research paper not opinion.

26. Matsuoka, S., H. Aiga, et al. Perceived barriers to utilization of maternal health services in rural Cambodia. Health Pol 2010;95.

Reason for Exclusion: Research paper not opinion.

27. McDonald, S., T. Turner, et al. Building capacity for evidence generation, synthesis and implementation to improve the care of mothers and babies in South East Asia: methods and design of the SEA-ORCHID Project using a logical framework approach. BMC Med Res Methodol 2010;10:61.

Reason for Exclusion: Uncontrolled before-and-after study design.

28. Morrison, V. Contraceptive need among Cambodian refugees in Khao Phlu Camp. Int Fam Plann Persp 2000;26:4.

Reason for Exclusion: Research paper not opinion.

29. Nagai, M., S. Abraham, et al. Reconstruction of health service systems in the postconflict Northern Province in Sri Lanka. Health Policy 2007;83.

Reason for Exclusion: Research paper not opinion. 
30. Paxton, A., D. Maine, et al. The evidence for emergency obstetric care. Int J Gynaecol Obstet 2005;88.

Reason for Exclusion: Systematic review of empirical evidence - not opinion.

31. Ray AM, Salihu HM. The impact of maternal mortality interventions using traditional birth attendants and village midwives. J Obstet Gynaecol 2004;24:1.

Reason for Exclusion: Systematic review of empirical evidence.

32. Riddell, E. Community-led safe motherhood advocacy, Ratanakiri, Cambodia. J R Soc Promot Health 2006;126.

Reason for Exclusion: Action research study design, not text and opinion.

33. Shiffman J, Smith S. Generation of political priority for global health initiatives: a framework and case study of maternal mortality. The Lancet 2007;370.

Reason for Exclusion: Excellent paper but doesn't refer to the 4 countries.

34. Sibley, L. M., T. A. Sipe. Transition to skilled birth attendance: is there a future role for trained traditional birth attendants? J Health Popul nutr 2006;24:4.

Reason for Exclusion: Experimental and quasi-experimental studies.

35. Simetka, O., B. Reilley, et al. Obstetrics during civil war: six months on a maternity ward in Mallavi, northern Sri Lanka. Med Confl Surviv 2002;18:3.

Reason for Exclusion: Review of medical records and patient interviews - not text and opinion.

36. Sivaganesh, S., U. Senarath. Antenatal care utilization in a conflict-affected district of northern Sri Lanka. Pub Health Nurs 2009;26:6.

Reason for Exclusion: Cross-sectional study: evaluation of formal care delivery.

37. Skinner, J., T. Rathavy. Design and evaluation of a community participatory, birth preparedness project in Cambodia. Midwifery 2009;25.

Reason for Exclusion: A feasibility and outcome evaluation project - not text and opinion.

38. Stanton, C., A. K. Blanc, et al. Skilled care at birth in the developing world: progress to date and strategies for expanding coverage. J Biosoc Sci 2007;39.

Reason for Exclusion: Research paper not opinion.

39. The World Bank. Managing risk and vulnerability in Cambodia. 2006; June.

Reason for Exclusion: This is aimed more at managing risk and vulnerability in Cambodia.

40. The World Bank. Good practices in health financing: lessons from reforms in lowand middle-income countries. 2008. 
Reason for Exclusion: World Bank country reports on health financing - not maternal health.

41. Wagaarachchi, P. T., L. Fernando. Trends in maternal mortality and assessment of substandard care in a tertiary care hospital. Eur J Obstet Gynaecol Reprod Biol $2002 ; 101$.

Reason for Exclusion: Descriptive analysis study - not text and opinion.

42. White, P. M. Crossing the river: Khmer women's perceptions of pregnancy and postpartum. J Midwifery Womens Health 2002;47:4.

Reason for Exclusion: Qualitative research - not text and opinion.

43. White, P. M. Heat, balance, humors, and ghosts: Postpartum in Cambodia. Health Care Women Int 2004;25.

Reason for Exclusion: Qualitative research - not opinion.

44. Yanagisawa, S., S. Wakai. Professional healthcare use for life-threatening obstetric conditions. J Obstet Gynaecol 2008;28:7.

Reason for Exclusion: Research paper not opinion.

45. Yanagisawa, S., S. Oum, et al. Determinants of skilled birth attendance in rural Cambodia. Trop Med Int Health 2006;11.2.

Reason for Exclusion: Research paper not opinion. 